\section{orml}

\section{OAK RIDGE} NATIONAL LABORATORY

MARTIN MARUETRA

\title{
Validation and Verification of RELAP5 for Advanced Neutron Source Accident Analysis: Part I, Comparisons to ANSDM and PRSDYN Codes
}

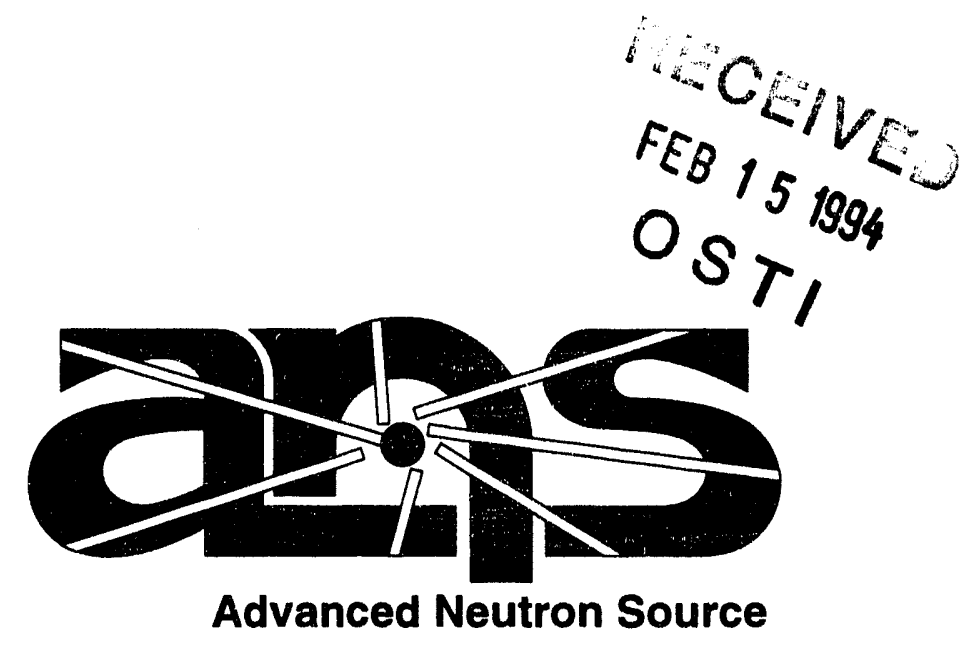


This report has been reproduced directly from the best availablis copy.

Available to DOE und DOE contractors from the Office of Scientific and Technical Information, P.O. Box 62, Oak Ridge, TN 37831; prices available from (615) 576-8401, FTs 626-8401.

Available to the public from the National Technical information Service, U.S. Department of Commerce, 5285 Port Royal Rd., Springfield, VA 22161.

This report was prepared as an account of work sponsored by an agency of the United States Government. Neither the United States Government nor any agency thereof, nor any of their employees, makes any warranty, express or implied, or assumes any legal liability or responsibility for the accuracy, completeness, or usefulness of any information, apparatus, product, or process disclosed, or represents that its use would not infringe privately owned rights. Reference herein to any specific commercial product, process, or service by trade name, trademark, manufacturer, or otherwise, does not necessarily constitute or imply its endorsement, recommendation, or favoring by the United States Government or any agency thereof. The views and opinions of authors expressed herein do not necessarily state or reflect those of the United States Government or any agency thereof. 


\title{
VALIDATION AND VERIFICATION OF RELAP5 FOR ADVANCED NEUTRON SOURCE ACCIDENT ANALYSIS: PART 1, COMPARISONS TO ANSDM AND PRSDYN CODES
}

\author{
N. C. J. Chen
}

M. Ibn-Khayat

J. A. March-Leuba

M. W. Wendel

December 1993

Prepared by the

OAK RIDGE NATIONAL LABORATORY

Oak Ridge, Tennessee 37831-6285

managed by

MARTIN MARIETTA ENERGY SYSTEMS, INC.

for the

U.S. DEPARTMENT OF ENERGY

under contract DE-AC05-84OR21400 


\section{CONTENIS}

Page

LIST OF FIGURES $\ldots \ldots \ldots \ldots \ldots \ldots \ldots \ldots \ldots \ldots \ldots \ldots \ldots \ldots$

LIST OF TABLES $\ldots \ldots \ldots \ldots \ldots \ldots \ldots \ldots \ldots \ldots \ldots \ldots \ldots \ldots$

LIST OF ACRONYMS $\ldots \ldots \ldots \ldots \ldots \ldots \ldots \ldots \ldots \ldots \ldots \ldots \ldots \ldots$

ACKNOWLEDGMENTS $\ldots \ldots \ldots \ldots \ldots \ldots \ldots \ldots \ldots \ldots \ldots \ldots \ldots$

ABSTRACT $\ldots \ldots \ldots \ldots \ldots \ldots \ldots \ldots \ldots \ldots \ldots \ldots \ldots \ldots \ldots \ldots \ldots \ldots \ldots$

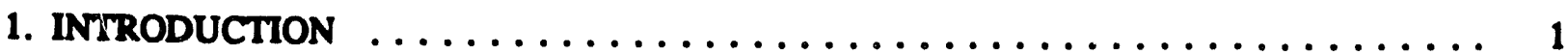

2. MODEL DESCRIPTIONS $\ldots \ldots \ldots \ldots \ldots \ldots \ldots \ldots \ldots \ldots \ldots \ldots \ldots \ldots \ldots$

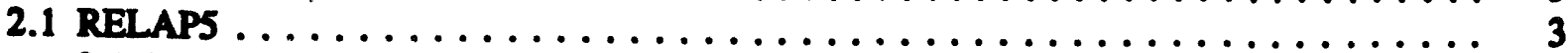

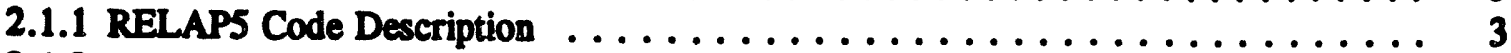

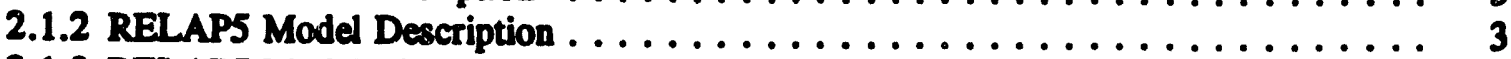

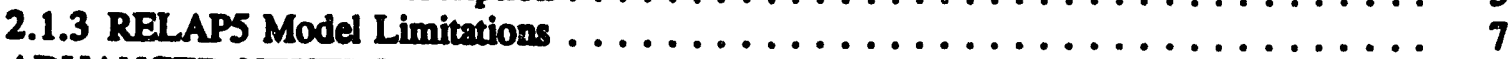

2.2 ADVANCED NEUTRON SOURCE DYNAMIC MODEL $\ldots \ldots \ldots \ldots \ldots \ldots \ldots \ldots$. $\ldots \ldots$

2.2.1 Advanced Neutron Source Dynamic Model Code Description . . . . . . . . . . . . 7

2.2.2 Advanced Neutron Source Dynamic Model Description . . . . . . . . . . . . . 8

2.2.3 Advanced Neutron Source Dynamic Model Correlations . . . . . . . . . . . . . 12

2.2.4 Advanced Neutron Source Dynamic Model Limitations . . . . . . . . . . . . . . 13

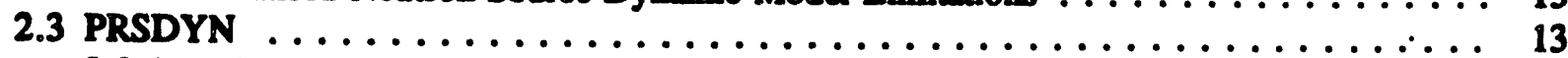

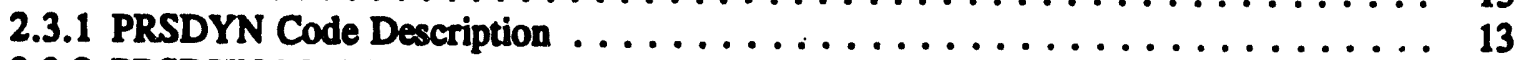

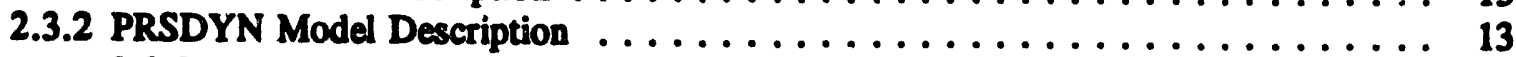

2.3.2.1 Core Neutronies . . . . . . . . . . . . . . . . . . . 14

2.3.2.2 Channel Thermal Hydraulics . . . . . . . . . . . . . . . 16

2.3.2.3 Pipe Thermal Hydraulics .................... 20

2.3.2.4 Heat Exchangers . . . . . . . . . . . . . . . . . . 22

2.3.2.5 Main Circulation Pumps . . . . . . . . . . . . . . . . 24

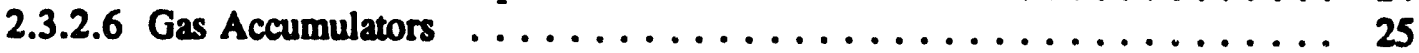

2.3.2.7 Loss of Cool..nt Accident Modeling ............... 26

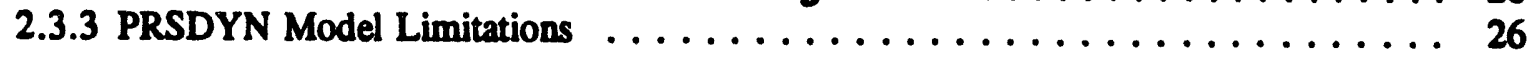

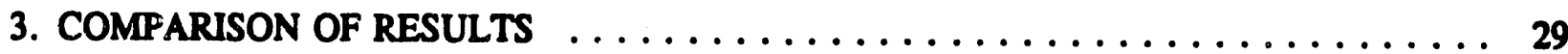

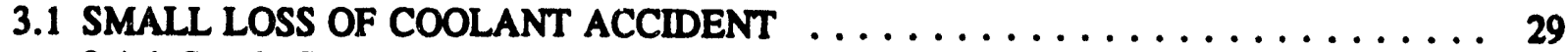

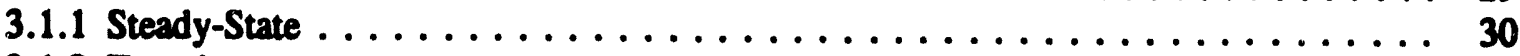

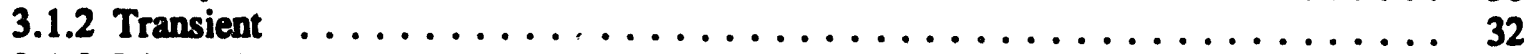

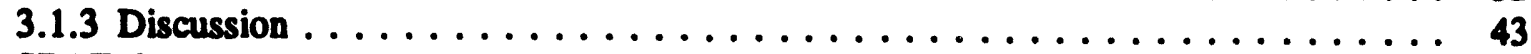

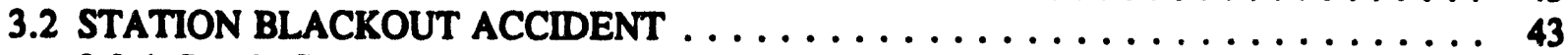

3.2.1 Steady-State .............................. 43

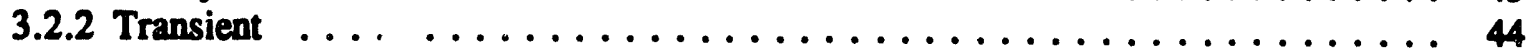

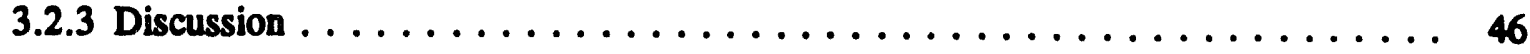


3.3 LARGE LOSS OF COOLANT ACCIDENT $\ldots \ldots \ldots \ldots \ldots \ldots \ldots \ldots \ldots \ldots$

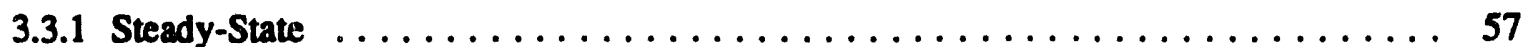

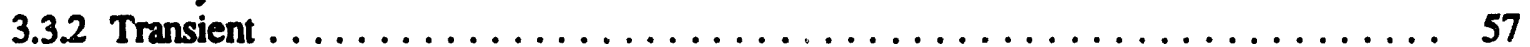

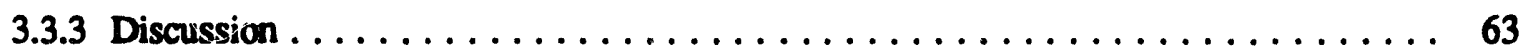

3.4 REACTIVITY INSERTION ACCIDENT $\ldots \ldots \ldots \ldots \ldots \ldots \ldots \ldots \ldots \ldots$

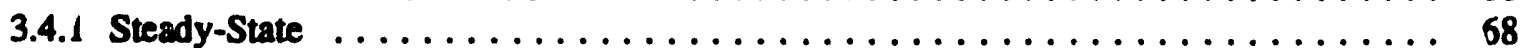

3.4 .2 Transient . . . . . . . . . . . . . . . . . . . . . . . . . . 69

3.4 .3 Discussion . . . . . . . . . . . . . . . . . . . . . . . . . 69

4. CONCLUSIONS AND RECOMMENDATIONS $\ldots \ldots \ldots \ldots \ldots \ldots \ldots \ldots \ldots \ldots$

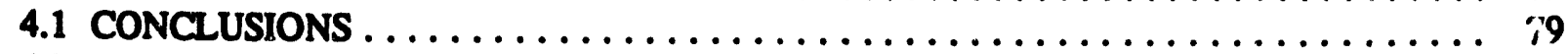

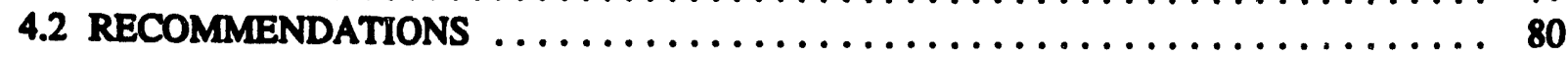

REFERENCES $\ldots \ldots \ldots \ldots \ldots \ldots \ldots \ldots \ldots \ldots \ldots \ldots \ldots \ldots \ldots \ldots \ldots \ldots, \ldots \ldots \ldots$ 


\section{LIST OF FIGURES}

1 RELAP5-Advanced Neutron Source reactor nodalization diagram $\ldots \ldots \ldots \ldots \ldots$

2 Advanced Neutron Source dynamic model nodalization diagram . . . . . . . . . . . . 9

3 Advanced Neutron Source reactor primary loop dynamic model block diagram . . . . . 15

4 Comparison in fission, decay, and total power during the 51-mm-diam core pressure boundary tube break with 250 -ms opening time . . . . . . . . . . . Break flow comparison during the 51-mm-diam core pressure boundary tube outlet break with 250 -ms opening time . . . . . . . . . . . . . . . . . .

6 Mass flow comparison at locations upstream and downstream of the break during the 51-mm-diam core pressure boundary tube outiet break with

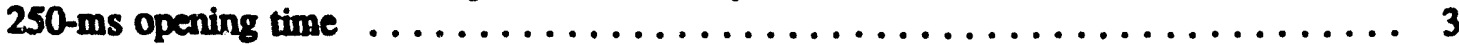

7 Comparison in pressure responses at the core pressure boundary tube (CPBT) inlet and outlet during the 51-mm-diam CPBT outlet break with 250-ms opening time . . 37 Heat flux comparison at the hot spot of the upper core showing Costa, Gambill/Weatherhead, and local surface heat fluxes during the 51-mm-diam core pressure boundary tube outlet break with 250-ms opening time

Heat flux comparison at the hot spot of the lower core showing Costa, Gambill/Weatherhead, and local surface heat fluxes during the 51-mm-diam core pressure boundary tube outlet break with 250 -ms opening time $\ldots \ldots \ldots \ldots \ldots$

10 Comparison in bulk coolant temperature at the hot channel outlet for the lower and upper cores during the 51-mm-diam core pressure boundary tube outlet break with 250 -ms opening time $\ldots \ldots \ldots \ldots \ldots \ldots \ldots \ldots \ldots \ldots$

11 Makeup and letdown flow comparison during the 51-mm-diam core pressure boundary tube outlet break with 250 -ms opening time $\ldots \ldots \ldots \ldots \ldots \ldots \ldots \ldots$

12 Accumulator injection flow comparison during the 51-mm-diam core pressure boundary tube outlet break with 250 -ms opening time .............

13 Total (fission plus decay heat) power generated in the two mociels during the station blackout accident Comparison in coolant temperature at the lower-core hot-channel outlet during the station blackout accident

15 Coolant temperature at the lower-core hot-channel outlet during the station blackout accident $\ldots \ldots \ldots \ldots \ldots \ldots \ldots \ldots \ldots \ldots$

16 Main circulation pump coastdown speed during the station blackout

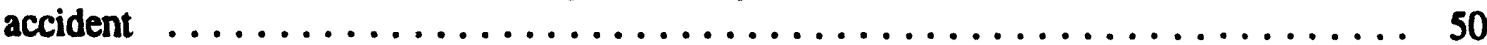

17 Core coolant velocity during the station blackout accident $\ldots \ldots \ldots \ldots \ldots \ldots \ldots$

18 Core coolant mass flow during the station blackout accident $\ldots \ldots \ldots \ldots \ldots \ldots \ldots$

19 Comparison in core outlet pressure during the station blackout

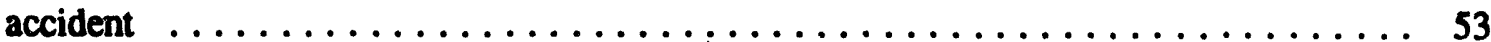

20 Comparison in core outlet pressure during the sidtion blackout

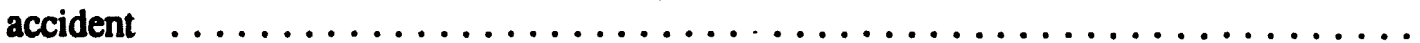

21 RELAP5-calculated thermal limit ratios during the station blackout

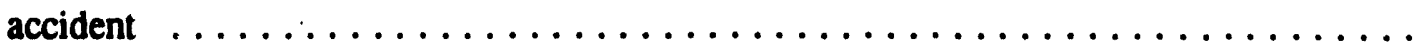


22 Advanced Neutron Source reactor core region showing the primary supply vessel adapter weldment $\ldots \ldots \ldots \ldots \ldots \ldots \ldots \ldots \ldots \ldots \ldots \ldots \ldots$

23 Commarison in total core and break flows during the double-ended guillotine break at primary supply vessel adapter weldment with

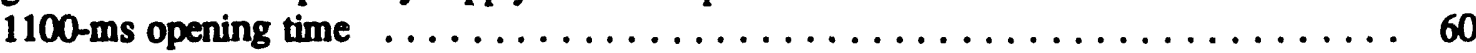

24 Comparison in pressures at the lower core inlet and outlet during the double-ended guillotine break with 1100 -ms opening time $\ldots \ldots \ldots \ldots \ldots 1$

25 Costa limit and local surface heat fluxes at the lower core exit during the double-ended guillotine break with 1100-ms opening time . . . . . . . . . 62

26 Good agreement in heat fluxes at the lower core exit during the double-ended guillotine break at primary supply vessel adapter weldment when three models used the same setpoint . . . . . . . . . . . . . . . . 64

27 Pressure difference (change from steady state) at the hot leg riser outlet and accumulator inlet during the double-ended guillotine break with 1.1 s opening time $\ldots \ldots \ldots \ldots \ldots \ldots \ldots \ldots \ldots \ldots \ldots \ldots \ldots \ldots \ldots \ldots$

28 Advanced Neutron Source dymamic model-calculated heat fluxes showing the importance of pressure setpoints in terms of the nominal value during the double-ended guillotine break with 1100 -ms opening time $\ldots \ldots \ldots \ldots \ldots \ldots 66$ RELAPS-calculated flows showing the total core flow, break flows upstream and dowinstream of the break, and individual accumulator flows during the double-ended guillotine break with 1100 -ms opening time $\ldots \ldots \ldots \ldots \ldots \ldots \ldots$

30 Advanced Neutron Source dynamic model (ANSDM) vs RELAPS comparison in total and fuel surface heat powers for the $\$ 0.80$ reactivity step accident before comection of ANSDM fuel heat capacity .............. 70

31 Advanced Neutron Source dynamic model (ANSDM) vs RELAP5 comparison in total and fuel surface heat powers for the $\$ 0.80$ reactivity step accident after correction of ANSDM fuel heat capacity . . . . . . . . . . . 71

32 Advanced Neutron Source dynamic model vs RELAPS comparison in thermal limit ratios for the $\$ 0.80$ reactivity step accident $\ldots \ldots \ldots \ldots \ldots \ldots \ldots \ldots \ldots \ldots$

33 Advanced Neutron Source dynamic model vs RELAP5 comparison in local surface heat flux at the lower core exit for the $\$ 0.80$ reactivity step accident

34 Advanced Neutron Source dynamic model vs RELAP5 comparison in the local coolant velocity and saturation temperature at the lower core exit for the $\$ 0.80$ reactivity step accident $\ldots \ldots \ldots \ldots \ldots \ldots \ldots \ldots \ldots$ Advanced Neutron Source Jynamic model vs RELAP5 comparison in the local pressure and coolant temperalure for the $\$ 0.80$ reactivity step accident . . . . . . . 75

36 RELAP5-calculated pressure changes with reference to the steady-state showing the acoustic propagation during the power burst along the loop for the $\$ 0.80$ reactivity step accident 


\section{LIST OF TABLES}

Table

Page

1 Distribution of fission and decay-heal powers used by RELAP5,

Advanced Neutron Source dynamic model and PRSDYN at $100 \%$ power . . . . . . . 5

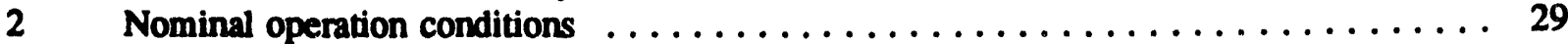

3 Normalized power density of 13 fuel grading at the end-of-cycle $\ldots \ldots \ldots \ldots \ldots$

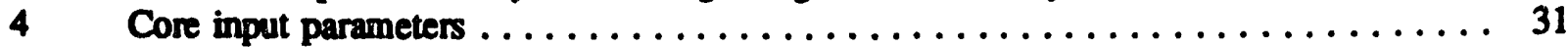

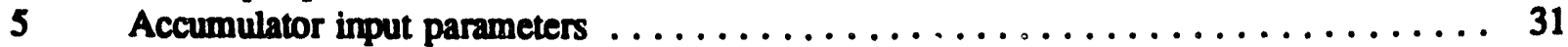

6 Inertial flow diode input parameters $\ldots \ldots \ldots \ldots \ldots \ldots \ldots \ldots \ldots \ldots \ldots \ldots$

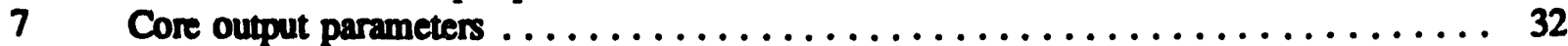

$8 \quad$ Main circslation pump output parameters $\ldots \ldots \ldots \ldots \ldots \ldots \ldots \ldots \ldots \ldots \ldots$

9 Initial conditions for a station blackout comparison $\ldots \ldots \ldots \ldots \ldots \ldots \ldots \ldots \ldots$

10 Steady-state comparison for $200-\mathrm{MW}$ nominal core $\ldots \ldots \ldots \ldots \ldots \ldots \ldots \ldots \ldots$

11 Sequence of events for station blackout benchmark . . . . . . . . . . . . 46

12 Post-scram decay heat regional distribution extrapolated from the

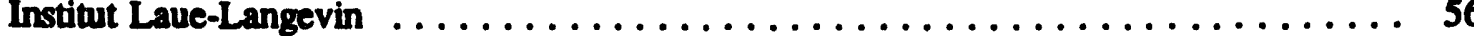

13 Parameters for a large loss of coolant accident $\ldots \ldots \ldots \ldots \ldots \ldots \ldots \ldots \ldots \ldots$

14 Steady-state comparison for $330-\mathrm{MW}$ nominal core $\ldots \ldots \ldots \ldots \ldots \ldots \ldots \ldots \ldots$

15 Improvement to the Advanced Neutron Source reactor thermal-hydraulic

models based on comparison findings $\ldots \ldots \ldots \ldots \ldots \ldots \ldots \ldots \ldots \ldots$ 


\section{LIST OF ACRONYMS}

ACSL

ANSDM

ANSI/ANS

ANS

ANSR

BOC

CDR

CHF

CSAR

CPBT

DEG

EOC

FE

HFIR

IB

III

INEL

LOCA

LWR

NPSH

ORNL

PSVAW

SDD

THIL
Advanced Continuous Simulation Language

Advanced Neutron Source dynamic model

American National Standards Institute/American Nuclear Society

Advanced Neutron Source

Advanced Neutron Source reactor

beginning-of-cycle

conceptual design report

critical heat flux

conceptual safety analysis report

core pressure boundary tube

double-ended guillotine

end-of-cycle

flow excursion

High Flux Isotope Reactor

incipient boiling

Institut Laue-Langevin

Idaho National Engineering Laboratory

loss-of-coolant accident

light water reactor

net positive suction head

Oak Ridge National Laboratory

primary supply vessel adapter weldment

system design description

Thermal-Hydraulic Test Loop 


\section{ACKNOWLEDGMENTS}

The authors would like to acknowledge the support of the ANS Project Office that made this work possible. The authors also thank R. M. Harrington for his enthusiastic encouragement and support, and C. D. Fletcher of INEL for his consultation on RELAP5 analyses and comments on the report. 


\begin{abstract}
As part of verification and validation, the Advanced Neutron Source reactor RELAP5 system model was benchmarked by the Advanced Neutron Source dynamic model (ANSDM) and PRSDYN models. RELAP5 is a one-dimensional, two-phase transient code, developed by the Idaho National Engineering Laboratory for reactor safety analysis. Both the ANSDM and PRSDYN models use a simplified single-phase equation set to predict transient thermal-hydraulic performance. Brief descriptions of each of the codes, modeis, and model limitations were included. Even though comparisons were limited to single-phase conditions, a broad spectrum of accidents was benchmarked: a small loss-of-coolant-accident (LOCA), a large LOCA, a station blackout, and a reactivity insertion accident. The overall conclusion is that the three models yield similar results if the input parameters are the same. However, ANSDM does not capture pressure wave propagation through the coolant system. This difference is significant in very rapid pipe break events. Recommendations are provided for further model improvements.
\end{abstract}




\section{INTRODUCTION}

This report documents a series of code-to-code comparisons that are part of the verification and validation of the RELAP5 Advanced Neutron Source reactor (ANSR) model that will be used for ANSR safety analyses. Two codes have been used for these comparisons: Advanced Neutron Source dynamic model (ANSDM), and PRSDYN. Both of these codes are in-house developed and both use models that have been developed independently of RELAPS.

These code-to-code comparisons are only a partiai step in the verification of RELAP5 for this purpose. Other activities to reach the final goal include (1) comparison of RELAP5 prdictions for pressure drop, flow excursion (FE), and critical heat flux (CHF) to experimental results from the ANSR thermal-hydraulic test loop (THTL) being operated at Oak Ridge National Laboratory (ORNL), (2) comparison of RELAP5 predictions of flow excursion to the data gathered by Costa in support of Institut Laue-Langevin (ILL) design, (3) investigation of RELAPS ability to predict correct void fractions under prototypic ANSR FE conditions, and (4) follow-on thermal-hydraulic experiments and activities that are still in the planning stage.

To accomplish these comparisons, a broad spectrum of accidents have been modeled. The particular conditions and transients benchmarked include: a series of steady states, a small loss-ofcoolant accident (LOCA), a large LOCA, a station blackout, and a reactivity insertion accident. The LOCA calculations include a small core outlet break and a double-ended guillotine (DEG) core inlet break, both assuming a finite time break opening. The station blackout accident analysis is an unusual case that includes a simultaneous cccurrence of a standard loss of off-site power, a loss of pony motors, and a small LOCA because of a stuck-open letdown valve. A reactivity step of \$0.8 was chosen for reactivity insertion accident studies because it is the most limiting reactivity event considered in the Conceptual Safety Analysis Report (CSAR). ${ }^{2}$

This code comparison study is limited to single-phase and noninstantaneous break comparisons. The RELAP5 ${ }^{3}$ code is a one-dimensional, transient, and two-phase flow code developed at the Idaho National Engineering Laboratory (INEL). By contrast, ANSDM uses a simplified singlephase incompressible equation set to predict transient thermal-hydraulic performance. PRSDYN assumes single-phase condiuions but takes into account the compressibility of heavy water (i.e., finite sound speed). The use of three different models is beneficial because it allows cross-checking of the results of independently developed models. Furthermore, the speed and ease of use of both ANSDM and PRSDYN allow many scoping calculations to be run to define trends more completely.

This study spans 1.5 years-from the preconceptual to the conceptual designs. Over this time, numerous changes in reactor operating conditions, fuel grading, and system designs took place.

Because steady-state conditions varied, a reference steady state was established for each case studied, so that a consistent initial condition was ensured for transient comparisons. To reach a meaningful comparison in steady-state results requires a set of common input parameters: power, pressure, velocity, oxide growth, correlations, peaking factors, and probability levels. Moreover, to reach a meaningful comparison in transient results further requires another set of common input parameters: pump performance characteristics, break opening formation, reactivity profile after scram, engineered safety feature actuations, and a plant protection system.

The cross-checking among three models is a painstaking process, but rewarding. In general, for every comparison, a number of iterations is required before a satisfactory agreement can be obtained. The initial comparisons revealed good agreements in some parameters but disagreements in other parameters. Once these discrepancies were identified, possible causes were evamined by performing additional parametric studies until the discrepancies were resolved within acc. ptable accuracy. Through 
this repeated process, a better understanding in models is gained, so that a better improvement in models becomes possible. Discussions of results, comments for future updates, and reasons for discrepancies are provided whenever possible in the conclusions and recommendations. 


\section{MODEL DESCRIPTIONS}

\subsection{RELAPS}

The RELAP5 code has been and is being used in several other research reactor safety analysis efforts. Other similar, highly subcooled, plate-type fuel systems being analyzed with RELAP5 include the High Flux Isotope Reactor (HFIR) ${ }^{4}$ at ORNL, the High Flux Beam Reactor (HFBR) at Brookhaven National Laboratory, the Advanced Test Reactor (ATR) ${ }^{6}$ at INEL, the heavy water production reactors' at Savannah River Laboratory and the Heavy Water New Production Reactor design studies. Each of these efforts has expanded both the experience and confidence in using RELAP5 for highly subcooled reactor systems while concurrently identifying areas in the code that need improvement.

\subsubsection{RELAPS Code Description}

RELAP5 is a one-dimensional systems analysis computer code based on nonhomogeneous, nonequilibrium, two-phase fluid models in a six-equation formulation for mass, momentum, and energy conservation. Through the companion studies, two versions of RELAPS were usedRELAP5/MOD2/VERSION3t and RELAP5/MOD3/VERSION7AC.

The ANSR core geometry and conditions are significantly different from those found in the commercial nuclear power plants for which the RELAPS code was developed and previously assessed. The ANSR features plate-type geometries with narrow coolant gaps and high coolant velocities, and LWR power plants use assemblies of pin-type fuel rods and have moderate nomal coolant velocities. To account for these differences, RELAP5/MOD3/VERSION7AC was modified to better represent thermal-hydraulic phenomena in the ANSR geometry. The code modifications were based on ANSR steady-state design conditions and relevant experimental data. Three code modifications were. implemented for the core region of the model.

The first modification replaced the Dittus-Boelter? single-phase turbulent forced convection heat transfer correlation with the Petukhov ${ }^{10}$ correlation. The Petukhov correlation has been shown to provide better predictive capability than the Dittus-Boelter correlation at the conditions of ANSR normal operation.

The second modification implemented the Gambill correlation ${ }^{11}$ for subcooled CHF prediction, along with the Weatherhead ${ }^{12}$ correlation for predicting the wall temperature. The Gambill correlation is used for mass fluxes $>10,000 \mathrm{~kg} / \mathrm{m}^{2} / \mathrm{s}$; the Groeneveld ${ }^{13}$ lookup table is retained for mass fluxes $<7,500 \mathrm{~kg} / \mathrm{m}^{2} / \mathrm{s}$; and a linear interpolation is used between these limits.

The third modification altered the interfacial drag in the slug-flow regime with a disk-chum flow regime based on the drift-flux formulation developed by Griffith ${ }^{14}$ to describe two-phase density in narrow channels. The modification lowers the interfacial drag, resulting in a lower void fraction for a given flow quality.

\subsubsection{RELAP5 Model Description}

The ANSR RELAPS system model includes three major regions (see Fig. 1). The core model (region 1) consists of the two fuel elements (each constituting approximately half of the core), the core bypass channels, and the central control rod region. The core is surrounded by the core pressure boundary tube (CPBT), which separates the high-pressure primary system from the low-pressure reflector tank. 


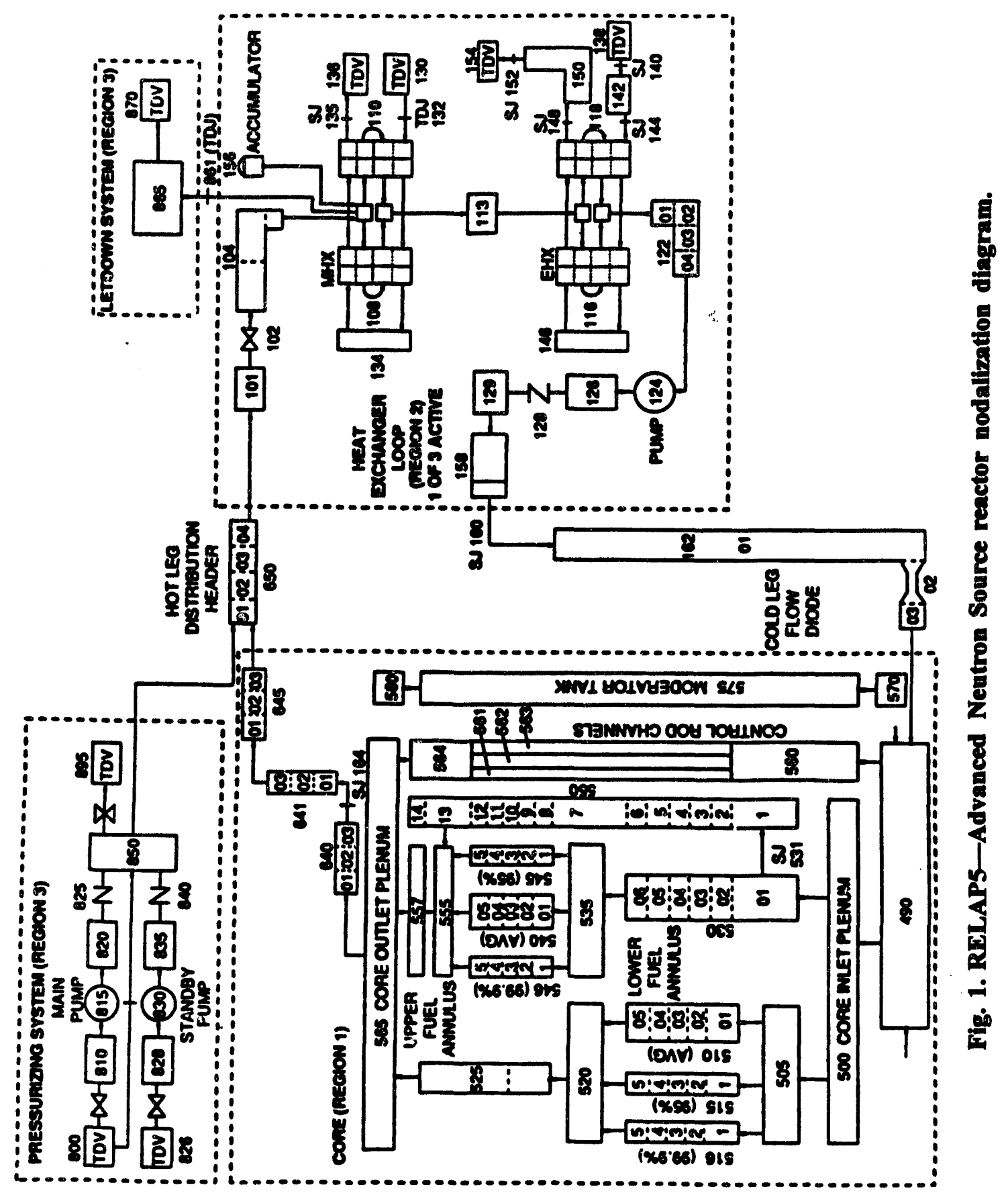


Core power is calculated using a point kinetics model with reactivity feedback from coolant density change and reactivity input as a function of control rod movement. Power is distributed among the various metal and fluid regions according to independent, off-line, steady-state calculations that use the MCNP's computer code to calculate the transport of neutrons and gamma rays from the fuel to all parts of the reactor core and reflector. Table 1 summarizes the regional distribution for several key regions. In addition, the axial nodal power distribution input for each average and hot channel in the core is based on similar detailed, off-line nuclear calculations (BOLD-VENTURE) ${ }^{16}$ that take into account the design distribution of fuel within the plates. The ANSR uses both axial and radial grading of fuel within each fuel plate to reduce power peaking and put the highest heat fluxes nearest the core inlet, to the extent possible, to increase the CHF ratios.

Table 1. Distribution of fission and decay-heat power used by RELAPS, Advanced Neutron Source dynamic model and PRSDYN at $100 \%$ power

\begin{tabular}{lcc}
\hline Reactor component & $\begin{array}{c}\text { Fraction of } \\
\text { fission power }\end{array}$ & $\begin{array}{c}\text { Fraction of decay } \\
\text { heat power }\end{array}$ \\
\hline Fuel elements & 0.94050 & 0.6302 \\
Reactor core coolant & 0.01 & 0.01 \\
Bypass components & 0.02908 & 0.2106 \\
Annulus components & 0.01042 & 0.0700 \\
Reactor components & 0.010 & 0.0792 \\
\hline
\end{tabular}

Each fuel element is modeled as an average channel (which incorporates all but two of the fuel plates) and two hot channels representing the most limiting axial relative power density profile in each core half. Manufacturing, design, correlation, and measurement uncertainties are combined in an appropriate manner, considering the frequency category of the event being analyzed. For each fuel element, the uncertainties affecting heat flux in one of the hot channels are combined at a 95\% probability of nonexceedance for analysis of unlikely events (i.e., frequency $<0.01 /$ year but $>10^{-4} /$ year), and the uncertainties in the other hot channel are combined at a $99.9 \%$ nonexceedance probability level for analysis of anticipated events (frequency $>0.01 /$ year). The purpose of the hot channels is to calculate the most severe axial bulk temperatire profile within the core that is consistent with the two probability levels. This calculation is performed primarily for the prediction of FE, which is of concem because it could lead to CHF and probable fuel damage.

Each of the three channels (average, 95\% hot, and 99.9\% hot) is divided into five axial nodes, and results of off-line, steady-state BOLD-VENTURE neutronic calculations determine the input for the relative power level in the five nodes. The relative power density assigned to each axial segment of the average channel is determined by averaging the neutronically calculated relative power density of all radial regions in that axial segment. The relative power density for each of the five axial segments in the hot channel is determined from the most limiting radial region of the core (as determined from steady-state neutronic and thermal-hydraulic calculations). The hot spot factors for the "hot stripe" used to predict spot CHF are based on the neutronically determined maximum relative 
power density within each segment. The hot spot heat flux is much greater because it includes the uncertainties on spot fuel distribution.

The loop model (region 2) contains four independent heat exchanger loops-three active and one standby. Each loop further consists of an isolation valve, a hot/cold leg, an accumulator, horizontal $U$-tube main and emergency heat exchangers, a centrifugal main circulating pump, and an inertial flow diode (a preferred directional flow device). The heavy water primary coolant is located on the shell side of both heat exchangers for easier maintenance. In the event of a loss of secondary cooling, the temperature rise in the primary system coolant and corresponding increase in temperature differential between the primary system and the pool light water initiates natural circulation of the pool water on the secondary side of the emergency heat exchanger. The heat transfer coefficients and pressure drop coefficients used in the main and emergency heat exchanger models are derived from design data. The single-phase homologous curve of the main circulation pumps was developed from three-quadrant Byron Jackson ${ }^{17}$ design curves, and correlations used to describe pumping behavior in the event that two-phase flow should develop during a transient are based on Semiscale ${ }^{16}$ data.

An open-loop representation of the letdown and pressurizing system (region 3 ) is included in the model. Letdown flow is extracted from the inlet plena of the three main heat exchangers, directed through letdown valves into the large $\left(-50 \mathrm{~m}^{3}\right)$ letdown tank, and retumed through high-head pressurizing pumps to the hot leg distribution header. The primary system core outlet pressure is controlled through modulation of the letdown valves. The input for initial valve opening allows the valve to pass the design nominal $15 \mathrm{~kg} / \mathrm{s}$ letdown flow at normal operating pressure. A feedback loop based on deviation of core outlet pressure from nominal determines the valve modulation open or closed after time zero.

The pressurizing system contains two independent parallel operating pumps-main and standby. Injection flow is drawn from a constant temperature heavy-water source (e.g., the letdown tank) by the main pressurizing pump. The standby pump does not operate during normal operation but is started if the letdown valve closes on a low pressure signal. Following letdown isolation, flow through the pressurizing pump is assumed to continue until the integrated injected flow exhausts the letdown tank.

In the model, letdown flow is controlled via valves and isolated gradually, such as would occur with a motor operated valve. Primary coolant system pressure is controlled by adjusting the letdown flow area, which is represented as follows:

$$
d=k\left(P-P_{d}\right)
$$

and

$$
t=\frac{d-x}{\tau}
$$

where

$$
\begin{aligned}
& d=\text { demanded valve position (normalized), } \\
& k=\text { the proportional-controller constant }\left(\mathrm{Pa}^{-1}\right), \\
& P=\text { the measured sensor pressure }(\mathrm{Pa}), \\
& P_{3}=\text { th setpoint pressure }(\mathrm{Pa}),
\end{aligned}
$$


$\dot{x}=$ time derivative of normalized valve position $\left(\mathrm{s}^{-1}\right)$,

$x=$ normalized valve position ( -1 for fully closed, 1 for fully open, and 0 at normal position),

T = the valve time constant (s).

\subsubsection{RELAPS Model Limitations}

As do ANSDM and PRSDYN, RELAP5 uses a point kinetics space independent (zerodimensiona) formalism for the neutron dynamics in the core region. The power is distributed among different components (e.g., fuel elements, reflector, bypass region, etc.) based on steady-state power fraction distributions that have been estimated for the specific ANSR conditions. This estimation is not a bad approximation since most transients result in a reastor scram within the first few milliseconds, and then the power is determined by a decay heat calculation using the American National Standards Institute/American Nuclear Society (ANSIANS) ${ }^{10}$ standard that is built into the RELAPS code. IN L has developed a one-dimensional (axial) model to account for spatial variation in the core power response during control rod insertions. A full three-dimensional model is under development for beam tube flooding events.

The RELAP5 accumulator model is deficient for modeling the ANSR accumulator because is is incapable of representing flow into the tank and the honeycomb insert heat structure. INEL is developing a new model and assessing the validity of the model against the Savannah River Laboratory data. In the interim, a simple sccumulator model without these limitations was used.

The RELAPS pump model fertures the capability (with suitable test data to support the input) for modeling two-phase degredation effects resulting from the appearance of void in the pump suction but does not include the more limitin. cavitation effects resulting from the appearance of void on the pump impeller. The easiest cavitation modeling is to degrade pump performance by reducing pump speed to effect the desired head degradation whenever indication of pump cavitation is sensed. This approach was incorporated in the HFIR upgraded safety analysis and implemented in the current ANSR RELAP5 system model.

\subsection{ADVANCED NEUTRON SOURCE DYNAMIC MODEL}

ANSDM has been programmed in the Advanced Continuous Simulation Language (ACSL), ${ }^{20}$ which gives it fairly good flexibility of operation at run time. This model was originally designed to test and define control and plant protection system design requirements, but it has also been used to evaluate the reactivity events in the Conceptual Safety Analysis Report (CSAR). ${ }^{2}$ ANSDM is composed of a collection of modules, most of which are reused throughout the model.

\subsubsection{Advanced Neutron Source Dynamic Model Code Description}

The "code" for ANSDM is ACSL, level 10R: ACSL automatically controls all numerical aspects of the equations used to model the physical behavior of the reactor (e.g., time-steps used, numerical convergence, etc.). This programming language contains only the numerical aspects and no physics. All aspects of fluid flow, heat transfer, neutronics, etc. are contained within the model described belor At run time, the user can select the integration algorithm and precision. As a default, ANSDM uses a Gears-stiff, fully implicit integration method; ACSL automatically adjusts 
the time step size to maintain the estimated error within $<10^{-3}$ relative or $10^{-4}$ absolute for every integration interval.

\subsection{Advanced Neutron Source Dynamic Model Description}

A simplified nodalization diagram is shown in Fig. 2. The main characteristics of ANSDM can be described as follows.

- Core neutronics are modeled using the point kinetics approximation. The photodelayed neutrons are treated as an additional group of delayed neutrons. Decay heat is tabulated based on an ANSspecific correlation, which includes the distribution of decay heat among reactor intemals. As a default it is assumed that $-94 \%$ of the fission power remains inside the fuel plate and the rest is deposited by direct energy deposition in the reflector and vessel components. However, only $-65 \%$ of the decay heat is deposited in the fuel plate (see Table 1). The difference is caused by the fact that decay heat generates mostly gamma rays, which deposit their energy outside the core. The 65\% is based on IIL extrapolations; new INEL calculations appear to indicate that the fraction of decay heat deposited in the fuel should be on the order of $72 \%$.

- The fuel and coolant dynamics are modeled on an average channel basis. The average channel determines the core outlet conditions as well as the neutronic and thermohydraulic feedback that couples the core to the rest of the cooling system. A single axial node is used for this calculation. As a default, a constant 25- $\mu \mathrm{m}$ oxide layer is assumed to estimate fuel temperatures, and oxide growth is not modeled.

- The hot channels' fuel and coolant dynamics are simulated to represent the dynamic behavior of the hot streak of the upper and lower element. The lower element is typically limited at beginningof-cycle (BOC) and the upper element at end-of-cycle (EOC). Thus, in this model, the BOC axial power shape and hot streak factors for the lower element hot channel and the EOC conditions for the upper element are used. The hot channels are divided into as many as $\mathbf{5 0}$ axial nodes (typically 27) where local temperatures, pressures, and heat fluxes are estimated to determine their margin to incipient boiling (IB), CHF, and FE instability. Hot channels do not contribute any feedback to the neutronics or thermohydraulic calculaticns of the rest of the cooling system.

- A bypass region models the flow of leavy water that bypasses the fuel elements inside the CPBT. This coolant is typically colder than the core outlet coolant so that when it mixes, the vessel outlet temperature (which is computed dynamically) is lower than the core outlet temperature.

- A reflector region is modeled with a very simplified one node approach. The reflector provides some (but not much) reactivity fee zack to the core as a result of direct neutron and gamma heating.

- Cooling system pipes that release heat to the appropriate surrounding light water pools are modeled.

- In-containment light water pools are modeled including the main reactor pipe chase and heat exchanger pools. These pools remove heat from the reactor piping according to relative temperature and natural convection heat transfer coefficients. The heat exchanger pool also cools the emergency heat exchanger secondary side by natural circulation. 
ANS DYNAMIC MODEL (ANSDM) COMPONENTS

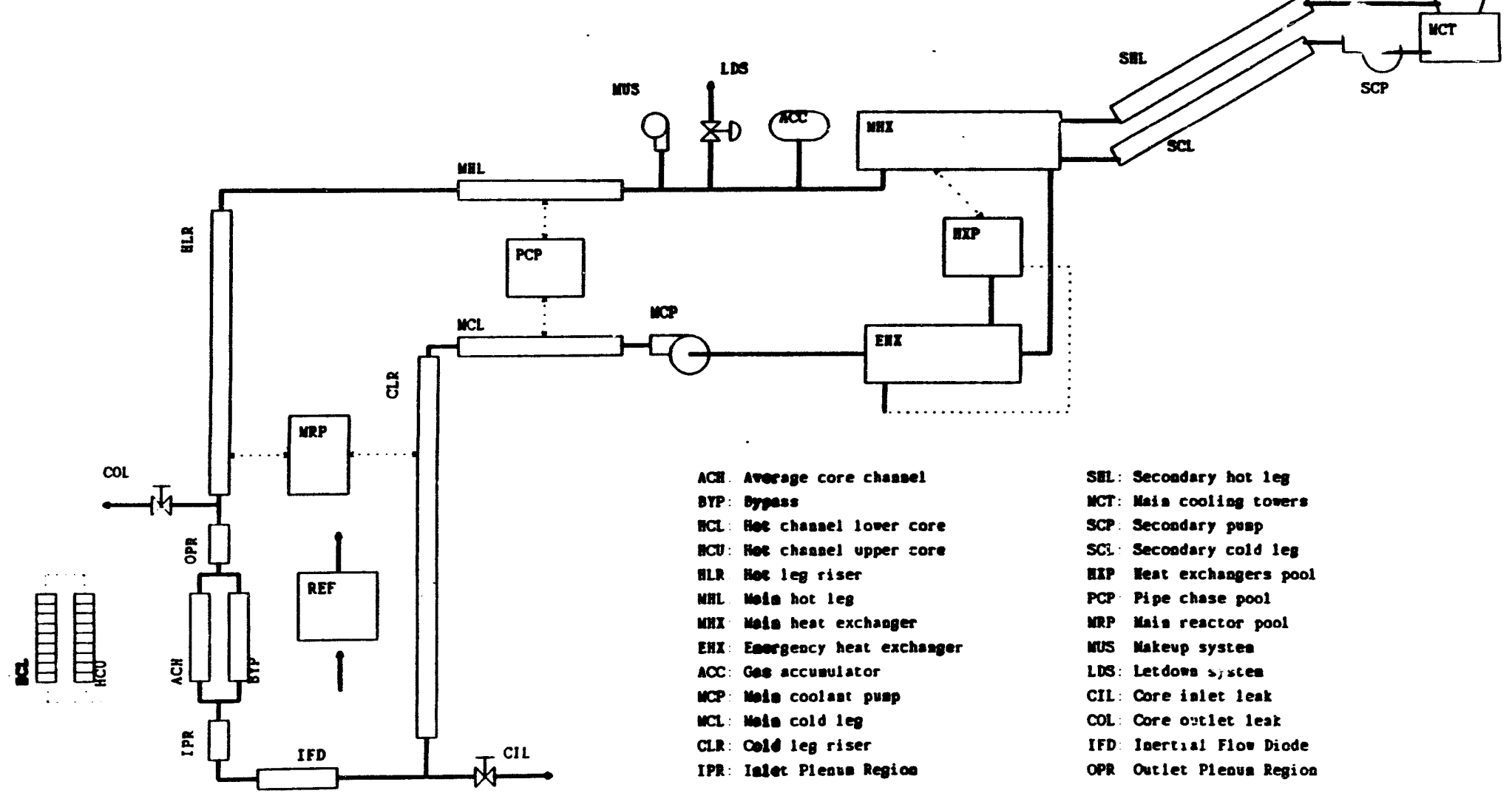

Fig. 2. Advanced Neutron Source dynamic model nodalization diagram. 
- The main heat exchanger is modeled with the primary flow in the shell side and the secondary flow in the tube side. Hear transfer characteristics are adjustable; typically used values include a fouling heat transfer resistance factor. The heat exchanger model uses a single node with the logarithmic mean-temperature approximation.

- The emergency heat exchanger is modeled in series with the main heat exchanger. Primary flow is in the shell side and secondary flow is on the tube side. The shell side (primary) assumes that the flow is never laminar, regardless of Reynolds number. The diameter of the tubes is designed to be on the order of $0.05 \mathrm{~m}(2 \mathrm{in}$.) 20 that the Reynolds number will be large enough to ensure turbulent flow even at the low natural circulation flow rates. The eccondary side of the emergency heat exchanger is connected to the heat exchangers pool; cooling flow occurs by natural circulation.

- Main circulation pumps are modeled according to the head-fiow characteristic curve. The characteristic curve scales the flow directly proportional to the pump rotational speed; the pump head is proportional to the square of the pump speed; and the power required is proportional to the third power of the speed. Pump cosstdown is modeled based on a conservation of angular momentum and assuming no friction. The resulting differential equation that is colved by the model is:

$$
\frac{d n}{d t}=\frac{\left(n^{2}-n_{0}^{2}\right)}{T}
$$

where

$n$ =the pump rotational speed $\left(8^{-1}\right)$,

$n_{0}=$ the desired equilibrium speed (e.g., $n_{0}=10 \%$ if a reduction to pony flow is desired),

$T=$ the pump half speed time constant (nominally 28 in ANSR).

The coastdown flow and pump head are computed by scaling the characteristic pump curve using the calculated speed, $n$. To simulate the effects of friction, a negative equilibrium speed $\left(n_{0}\right)$ may be input to force the speed $(n)$ to drop to zero in a finite time. By adjusting $n_{0}$ and $\tau$, practically any pump coastdown may be achieved. During normal operation, the pump speed is assumed to remain constant (i.e., sysichronous ac motors) regardless of the coolant conditions.

- The gas accumulator is assumed to follow the ideal gas law, 80 that the accumulator gas pressure is estimated from the following equations:

$$
P=P_{0}\left(\frac{V_{0}}{V}\right)^{\gamma}
$$


and

$$
\frac{d V}{d t}=\frac{\omega}{p}
$$

where

$$
\begin{aligned}
P & =\text { pressure }(\mathrm{Pa}), \\
P_{0} & =\text { initial pressure }(\mathrm{Pa}) \\
V_{0} & =\text { initial volume }\left(\mathrm{m}^{3}\right) \\
V & =\text { volume }\left(\mathrm{m}^{3}\right) \\
\gamma & =\text { expansion coefficient, } \\
\omega & =\text { the mass flow rate of liquid leaving the accumulator }(\mathrm{kg} / \mathrm{s}), \\
P & =\text { the density }\left(\mathrm{kg} / \mathrm{m}^{3}\right) .
\end{aligned}
$$

It is assumed that the accumulators expand isothermally (i.e., $\gamma=1.0$ ) as a default, but the parameter $\gamma$ can be changed to 1.4 on demand to simulate an adiabatic expansion. The initial gas to liquid ratio is such that the liquid level will not reach the bottom of the accumulator after the gas has expanded to the depressurized condition. In the ANS baseline conceptuin design, each accumulator has 0.52 and $7 \mathrm{~m}^{3}$ of gas and liquid, respectively. Because ANSDM is a single-loop model, the single accumulator in ANSDM has three times those volumes.

- Primary coolant is maintained at pressure by the makeup flow. The model simulates this flow with a pump module (the pressurizer pump) that takes suction on a constant pressure tank (the letdown tank). The makeup pump speed is maintained constant unless a coastdown (i.e., loss of off-site power) is required. The pump speed can be altered on demand to simulate the initiation of the standby makeup pump. Pressure regulation is accomplished by modulating the flow through the letdown valves. The letdown valves are modeled as a pressure drop with variable coefficient (according to valve opening); the letdown flow is collected in the letdown tank. The model does not simulate the low pressure cleanup system; the letdown tank is assumed to have an infinite supply of $\mathrm{D}_{2} \mathrm{O}$ so that makeup can always be maintained. Makeup supply problems can be simulated at any time by tripping the makeup pump. The makeup pump is assumed to have a perfect (i.e, no reverse flow) check valve.

- The secondary side of the ANS cooling system is represented by: (1) the secondary side of the main heat exchanger in the tube side, (2) the secondary hot leg, (3) the main cooling towers and cooling towers basin, (4) the secondary circulation pump, and (5) the secondary cold leg. All of these components use approximations similar to those in the primary system.

- A preliminary control system is simulated in the model. The control system includes: (1) control rod position based on the measured power-to-flow. ratio, (2) pressure contrul that actuates the letdown valve based on hot leg pressure measurements, and (3) core inlet temperature control that actuates on the secondary flow based on the temperature measured at heat exchangers outlet.

- Sensor dynamics are modeled as first-order lag systems. The required time constants have been determined through simulation of control and plant protection system challenges. The time constants currently in the model are those required to satisfy most design basis events 
requirements. The neutron flux sensors have a conservative 25-ms delay to simulate the "neutronwave" time delay introduced by the large heavy water reflector.

- Breaks are simulated as a flow through an orifice (of the break effective diameter) from the inside of the main piping system to the light water pools. The leak flow, $W_{l k}$ is estimated from the orifice relation as:

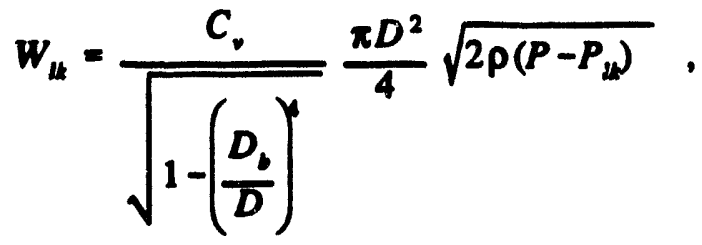

where

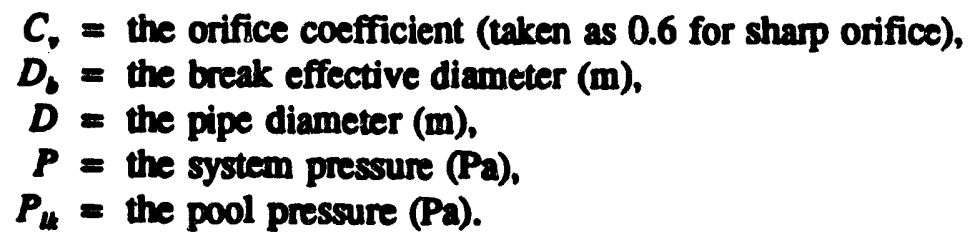

\subsubsection{Advanced Neutron Source Dynamic Model Correlations}

ANSDM uses the standard set of correlations developed by the ANS Project. These correlations are fully documented in Sect. 4.4.2.7 of the CSAR ${ }^{2}$ and can be summarized as follows.

- Filonenko correlation for friction coefficient in the core region. A multiplier can be input to ANSDM to adjust the pressure drop calculated using Filonenko. In this way, agreement may be forced between different codes. As an example, for the benchmarks in this report, a multiplier of 113\% was added to match ANSDM pressure drops with those of RELAP5. This large multiplier was required because ANSDM computes coolant parameters (especially viscosity) using the core outiet temperature (i.e., hot conditions), and RELAPS was adjusted to agree with the ANSR steady-state model that uses local conditions.

- Colebrook and White correlation for friction in the piping system. Note that Filonenko is only valid for the smooth surfaces in the core, the piping surfaces require a surface roughness of 4.5.7 $\mu \mathrm{m}$.

- Petukhov heat transfer coefficient in the core region.

- Gambill-Weatherhead correlation for CHF in subcooled flow. ANSDM computes the ratio of actual flux to CHF at each of the (typically 27) axial nodes for the hot channels in the upper and lower core using the local pressure and temperature conditions. ANSDM typically prints the minimum of these ratios and their respective axial locations to the screen.

- Costa correlation for FE. Although the Costa correlation was deveioped based on outlet conditions only, ANSDM computes the FE limiting heat flux ratio at every axial location and prints out the minimum ratio and its axial location. 
- Standard coolant properties correlations developed by the ANS Project for $D_{2} O$ properties.

- Gibson correlation (shell side) and the Churchill correlation (tube side) for heat transfer characteristics in the heat exchangers.

\subsubsection{Advanced Neutron Source Dynamic Model Limitations}

The most important limitations of the ANSDM are described below.

- Point kinetics for the neutron dynamics in the core region. The power is distributed among different components (e.g., upper and lower elements, reflector, bypass region, etc.) based on steady-ata power fraction distributions that have been estimated for the specific ANSR conditions. This method of approximation is not particularly bad since most transients result in a reactor scram within the first few milliseconds, and thea the power is determined by a decay heat correlation.

- Incompressible flow. The model is limited to liquid and incompressible phase state. This assumption results in an infinite speed of round and yields significant errors when acoustic-wave propagation is a relevant phenomenon (for instance, during fast-opening large break LOCAs). This approximation, however, is fairly accurate for other scenarios that do not involve fast pressure transients.

- Single phase flow. The model is limited to the liquid phase state; whenever a transient results in saturated boiling, the simulation fails. Note that the core typically is damaged (resulting from either CHF or FE instabilities) well before saturated boiling can be established, and, thus, this approximation is fairly accurate for most scenarios.

- Single bop now dynamics. All three loops are simulated by one effective loop. Because of this approximation, the model is not able to simulate imbalances between loops; for instance, the shutdown of side pump cannot be modeled while the other two pumps are operating.

- Poor reverse flow model. The model fails to compute enthalpies properly if reverse flow is established. Note, however, that reverse flow occurs only during large break LOCAs in the hot leg, and the hot leg enthalpy is fairly irrelevant during these transients.

\subsection{PRSDYN}

\subsubsection{PRSDYN Code Description}

PRSDYN is similar to ANSDM in that ACSL is used to take care of all numerical details, and the PRSDYN model contains all of the physics necessary to describe the transient behavior of the reactor.

\subsubsection{PRSDYN Model Description}

This section deals with the description of a dynamic model (PRSDYN) for ANSR that is capable of simulating possible accident and operation scenarios of the plant, including events with 
very rapid pressure dynamics. The model is written in modular form as shown in the block diagram in Fig. 3 and is programmed in ACSL. The model includes the following modules: core neutronics, channei and pipe thermal hydraulies, vessel bypass and annulus, heat exchangers, main circulation pumps, gas accumulators, makeup and control systems, and sensor and break modules.

\subsubsection{Core Neutronics}

The ANSR neutronics are described by a point kinetics model that includes both delayed neutrons and photo-neutrons. Equations 6 and 7 show the mathematical formulation for the neutron flux and the precurcor concentrations normalized to the nominal reactor power.

$$
\$=\frac{\left(p_{m}-1\right) \beta^{\beta}}{\Lambda} \Phi+2 \lambda_{1} C_{1}
$$

where

$$
\begin{aligned}
& \text { = rate of change of normalized flux, }\left(8^{-1}\right) \\
& P_{\text {m. }}=\text { total resctivity (S), } \\
& \beta=\text { total delayed neutron fraction, } \\
& \text { A = efiective neutron lifetime (8), } \\
& \Phi=\text { normalized flux (fraction of full power value), } \\
& \lambda_{1}=\text { decay constant of the } i^{-1} \text { group of delayed neutrons }\left(\mathrm{s}^{-1}\right) \text {, } \\
& C_{1}=\text { normalized precureor concentration (fraction of full power value). } \\
& C_{1}=\frac{\beta_{1}}{\Lambda}-\lambda_{1} C_{1}
\end{aligned}
$$

where

$C=$ rate of change of normalized $i^{\star}$ precursor concentration $\left(\mathrm{s}^{-1}\right)$,

$\beta_{1}=$ delayed fraction fo the delay group,

$\Lambda=$ effective neutron lifetime (s).

The reactivity feedback, $p_{\text {son }}$ is computed as follows:

$$
P_{s}=\alpha_{c} \frac{Q_{c}}{Q_{\infty}}+\alpha_{b} \frac{Q_{b}}{Q_{\infty}}+\alpha_{i} \frac{Q_{p}}{Q_{\infty}}+\alpha_{j}\left(T_{f}-T_{s 0}\right)
$$

where
$\alpha_{c}=$ core coolant density reactivity coefficient (\$),
$Q_{e}=$ core coolant density $\left(\mathrm{kg} / \mathrm{m}^{3}\right)$,
$Q_{n}=$ initial core coolant density $\left(\mathrm{kg} / \mathrm{m}^{3}\right)$,
$\alpha_{b}=$ bypass coolant density reactivity coefficient (\$),
$Q_{b}=$ bypass coolant derisity $\left(\mathrm{kg} / \mathrm{m}^{3}\right)$,
$Q_{\infty}=$ initial bypass coolant density $\left(\mathrm{kg} / \mathrm{m}^{3}\right)$, 


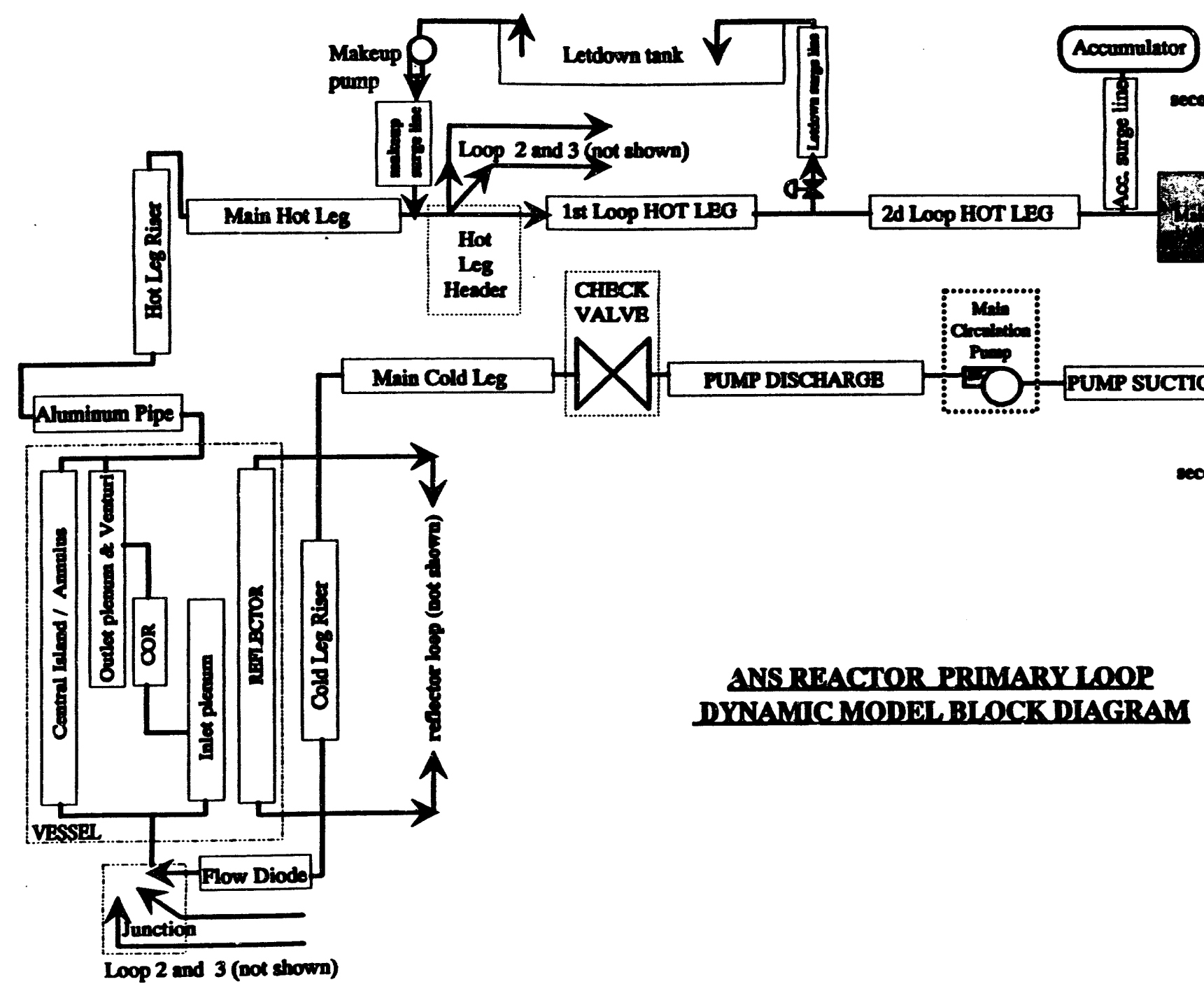

Fig. 3. Advanced Neutron Source reactor primary loop dynamic model block diagram. 
$\alpha_{r}=$ reflector coolant density reactivity coefficient (\$),

$Q_{r}=$ reflector coolant density $\left(\mathrm{kg} / \mathrm{m}^{3}\right)$,

$Q_{10}=$ reflector coolant density at time $0\left(\mathrm{~kg}^{\mathrm{m}} \mathrm{m}^{3}\right)$,

$\alpha_{1}=$ fuel temperature reactivity coefficient $\left(\$ /{ }^{\circ} \mathrm{C}\right)$,

$T_{f}=$ fuel temperature $\left({ }^{\circ} \mathrm{C}\right)$.

$T_{f 0}=$ initial fuel temperature $\left({ }^{\circ} \mathrm{C}\right)$.

The total reactivity is

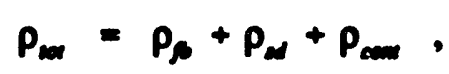

where

$$
\begin{aligned}
\rho_{\rho} & =\text { reactivity feedback }(\$), \\
\rho_{\mu} & =\text { shutdown system reactivity }(\$) \\
P_{c o m} & =\text { control system reactivity }(\$) .
\end{aligned}
$$

The total power, $P_{n}$ is the sum of the fission power, $P_{n,}$ and decay-heat power, $P_{g}$. The distribution of fission power and decay-heat power among reactor components is shown in Table 1.

\subsubsection{Channel Thermal Hydraulice}

This subsection deals with thermal-hydraulics of the average channel, which is modeled in a singie-node approximation. PRSDYN describes the coolant enthalpy and the oxide surface cladding, and fuel surface temperatures.

The channel exit enthalpy, $h_{\text {our }}$ is determined from an energy balance that results in the following differential equation:

$$
h_{\text {ow }}=\frac{q_{\text {cood }}-\Delta(\omega h)}{m_{\text {cod }}} \text {, }
$$

where

$$
\begin{aligned}
q_{\text {cood }} & =\text { power transferred to coolant }(\mathrm{W}), \\
\omega & =\text { coolant flow rate }(\mathrm{kg} / \mathrm{s}) \\
h & =\text { enthalpy }(\mathrm{J} / \mathrm{kg}) \\
m_{\text {cod }} & =\text { node coolant mass }(\mathrm{kg}) .
\end{aligned}
$$

An equation for determination of the wall temperature, $T_{\text {wall }}$ is obtained from:

$$
\frac{d\left(M_{\text {mell }} C_{p_{\text {-1 }}} T_{\text {mell }}\right)}{d t}=q_{\text {ded }}-H_{\text {find }} A_{\text {mell }}\left(T_{\text {mel }}-T_{D_{p} \rho}\right) \text {, }
$$


where

$M_{\text {m }}=$ mass of the wall [oxide $(\mathrm{kg})$ ],

$C_{p_{1}}=$ wall hest capacity $\left(J / \mathrm{kg} /{ }^{\circ} \mathrm{C}\right)$,

$T_{\text {mall }}=$ wall (oxide) temperature $\left({ }^{\circ} \mathrm{C}\right)$,

$q_{\text {dw }}=$ power inside the wall $(W)$,

$H_{m_{m}}=$ film beat transfer $\left(W /{ }^{\circ} \mathrm{C} / \mathrm{m}^{2}\right)$,

$A_{m}=$ wall heat transfer area $\left(\mathrm{m}^{2}\right)$,

$T_{D_{2} \rho}=$ average coolant temperature $\left({ }^{\circ} \mathrm{C}\right)$;

and

$$
T_{m}=\frac{q_{m}-H_{m} A_{m}\left(T_{m-1}-T_{D_{0}}\right)}{M_{m} C_{p_{1}}},
$$

where

$q_{\text {ma }}=$ power transferred from the cladding to the wall (oxide) as defined in Eq. 13 (W),

$H_{\mu_{m}}=$ film heat transfer $\left(W /{ }^{\circ} \mathrm{C} / \mathrm{m}^{2}\right)$,

$A_{m}=$ wall heat transfer area $\left(m^{2}\right)$,

$T_{\text {mal }}=$ wall (oxide) temperature $\left({ }^{\circ} \mathrm{C}\right)$,

$T_{D, 0}=$ average coolant temperature $\left({ }^{\circ} \mathrm{C}\right)$,

$M_{\text {m }}=$ mass of the wall [oxide $(\mathrm{kg})$ ],

$C_{n_{\text {ma }}}=$ wall heat capacity $\left(\mathrm{J} / \mathrm{kg} /{ }^{\circ} \mathrm{C}\right)$.

The power transferred from the cladding to the wall (oxide), $q_{\text {mon }}$ is given by:

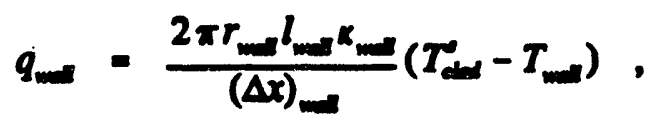

where

$r_{\text {mal }}=$ average wall radius $(m)$,

$l_{\text {mal }}=$ wall length $(m)$,

$\kappa_{\text {mall }}=$ thermal conductivity $\left(W / m /{ }^{\circ} \mathrm{C}\right)$,

$(\Delta x)_{\text {mal }}=$ wall thickness $(m)$,

$T_{\text {dud }}^{\prime}=$ cladding surface temperature $\left({ }^{\circ} \mathrm{C}\right)$,

$I_{\text {mal }}=$ wall (oxide) temperature $\left({ }^{\circ} \mathrm{C}\right.$ ).

The cladding outer surface temperature, $T_{d w}$ is given by:

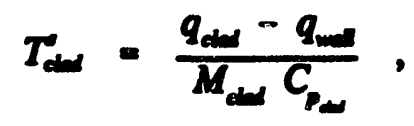


where

$q_{\text {den }}=$ power inside the wall $(W)$,

$q_{\text {mal }}=$ power transferred from the cladding to the wall (oxide) as defined in Eq. 13 (W),

$M_{\text {aw }}=$ mass of the clad [oxide $(\mathrm{kg})$ ],

$T_{\text {and }}=$ cladding temperature $\left({ }^{\circ} \mathrm{C}\right)$,

$C_{p_{\text {che }}}=$ cladding heat capacity $\left(\mathrm{J} / \mathrm{kg} /{ }^{\circ} \mathrm{C}\right)$.

The power transferred from the fuel to the cladding, $a_{\text {en }}$ is determined by:

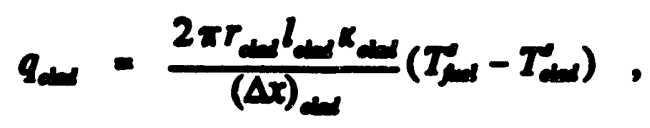

where

$r_{\text {and }}=$ average cladding radius $(m)$,

$l_{\text {ard }}=$ cladding leagth $(m)$,

$\mathrm{x}_{\mathrm{ow}}=$ cladding thermal conductivity $\left(W / \mathrm{m} /{ }^{\circ} \mathrm{C}\right)$,

$(\Delta x)_{\text {dur }}=$ cladding thickness $(m)$,

$T_{\text {Ind }}^{\prime \prime}=$ fuel surface temperature $\left({ }^{\circ} \mathrm{C}\right)$,

$T_{\text {dud }}^{0}=$ cladding surface temperature $\left({ }^{\circ} \mathrm{C}\right)$.

The fuel surface temperature, $T_{i m}^{\prime}$ is given by:

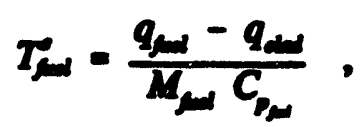

where

$q_{\text {md }}=$ power inside the cladding $(W)$,

$q_{\text {dud }}=$ power inside the wall $(W)$,

$M_{\text {sud }}=$ mass of the fuel $(\mathrm{kg})$,

$C_{p_{\text {md }}}=$ fuel heat capacity $\left(\mathrm{J} / \mathrm{kg} /{ }^{\circ} \mathrm{C}\right)$,

$T_{\text {sind }}=$ fuel temperature $\left({ }^{\circ} \mathrm{C}\right)$.

The localized film heat transfer $H_{m}$ is given by:

$$
H_{m}=\frac{N_{b}}{x_{b_{0}} D_{c}} \text {. }
$$

where

$$
\begin{aligned}
N_{b} & =\text { Nusselt number } \\
N_{D_{2}} & =\text { coolant thermal conductivity }\left(\mathrm{W} / \mathrm{m} /{ }^{\circ} \mathrm{C}\right), \\
D_{0} & =\text { equivalent diameter }(\mathrm{m}) .
\end{aligned}
$$


For the steady-state regime, the Nusselt number, $N_{b}$, is computed using the Petukhov correlation at the bulk coolant speed and temperature.

$$
\mathrm{N}_{b}^{0}=\frac{\left(\frac{f}{8}\right) \operatorname{Re}_{b} \operatorname{Pr}_{b}\left[1+0.334\left[\frac{D_{c}}{L}\right]^{\frac{2}{3}}\right]\left[\frac{\mu_{b}^{B_{0}}}{\mu_{b}^{B_{0}}}\right]^{0.11}}{(1+3.4 f)+\left[11.7+\frac{1.8}{\operatorname{Pr}_{b}^{\frac{1}{3}}}\right]\left[\frac{f}{8}\right]^{0.5}\left(\operatorname{Pr}_{b}^{\frac{2}{3}}-1\right)}
$$

where

$$
\begin{aligned}
f & =\text { friction factor, } \\
R e_{b} & =\text { bulk coolant Reynolds number, } \\
P r_{b} & =\text { bulk coolant Prandtl number, } \\
D_{c} & =\text { equivalent diameter }(m), \\
L & =\text { length of the heated area }(m), \\
\mu_{b}^{D} 0 & =\text { bulk coolant viscosity }(P a s), \\
\mu_{c}^{D-0} & =\text { wurface viscosity (Pas). }
\end{aligned}
$$

The friction factor $f$, used for the Petulhov correlation, is given by the Filonenko correlation:

$$
f=a_{f}\left[1.82 \log \left(R e_{b}\right)-1.64\right]^{-2} \text {, }
$$

where

$$
\begin{aligned}
f & =\text { friction factor, } \\
a_{f} & =\text { correction factor, } \\
R e_{b} & =\text { bulk coolant Reynolds number. }
\end{aligned}
$$

Solution of the Petukhov correlation requires an iterative process. To avoid this iteration during transient scenarios, the Nusselt number, $N_{b}$ is approximated by:

$$
N_{b}=N_{b}^{s}\left(\frac{\omega}{\omega_{0}}\right)^{0.8} \text {, }
$$

where

$$
\begin{aligned}
N_{b} & =\text { Nusselt number, } \\
N_{b}^{\prime} & =\text { Nusselt number at steady state, } \\
\omega & =\text { actual flow rate }(\mathrm{kg} / \mathrm{s}), \\
\omega_{0} & =\text { initial flow rate }(\mathrm{kg} / \mathrm{s}) .
\end{aligned}
$$


Thermal properties, such as $\mathrm{D}_{2} \mathrm{O}$ density, heat capacity, conductivity, surface tension, latent heat, and viscosity, which are used in the heat transfer calculations, are computed from tables based on experimental results.

\subsubsection{Pipe Thermal Hydraulies}

This subsection presents the dynamics modeling of the ANS flow rate and pressure state variables. The relationship between flow speed (u) and the pressure in each node is expressed by the relation:

$$
P_{\infty}=P_{m}-\Delta p-L_{0}
$$

where

$$
\begin{aligned}
& P_{-}=\text {pressure at the outlet of the node }\left(P_{2}\right) \text {, } \\
& P_{\text {wn }} \text { =preseure at the inlat of the node }\left(P_{2}\right) \text {, } \\
& \Delta p=\text { tntal pressure drop ( } \mathrm{Pa}) \text {, } \\
& L \text { length of the node (m), } \\
& \text { p = heavy water density (kg/m), } \\
& u=\text { flow acceleration }\left(\mathrm{m} / \mathrm{s}^{2}\right) \text {. }
\end{aligned}
$$

Rewriting the above equation in terms of flow rate $(\dot{b})$ and eliminating small-contribution terms, the following expression is obtained:

$$
\dot{\omega}=\frac{P_{\text {men }}-P_{\infty}-\Delta P}{\frac{L}{A}},
$$

where

$$
\begin{aligned}
\dot{\omega} & =\text { rate of change of flow }\left(\mathrm{kg} / \mathrm{s}^{2}\right), \\
P_{\text {wm }} & =\text { inlet node pressure }(\mathrm{Pa}), \\
\boldsymbol{P}_{\boldsymbol{m}} & =\text { outlet node pressure }(\mathrm{Pa}), \\
\Delta P & =\text { total pressure loss or drop }(\mathrm{Pa}), \\
L & =\text { length of the node/pipe }(\mathrm{m}), \\
A & =\text { flow area }\left(\mathrm{m}^{2}\right) .
\end{aligned}
$$

The total pressure drop, $\Delta P$, is given by:

$$
\Delta P=\frac{\left(\frac{f L}{D_{e}}+K_{f}\right) \omega^{2}}{2 \rho A^{2}}+\rho g z
$$


where

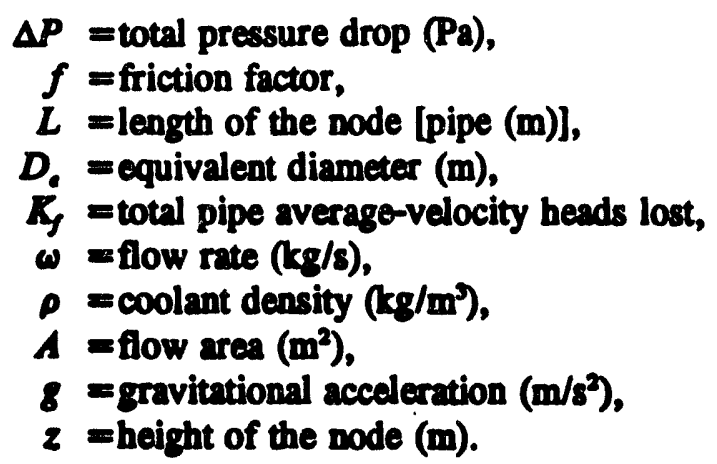

To calculate the nodo-outle pressure, $P_{-\infty}$ it is necessary to start from the time derivative of the equation of state:

$$
P_{\sim}=\frac{\partial P}{\partial m} l_{r} m_{\text {md }}+\frac{\partial P}{\partial h} l_{\nabla} h
$$

where

$$
\begin{aligned}
P & =\text { rate of change of pressure }(\mathrm{Pa} / \mathrm{s}), \\
\frac{\partial P}{\partial m} & =\text { pressure change with respect to mass at constant temperature }\left(\mathrm{m}^{-1} \mathrm{~s}^{-2}\right), \\
\frac{\partial P}{\partial h} & =\text { pressure change with respect to enthalpy at constant volume }\left(\mathrm{kg} / \mathrm{m}^{3}\right) \\
m_{\text {cad }} & =\text { rate of change of mass }(\mathrm{kg} / \mathrm{s}) \\
h & =\text { rate of change of enthalpy }(\mathrm{J} / \mathrm{kg} / \mathrm{s}) .
\end{aligned}
$$

The mass variation, $m_{\text {coud }}$ is given by:

$$
m_{\text {cod }}=\frac{d m}{d t}+\frac{\partial m}{\partial t}+\left(\frac{\partial m}{\partial h}\right)_{,} h,
$$

where

$$
\begin{aligned}
m_{\mathrm{ced}} & =\text { rate of change of mass }(\mathrm{kg} / \mathrm{s}), \\
{\left[\frac{\partial m}{\partial h}\right]_{h} } & =\text { mass changes with respect to enthalpy at constant pressure }\left(\mathrm{kg} \cdot \mathrm{s}^{2} / \mathrm{m}^{2}\right), \\
h & =\text { rate of change of enthalpy }(J / \mathrm{kg} / \mathrm{s}) .
\end{aligned}
$$


In terms of mass flow rate and density, the mass variation may be rewritten as follows:

$$
m_{\text {and }}=\omega_{\text {mex }}-\omega_{\text {man }}+v\left[\frac{\partial \rho}{\partial h}\right]_{,} h \text {, }
$$

where

$$
\begin{aligned}
\omega_{\min } & =\text { flow rate at the inlet of the node }(\mathrm{kg} / \mathrm{s}), \\
\omega_{\text {man }} & =\text { node flow rate }(\mathrm{kg} / \mathrm{s}), \\
V & =\text { volume of the node }\left(\mathrm{m}^{3}\right) \\
{\left[\frac{\partial \rho}{\partial h}\right]_{h} } & =\text { density changes with respect to enthalpy at constant pressure }\left(\mathrm{kg} \cdot \mathrm{s}^{2} / \mathrm{m}^{2}\right), \\
h & =\text { rate of changr of enthalpy }(\mathrm{J} / \mathrm{kg} / \mathrm{s}) .
\end{aligned}
$$
obtained:

After eliminating the irrelevant terms, the following equation for the node-outlet pressure is

$$
P_{-}=\frac{1}{V}\left(\frac{\partial P}{\partial \rho}\right)_{r}\left(\omega_{m}-\omega_{m}\right)
$$

where

$$
\begin{aligned}
& \dot{P}_{\text {w }}=\text { rate of change of outlet node pressure }(\mathrm{Pa} / \mathrm{s}) \text {, } \\
& \left(\frac{\partial P}{\partial \rho}\right)_{T}=\text { liquid compressibility at constant temperature }\left(\mathrm{m}^{2} / \mathrm{s}^{2}\right) \text {, } \\
& \omega_{\text {wh }}=\text { flow rate at inlet of node }(\mathrm{kg} / \mathrm{s}) \text {, } \\
& \omega_{\text {mem }}=\text { outlet node flow rate }(\mathrm{kg} / \mathrm{s}) \text {. }
\end{aligned}
$$

The heavy water compressibility factors $\partial P / \partial \rho$ and $\partial P / \partial \mathrm{h}$ are either determined from their dependence on the speed of sound and from the Joule-Thompson coefficient for $D_{2} \mathrm{O}$ or read from a table of experimental values. Both methods yield a consistent value of $2.043 \times 10^{6} \mathrm{~m}^{2} / \mathrm{s}^{2}$ for $\partial P / \partial \rho$ and $5 \mathrm{~Pa} / \mathrm{J}$ for $\partial \mathrm{P} / \partial \mathrm{h}$.

\subsubsection{Heat Exchangers}

PRSDYN uses the logarithmic-mean-temperature approximation to model the heat transferred through the heat exchanger, $q$.

$$
q=U_{\alpha} A_{\alpha}\left[\frac{\Delta T_{\text {m }}-\Delta T_{\text {max }}}{\ln \left(\frac{\Delta T_{\text {max }}}{\Delta T_{\text {max }}}\right)}\right]
$$


where

$q$ aheat exchange [rejected (W)],

$U_{c}$ overall heat transfer coefficient $\left(\mathrm{W} / \mathrm{m}^{2} /{ }^{\circ} \mathrm{C}\right)$,

$A_{d}=$ overall heat transfer area $\left(\mathrm{m}^{2}\right)$,

$\Delta T_{m}=$ temperature difference between the outlet of tube and shell side $\left({ }^{\circ} \mathrm{C}\right)$,

$\Delta T_{\text {ww }}=$ temperature difference between the inlet of tube and shell side $\left({ }^{\circ} \mathrm{C}\right)$.

The heat transfer coefficient used for the shell side, $\boldsymbol{H}_{\text {awl }}$ is given by Gibbon's correlation:21

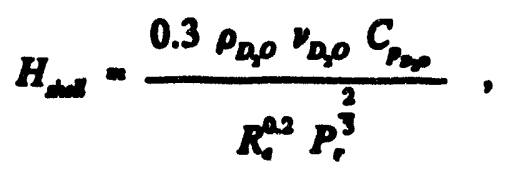

where

$H_{\text {det }}=$ film heat transfer shell side $\left(W / \mathrm{m}^{2} /{ }^{\circ} \mathrm{C}\right)$,

$Q_{D, 0}=$ liquid density for heavy water $\left(\mathrm{kg} / \mathrm{m}^{3}\right)$,

$C_{\text {mop }}=$ liquid heat capacity for heavy water $\left(\mathrm{J} / \mathrm{kg} /{ }^{\circ} \mathrm{C}\right)$,

$\boldsymbol{R}_{\boldsymbol{c}}=$ Reynolds number,

$P_{\text {, }}=$ Prandtl number,

$v_{D_{20}}=$ liquid surface tension for heavy water $\left(\mathrm{kg} / \mathrm{s}^{2}\right)$.

The heat transfer resistance coefficient (fouling), $F_{\text {reon }}$ is given by:

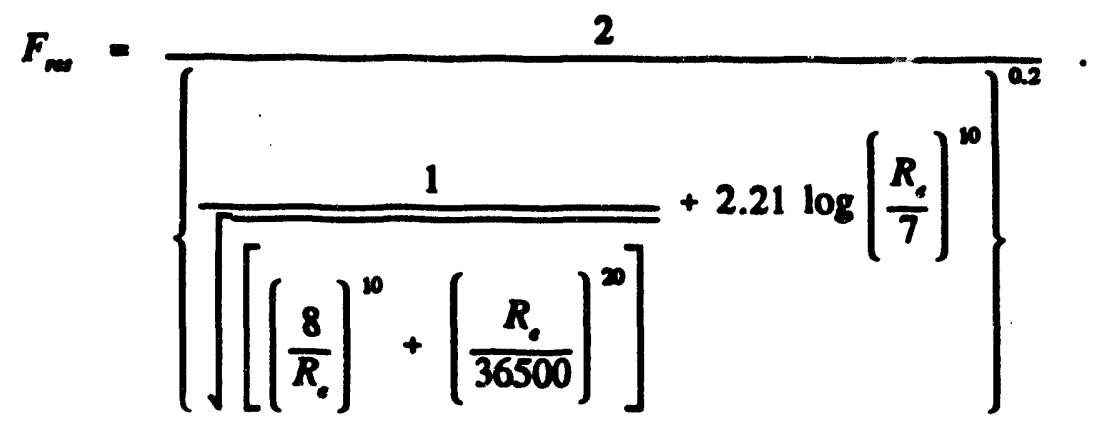


The tube side heat transfer coefficient, $H_{\text {mon }}$ is based on Churchill's correlation:2

$$
\begin{aligned}
& \theta_{1}=\frac{6.3+0.079 \sqrt{\frac{F_{m}}{2}} R_{c} P_{r}}{\left(1+P_{r}^{0.2}\right)^{\frac{5}{3}}}, \\
& \theta_{2}=\left\{4.364^{10}+\left[\frac{e^{\frac{0.00}{30}}}{19.0445}+\theta_{1}^{-2}\right]^{-5}\right\}^{0.1},
\end{aligned}
$$

and

$$
H_{\text {Le }}=\frac{\mu_{B_{0} O}\left(\theta_{1}+\theta_{2}\right)}{\mu_{B_{0} O}} \text {. }
$$

where

$H_{\text {m. }}=$ film heat transfer tube side $\left(W / \mathrm{m}^{2} /{ }^{\circ} \mathrm{C}\right)$,

$H_{D y 0}=$ coolant dynamic viscosity (Pa-s),

$x_{\text {Dap }}=$ =liquid thermal conductivity $\left(W / m /{ }^{\circ} \mathrm{C}\right)$.

The overall heat transfer coefficient, $U_{c}$, is given by:

$$
U_{d}=\left(\frac{1}{H_{d a}}+\frac{1}{H_{\text {a }}}+\frac{1}{H_{-}}\right)^{-1} A_{d} \text {, }
$$

\subsubsection{Main Circulation Pumps}

The main circulation pumps cosstdown is modeled on a conservation of angular momentum, which yields the relation:

$$
\frac{d n}{d t}=\frac{\left(n^{2}-n_{0}^{2}\right)}{T_{m}}
$$

where

$$
\begin{aligned}
n & =\text { normalized pump speed (fraction of reference value), } \\
t & =\text { time (s), }
\end{aligned}
$$


$n_{0}=$ nominal normalized pump speed (fraction of reference value),

$T_{\text {m }}$ =pump time constant (s).

The cosstdown flow and pump head are computed by scaling the characteristic pump curve using the calculated normalized speed, $n$.

\subsubsection{Ges Accumulatore}

The gas accumulator is a tank filled with heavy water with a high prese are gas bubble at the top designed to discharge its liquid quickly in the event of a reactor cooling failure. The gas accumulators are modeled aseuming the validity of the ideal gas law given by:

$$
P_{\infty}=\frac{P_{\infty}^{0} V_{m}}{V_{\infty}},
$$

where

$$
\begin{aligned}
& P_{\text {r }} \text { =pressure of } \mathrm{gas}(\mathrm{Pa}) \text {, } \\
& P_{F}=\text { =ominal gas prowsure (Pa), } \\
& V_{s}=\text { nominal gas voiume }\left(m^{3}\right) \text {, } \\
& V_{\infty}=\text { gas volume }\left(m^{3}\right) \text {. }
\end{aligned}
$$

The initial gas-to-liquid ratio is such that the liquid level will not reach the bottom of the accumulator after the gas has expanded to the deprescurized condition. The flow of liquid to and from the accumulator is given by:

$$
\dot{\omega}_{\infty x}=\frac{\left(P_{\infty}-P_{\infty x_{\infty}}-\Delta P_{\infty}\right)}{\frac{L}{A}},
$$

where

$$
\begin{aligned}
\dot{\omega}_{a x} & =\text { mass flow rate acceleration }\left(\mathrm{kg} / \mathrm{s}^{2}\right), \\
P_{\infty x} & =\text { pressure at the accumulation surge line }(\mathrm{Pa}), \\
P_{\infty m} & =\text { main hot leg pressure }(\mathrm{Pa}), \\
\Delta P_{\infty x} & =\text { total pressure drop at the surge line }(\mathrm{Pa}), \\
L & =\text { surge line length }(\mathrm{m}), \\
A & =\text { surge line flow area }\left(\mathrm{m}^{2}\right) .
\end{aligned}
$$

The gas volume inside the accumulator is given by:

$$
v_{\infty}=v_{e+\infty}+\int_{0}^{+} \frac{\omega_{\infty x}}{p_{\infty \infty}} d t
$$


where

$\omega_{c x}=$ flow rate out from the accumulator $(\mathrm{kg} / \mathrm{s})$,

$p_{a x c}=$ liquid density $\left(\mathrm{kg} / \mathrm{m}^{3}\right)$.

\subsubsection{Loss of Coolant Accident Modeling}

Breaks are simulated from any reactor component to the pool or from the annulus to the reflector as a flow through an orifice. The leak flow is computed and the orifice coefficient is given by the following equation:

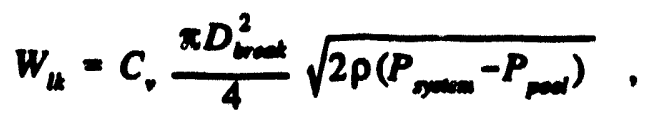

where

$$
\begin{aligned}
W_{u} & =\text { leak flow }(\mathrm{kg} / \mathrm{s}), \\
C_{v} & =\text { break loss coefficient. } \\
D_{\text {mact }} & =\text { break diameter }(\mathrm{m}), \\
P_{\text {mow }} & =\text { pressure at the leak location }(\mathrm{Pa}), \\
P_{\text {mod }} & =\text { pool pressure }(\mathrm{Pa}) .
\end{aligned}
$$

$C_{v}$ is determined by:

$$
c_{v}=C_{\infty} \frac{\pi \sqrt{\rho}}{4}
$$

where

$$
\rho=\text { coolant density }\left(\mathrm{kg}^{\mathrm{m}} \mathrm{m}^{3}\right) \text {. }
$$

The break diameter $\left(D_{\text {hreed }}\right)$ is represented by the following formulation:

$$
D_{\text {brax }}(t)=\min \left[D_{\text {treat }}^{\max } \times\left(2^{\frac{1}{\tau}}-1\right), D^{\max }\right]
$$

and

$$
D^{\max }=\max \left(2 \times D_{\min }\right)
$$

\subsubsection{PRSDYN Model Limitations}

The most important limitations of this model are described below.

- Point kinetics is used for the neutron dynamics in the core region. 
- The model is limited to liquid phase state (incompressible flow). Whenever a transient results in saturated boiling for a long time, the simulation fails. Note, however, that for most events initiated from full power, subcooled boiling would result in CHF or FE well before the establishment of saturated boiling. 


\section{COMPARISON OF RESULTS}

Results of two LOCAs, one station blackout, and one reactivity insertion accident are presented below. Steady-state results are compared first, followed by transient results. Following these comparisons, the findings are discussed, and the basis for the recommendations is explained.

ANSDM cannot model instantaneous pipe breaks because of its incompressible flow model. To allow for these comparisons, breaks were opened in all three models exponentially over a finite period of time, $\tau$, according to the following expressions.

$$
D(t)=D_{b}\left(2^{\frac{t}{\tau}}-1\right) \text { if } 0 \leq t \leq \tau
$$

and

$$
D(t)=D_{b} \text { if } t>\tau \text {, }
$$

where $D(t)$ is the break effective diameter $(m), D_{b}$ is the final break size $(m)$, and $\tau$ is the break time constant (typically $250 \mathrm{~ms}$ ).

\subsection{SMALL LOSS OF COOLANT ACCIDENT}

This comparison between RELAP5 (MOD2/VERSION3t) and ANSDM was based on the reactor system responses for a 51-mm-diam break opened in $250 \mathrm{~ms}$. Some of the operational and design parameters used for this simulation are different than those selected for the final conceptual designs. For example, for this transient, the main coolant pumps are not tripped when the reactor scrams. The nominal operating conditions are shown in Table 2.

Table 2. Nominal operation conditions

\begin{tabular}{lll}
\hline \multicolumn{1}{c}{ Parameter } & \multicolumn{1}{c}{ Value } & \multicolumn{1}{c}{ Comments } \\
\hline Fission power & $350 \mathrm{MW}$, & $\begin{array}{l}\text { Total nuclear energy deposited in fuel, structure, } \\
\text { and coolant of core and reflector }\end{array}$ \\
Core inlet pressure & $3.7 \mathrm{MPa}$ & \\
Core coolant velocity & $27.4 \mathrm{~m} / \mathrm{s}$ & Between fuel plates \\
Core inlet temperature & $49^{\circ} \mathrm{C}$ & \\
Accumulator volume & $5 \mathrm{~m}^{3}$ & Each of three active accumulators \\
Accumulator gas volume & $0.125 \mathrm{~m}^{3}$ & Each of three active accumulators \\
Break opening time & $250 \mathrm{~ms}$ & \\
Pressure scram setpoint & $80 \%$ & $20 \%$ below nominal pressure \\
\hline
\end{tabular}




\subsubsection{Steady State}

Input parameters are listed in Tables 3-6. The normalized power density profile is shown in Table 3 based on the 13 fuel grading* at EOC with the preconceptual design uncertainty multipliers. Table 4 lists the relevant core input parameters while Tables 5 and 6 provide the accumulator and inertial flow diode as part of the loop input parameters.

Table 3. Normalized power density of 13 fuel grading at the end-of-cycle

\begin{tabular}{cccc}
\hline Element zone & Average channel & Hot channer & Hot stripeb \\
\hline 5 & \multicolumn{3}{c}{ Upper } \\
\hline 4 & 1.243 & 1.517 & 1.991 \\
3 & 1.252 & 1.517 & 1.886 \\
2 & 1.261 & 1.566 & 1.886 \\
1 & 1.222 & 1.614 & 1.965 \\
& 0.991 & 1.362 & 1.900 \\
5 & & & \\
4 & 0.641 & 0.864 & 1.074 \\
3 & 0.651 & 0.901 & 1.218 \\
2 & 0.686 & 0.963 & 1.323 \\
1 & 0.749 & 1.034 & 1.454 \\
\hline
\end{tabular}

With multiplier 1.14 .

With multiplier 1.31.

Power split at the end-of-cycle (EOC) for the upper core $=0.702$ (70.2\%).

Power split at EOC for the lower core $=0.294(29.4 \%)$.

When this set of common input parameters was used, favorable agreement was found as shown in Tables 7 and 8. In Table 7, velocities, pressures, and bulk temperatures at key locations show insignificant differences, with the exception of wall temperatures. The discrepancy with wall temperatures can be attributed to different heat transfer coefficients. In the MOD2/VERSION3t, RELAP5 used the Dittus-Boelter correlation and ANSDM used the Petukhov for the single-phase forced convection. The heat transfer coefficient predicted by the Petukhov correlation is higher, which leads to the lower wall temperatures predicted by the ANSDM.

The RELAP5 loop model accounts for form losses resulting from isolation valves, check valves, pipe bends, and flow diodes in addition to wall friction losses over the loop. Because

T3 is an intemal designation representing a particular radial and axial distribution of fissile material within the active fuel region of each fuel plate. 
Table 4. Core input parameters

\begin{tabular}{|c|c|c|}
\hline Parameter & Value & Comments \\
\hline $\begin{array}{l}\text { Core mass flow (kg/s) } \\
\text { Total mass flow }(\mathrm{kg} / \mathrm{s})\end{array}$ & $\begin{array}{l}2053 \\
2463\end{array}$ & $\begin{array}{l}\text { Core flow consists of the lower and upper average } \\
\text { channels. Total mass flow consists of the core flow } \\
\text { plus flows in bypass and the control rod channels. }\end{array}$ \\
\hline $\begin{array}{l}\text { Lower element flow area }\left(m^{2}\right) \\
\text { Total core flow area }\left(m^{2}\right)\end{array}$ & $\begin{array}{l}0.02908 \\
0.06922\end{array}$ & Annuli cross-sectional areas less corroded fuel plates. \\
\hline Hydraulic diameter $(m)$ & 0.002489 & \\
\hline Fuel surface roughness (um) & 2.0 & $\begin{array}{l}\text { RELAPS uses a curve-fitting method to represent the } \\
\text { Colebrook friction factor comelation for various flow } \\
\text { regions, while ANSDM used Filonenko and } \\
\text { Colebrook. }\end{array}$ \\
\hline
\end{tabular}

Table 5. Accumulator input parameters

\begin{tabular}{|c|c|c|}
\hline Parameter & Value & Comments \\
\hline Tank volume ( $\left.m^{3}\right)$ & 5 & \\
\hline Surge line length (m) & 5 & $:$ \\
\hline $\begin{array}{l}\text { Initial liquid volume }\left(m^{3}\right) \\
\text { Initial gas volume }\left(m^{3}\right)\end{array}$ & $\begin{array}{l}4.875 \\
0.125\end{array}$ & $\begin{array}{l}\text { The ratio of the initial liquid to gas volume } \\
\text { was aet at } 40 \text { to prevent the bubble from } \\
\text { expanding into the primary coolant. }\end{array}$ \\
\hline \multicolumn{3}{|l|}{ Pressure (MPa) } \\
\hline $\begin{array}{l}\text { Cover gas inside the accimulator } \\
\text { At injection point }\end{array}$ & $\begin{array}{l}1.34 \\
1.45\end{array}$ & \\
\hline
\end{tabular}

Table 6. Inertial fow diode input parameters

\begin{tabular}{|c|c|c|}
\hline Parameter & Value & Comments \\
\hline $\begin{array}{l}\text { Normal flow direction } \\
\mathrm{Kc}\left(45^{\circ} \text { converging nozzle) }\right. \\
\mathrm{Ke}\left(10^{\circ} \text { diverging nozzle) }\right.\end{array}$ & $\begin{array}{l}0.3061 \\
0.2266\end{array}$ & $\begin{array}{l}\text { Optimal } \mathrm{K} \text { factors (with respect to the junction } \\
\text { area of } 203-\mathrm{mm} \text { diam) and nozzle length for the } \\
\text { minimum loss of inventory in event of LOCAs" } \\
\text { to be determined }\end{array}$ \\
\hline $\begin{array}{l}\text { Reversed flow direction } \\
\mathrm{Kc}\left(10^{\circ} \text { converging nozzle }\right. \\
\mathrm{Ke}\left(45^{\circ} \text { diverging nozle }\right.\end{array}$ & $\begin{array}{l}0.0697 \\
1.0\end{array}$ & \\
\hline
\end{tabular}

ZOCAs $=$ loss of coolant eccidents . 
Table 7. Core output parameters

\begin{tabular}{|c|c|c|c|}
\hline Parameter & RELAPS & ANSDM & Comments \\
\hline $\begin{array}{l}\text { Velocity (m/s) } \\
\text { Average core exit } \\
\text { Hot channel exit, l.c." } \\
\text { Hot chamel exit, uc." }\end{array}$ & $\begin{array}{l}27.6 \\
26.6 \\
27.2\end{array}$ & $\begin{array}{l}27.6 \\
26.15 \\
26.6\end{array}$ & $\begin{array}{l}\text { Density variation over heated } \\
\text { length }-3 \%\end{array}$ \\
\hline $\begin{array}{l}\text { Pressure (MPa) } \\
\text { Core inlet plenumi } \\
\text { Core inlet, Lc. } \\
\text { Core outlet, l.c. } \\
\text { Core outiet plenum } \\
\Delta p \text { over core }\end{array}$ & $\begin{array}{l}3.78 \\
3.73 \\
1.83 \\
1.83 \\
1.9\end{array}$ & $\begin{array}{l}3.76 \\
3.70 \\
1.82 \\
1.81 \\
1.88\end{array}$ & $\begin{array}{l}\text { Breakdown of the core } \Delta \mathrm{p}: \\
\text { friction loss }=1.750 \mathrm{MPa} \\
\text { entrance change }=0.325 \mathrm{MPa} \\
\text { exit change }=-0.204 \mathrm{MPa}\end{array}$ \\
\hline $\begin{array}{l}\text { Bull coolant temperature (K) } \\
\text { Core inlet plenum } \\
\text { Core outlet plenum } \\
\text { Hot channel outlet, l.c. } \\
\text { Hot channel outlet, u.c. }\end{array}$ & $\begin{array}{l}323 \\
357 \\
372 \\
401\end{array}$ & $\begin{array}{l}322 \\
356 \\
372 \\
401\end{array}$ & \\
\hline $\begin{array}{l}\text { Wall temperature (K) } \\
\text { Hot stripe exit, l.c. } \\
\text { Hot stripe exit, u.c. }\end{array}$ & $\begin{array}{l}412 \\
462.3\end{array}$ & $\begin{array}{l}405 \\
452.5\end{array}$ & $\begin{array}{l}\text { Both models used hot channel } \\
\text { exit bulk temperatures as } \\
\text { references for hot stripe wall } \\
\text { temperature calculations }\end{array}$ \\
\hline $\begin{array}{l}\text { Heat transfer coefficient }\left(\mathrm{W} / \mathrm{m}^{2} / \mathrm{K}\right) \\
\text { Hot chamel outlet, l.c. } \\
\text { Hot channel outlet, u.c. }\end{array}$ & $\begin{array}{l}1.465 \times 10^{5} \\
1.632 \times 10^{5}\end{array}$ & $\begin{array}{c}1.8 \times 10^{5} \\
2.06 \times 10^{5}\end{array}$ & $\begin{array}{l}\text { RELAPS used the Dittus-Boelter } \\
\text { correlation and ANSDM used } \\
\text { the Petulthov for the single- } \\
\text { phase forced convection; the } \\
\text { heat transfer coefficient } \\
\text { predicid by the Petulthov } \\
\text { correlation is higher as expected; } \\
\text { the higher heat transfer } \\
\text { coefficients lead to lower wall } \\
\text { temperatures. }\end{array}$ \\
\hline
\end{tabular}

ANSDM = Advanced Neutron Source dynamic model.

1.c. = lower fuel element.

u.c. = upper fuel element.

ANSDM does not model each component in the heat exchanger loops explicitly, the input must simulate the equivalent losses using discrete concentrated resistance. The RELAP5 and ANSDM pressures at the pump suction and discharge agree quite well when proper concentrated resistance is used in ANSDM (see Table 8).

\subsubsection{Transient}

After the good agreement in steady-state comparison was established, it was decided to compare results from a small LOCA. A $51-\mathrm{mm}$-diam break at the interface between the top of the CPBT and the inlet of the hot leg riser was chosen. There is no 51-mm pipe connecting to the primary 
Table 8. Main circulation pump output parameters

\begin{tabular}{lcc}
\hline & \multicolumn{2}{c}{$\begin{array}{c}\text { Pressure } \\
\text { (MPa) }\end{array}$} \\
\cline { 2 - 3 } \multicolumn{1}{c}{ Parameter } & RELAPS & ANSDM \\
\hline Pressure & & \\
Suction & 1.47 & 1.43 \\
Discharge & 4.13 & 4.09 \\
\hline
\end{tabular}

-ANSDM = Advanced Neutron Source dynamic model.

coolant pressure boundary in this region, so the chosen break actually represents a rapidly opening crack in the CPBT or hot leg riser, which has a much larger diameter.

The overall transient response (see Figs. 4-12) agrees well in both shape and magnitude of key parameters with the exception of accumulator injection mass flow (see Fig. 12 and discussion below). The transient results are displayed on $\log -\log$ or semi-log scales to allow detailed comparisons of thermal hydraulic behavior at all times between the break initiation and the end of the 30-s period of interest. The total power, which consists of neutron flux and decay heat, compares excellently as shown in Fig. 4. Both the neutron flux and the decay heat agree well before the scram and disagree insignificantly during post erram period, indicating that both models correctly implement their similar point kinetics models and reactivity profiles after scram.

The break flow is compared in Fig. 5. RELAP5 shows a slowly increasing but highly oscillatory break flow in the first $50 \mathrm{~ms}$ as opposed to the smooth and flat behavior predicted by ANSDM. After $50 \mathrm{~ms}$, discrepancy in break flows starts to diminish until the break is fully opened at $250 \mathrm{~ms}$. Beyond that, the maximum deviation remains $<6 \%$. The initial oscillatory behavior is a timestep-dependent numerical artifact that does not affect other predictions. It has been observed for other small LOCA calculations. ${ }^{23}$ Investigations reveal that the time-averaged flow out of the break is independent of time steps used.

Heat fluxes at hot spots for the upper and lower cores, respectively, are compared in Figs. 8 and 9. In each plot, the lower pair of curves are local surface heat flux at the hot spot whereas the upper pairs are the limiting heat flux as predicted by the Costa correlation. Both models predict the correct trend in that the Costa limiting heat flux declines slowly during initial depressurization and reaches a minimum after scram. After scram, the allowable heat flux increases rapidly because of the corresponding rapid increase in coolant subcooling. For additional information, the CHF limiting heat flux at the hot spot calculated by the Gambill/Weatherhead correlation is included.

Makeup and letdown flows are compared in Fig. 11. Early in the transient, the makeup flow should be balanced by the letdown flow as correctly predicted by RELAP5 and ANSDM. Both models predict a constant makeup flow up to $-4 \mathrm{~s}$ into the transient and followed by a rapid increase caused by the start of the standby makeup pump. Also, both models predict a somewhat similar trend for the letdown flow from the nominal to zero (with the valve fully closed) flow as the system pressure continues tô decline. Fluctuations (local pressurization and depressurization) in the letdown flow predicted by RELAP5 appear to respond to pressure fluctuations at the CPBT inlet and outlet when the break is fully opened (see Fig. 7).

Two significant differences in the injection flow from accumulator to primary coolani piping can be observed in Fig. 12. The ANSDM injection flow leads the RELAP5 injection by $50 \mathrm{~ms}$ or more during the initial depressurization because RELAPS accounts for the finite acoustic propagation 


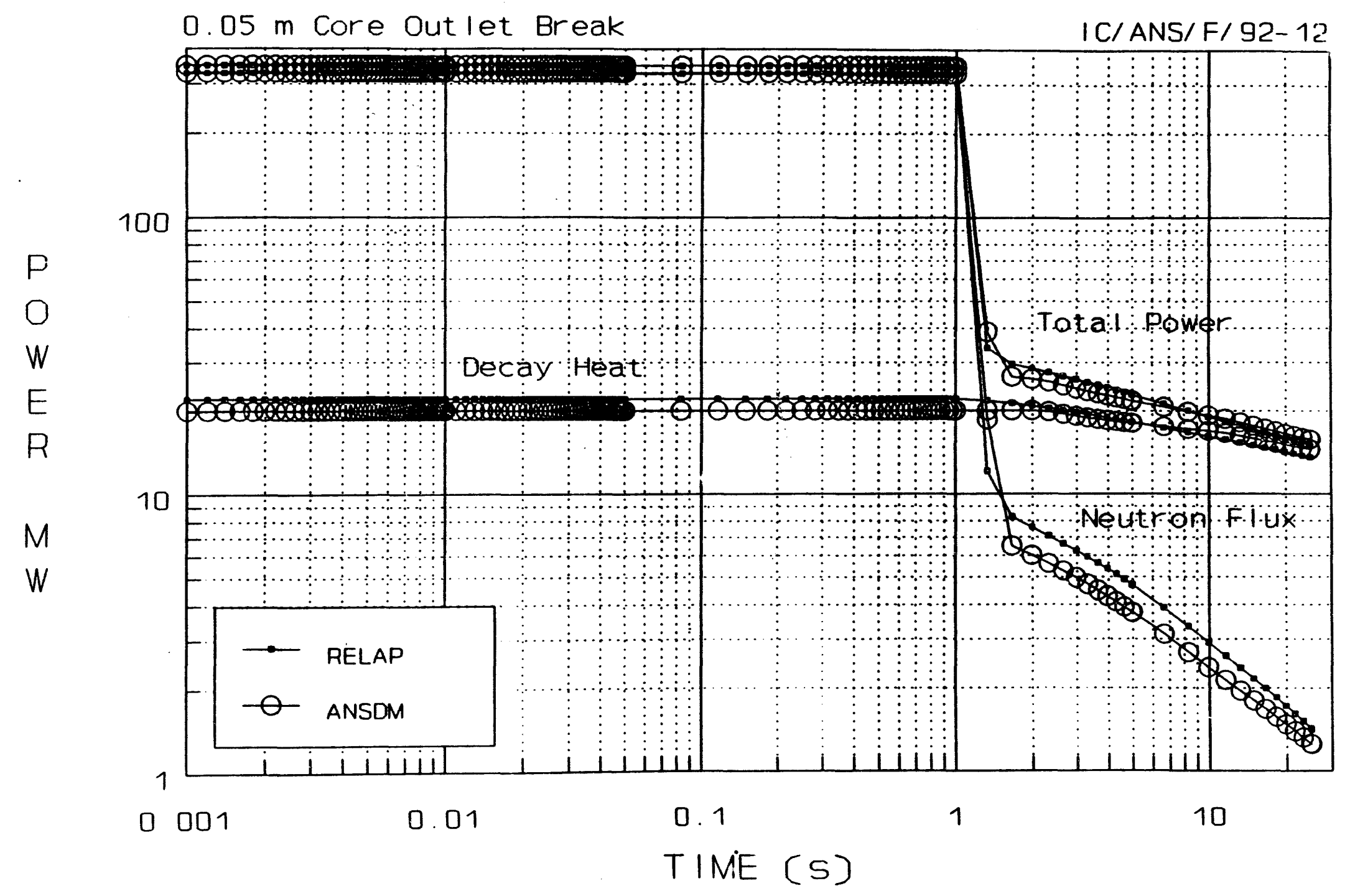

Fig. 4. Comparison in fission, decay, and total power during the 51-mm-diam core pressure boundary tube break with 250-ms opening time. 


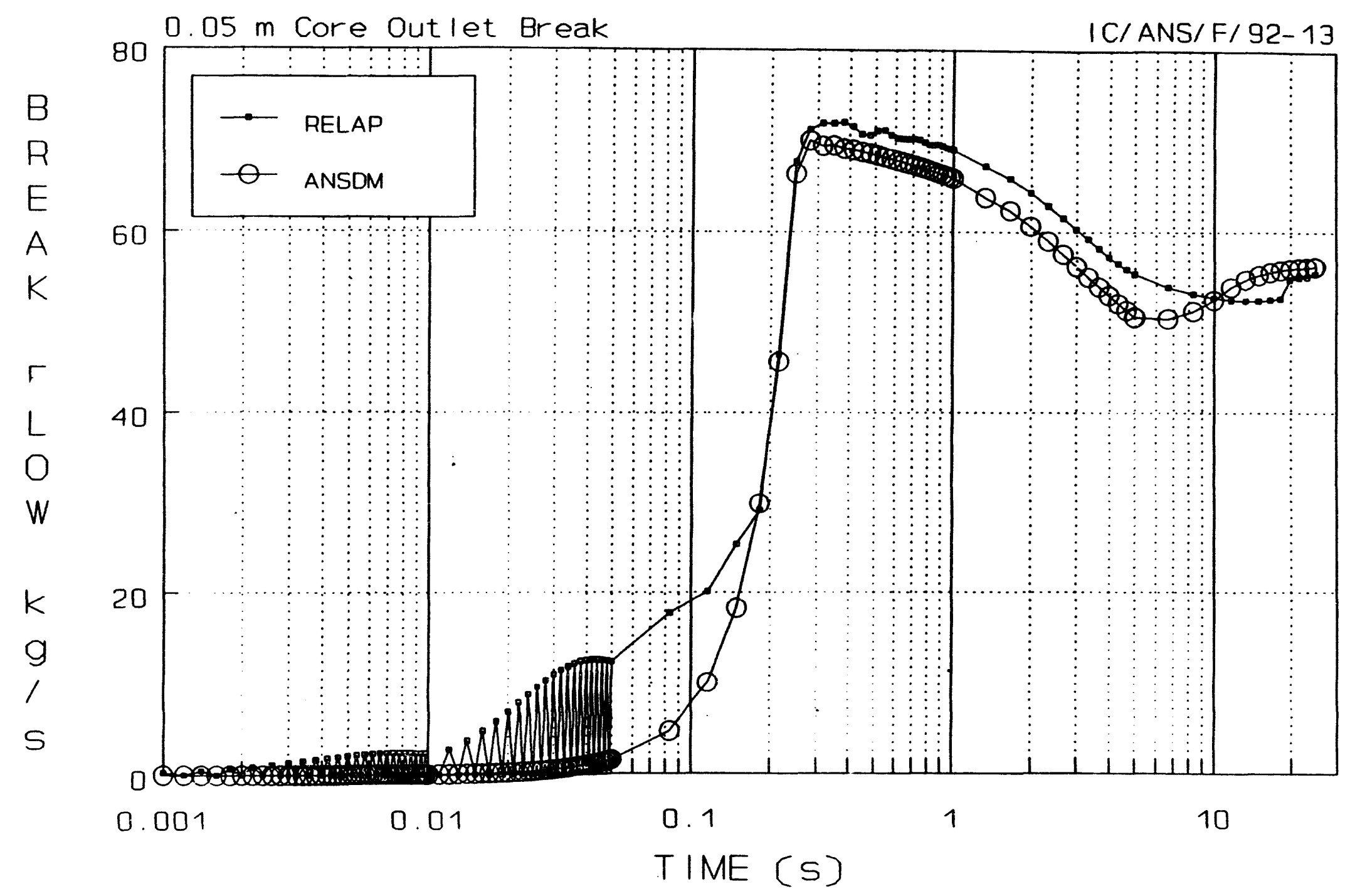

Fig. 5. Break now comparison during the 51-mm-diam core pressure boundary tube outlet break with 250-ms opening time. 


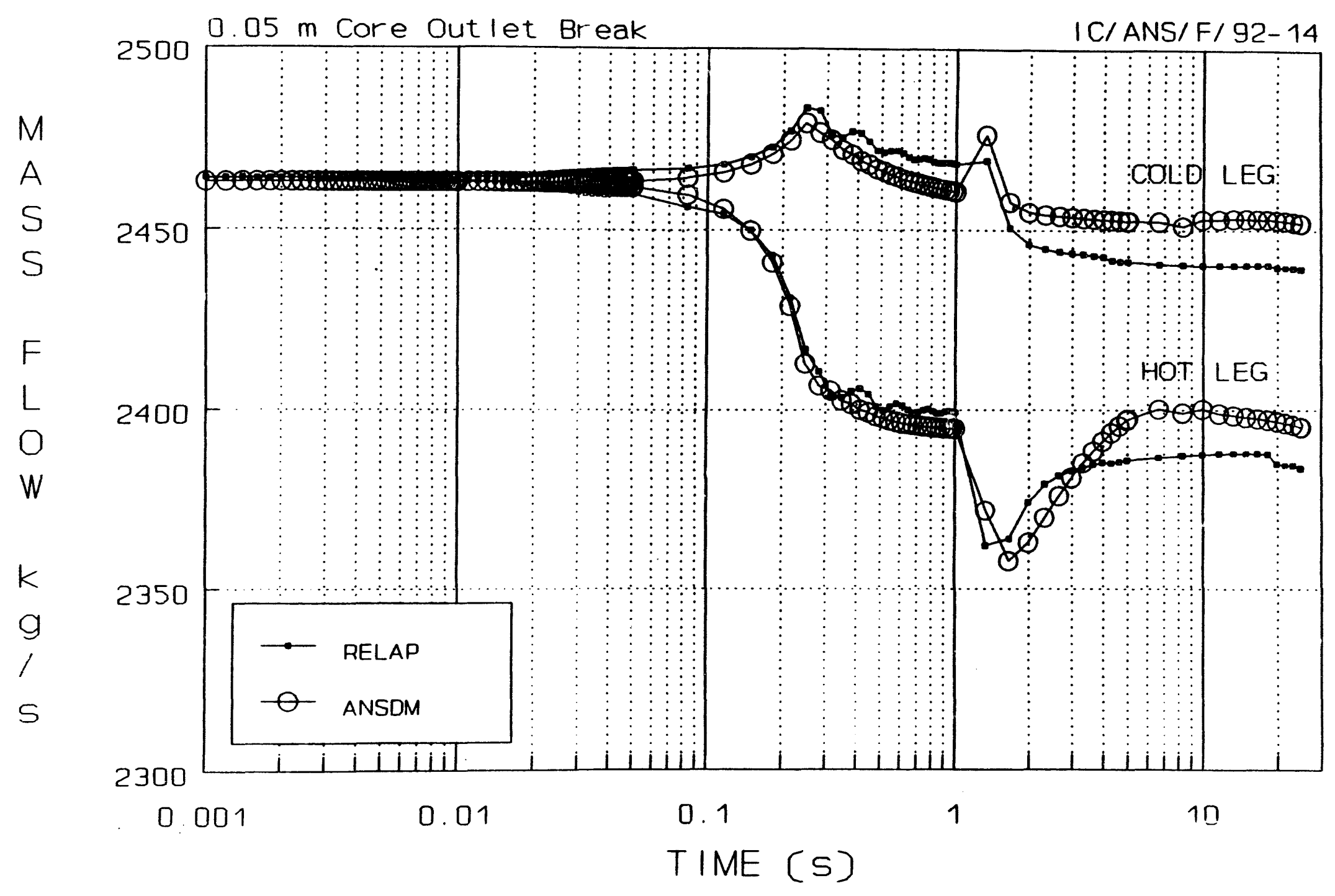

Fig. 6. Mass flow comparison at locations upstream and downstream of the break during the 51-mm-diam core pressure boundary tube outlet break with 250-ms opening time. 


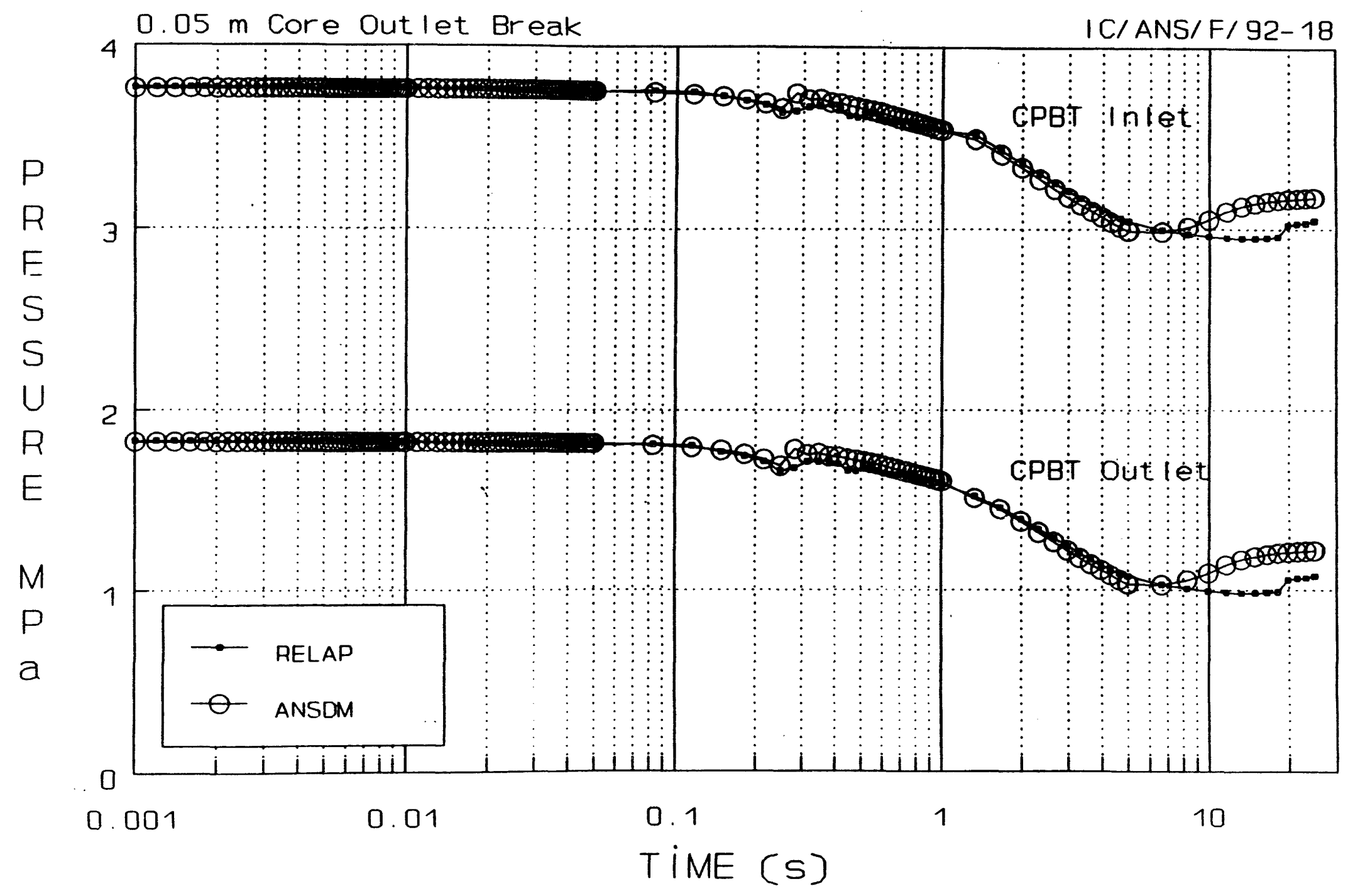

Fig. 7. Comparison in pressure responses at the core pressure boundary tube (CPBT) inlet and outlet during the 51-mm-diam CPBT outlet break with 250-ms opening time. 


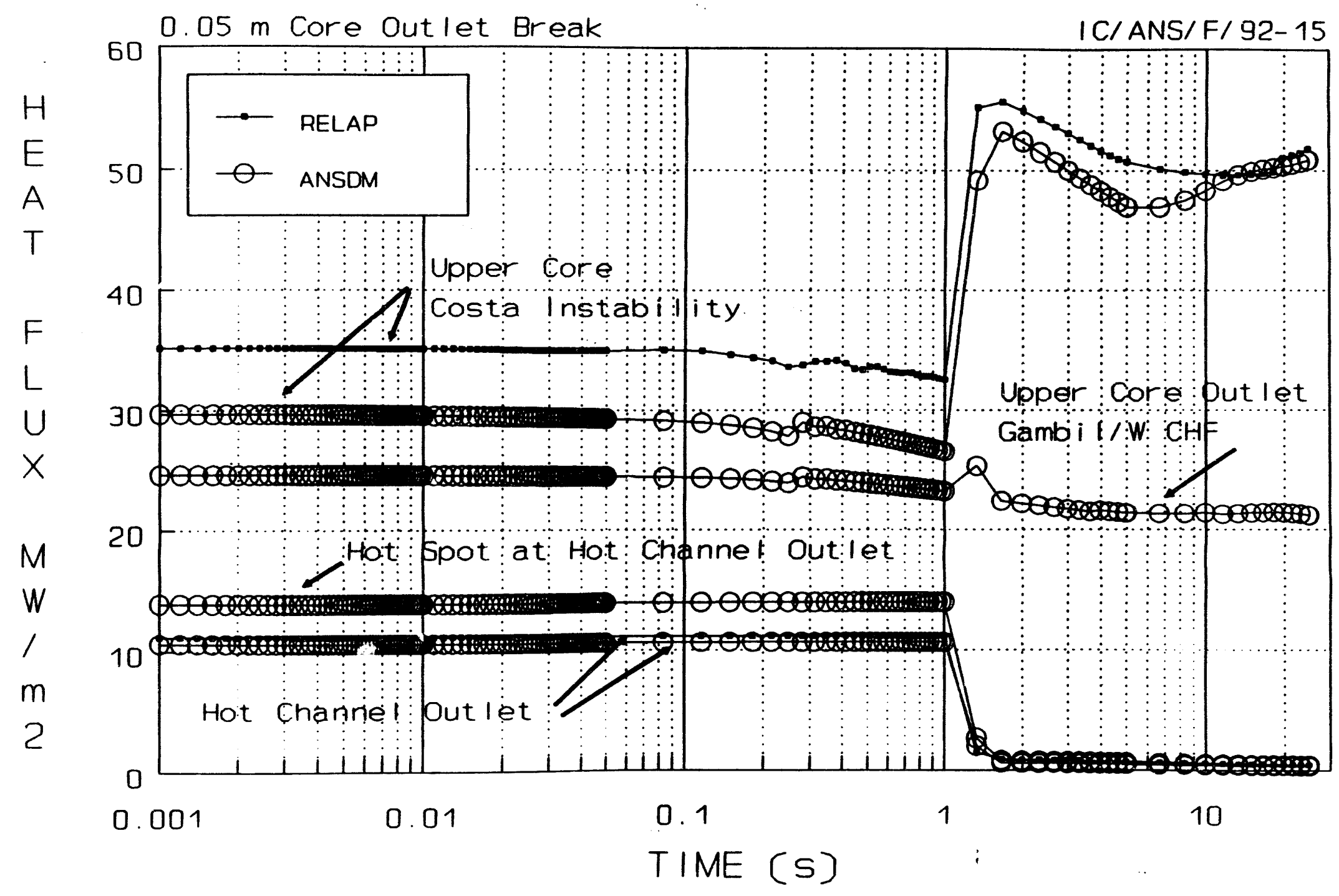

Fig. 8. Heat fux comparison at the hot spot of the upper core showing Costa, Gambill/Weatherhead, and local surface heat fuxes during the 51-mm-diam core pressure boundary tube outlet break with 250-ms opening time. 


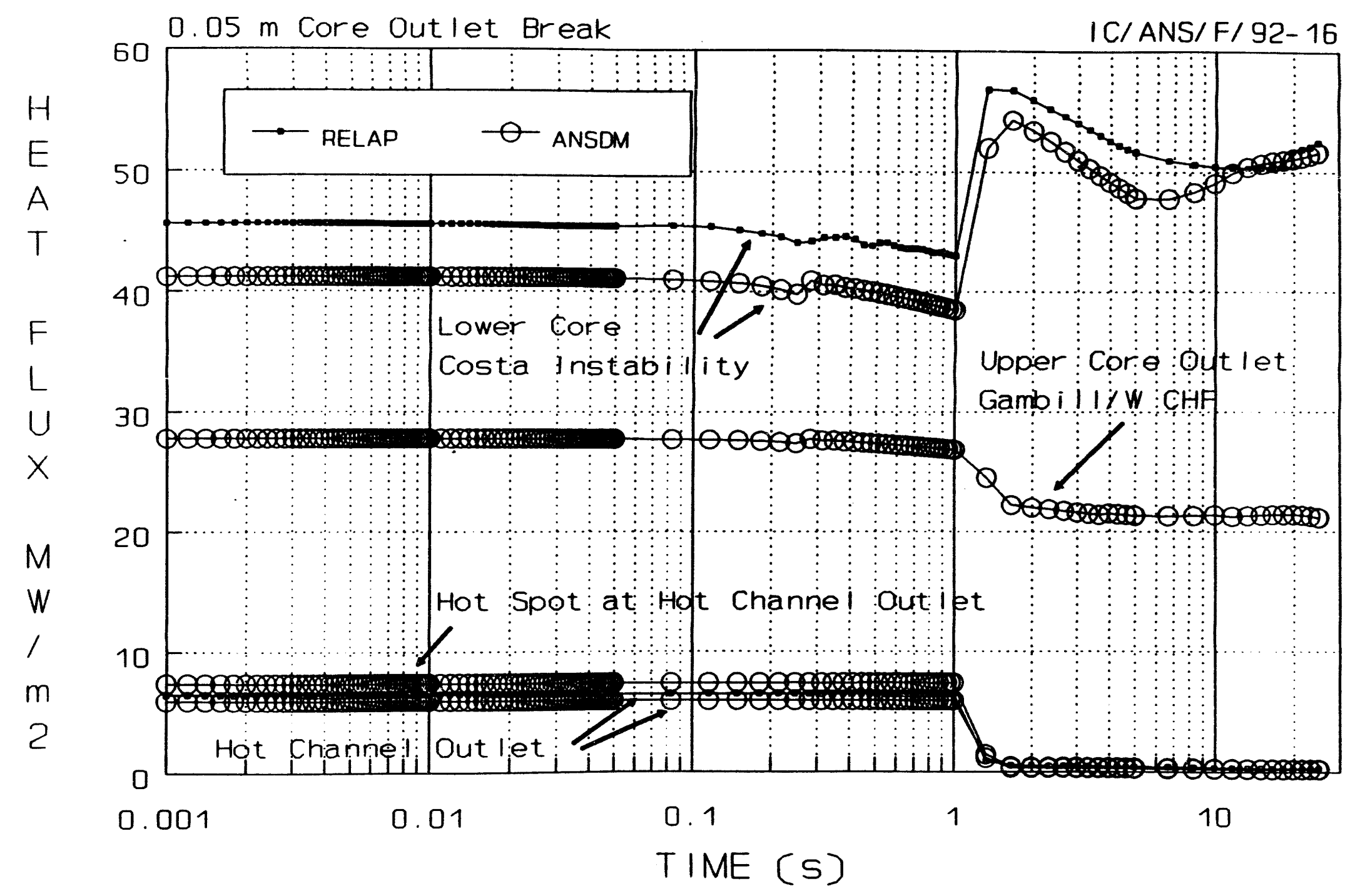

Fig. 9. Heat fux comparison at the hot spot of the bower core showing Costa, GambillWeatherhead, and local surface heat nuxes during the 51-mm-diam core pressure boundary tube outlet break with 250-ms opening time. 


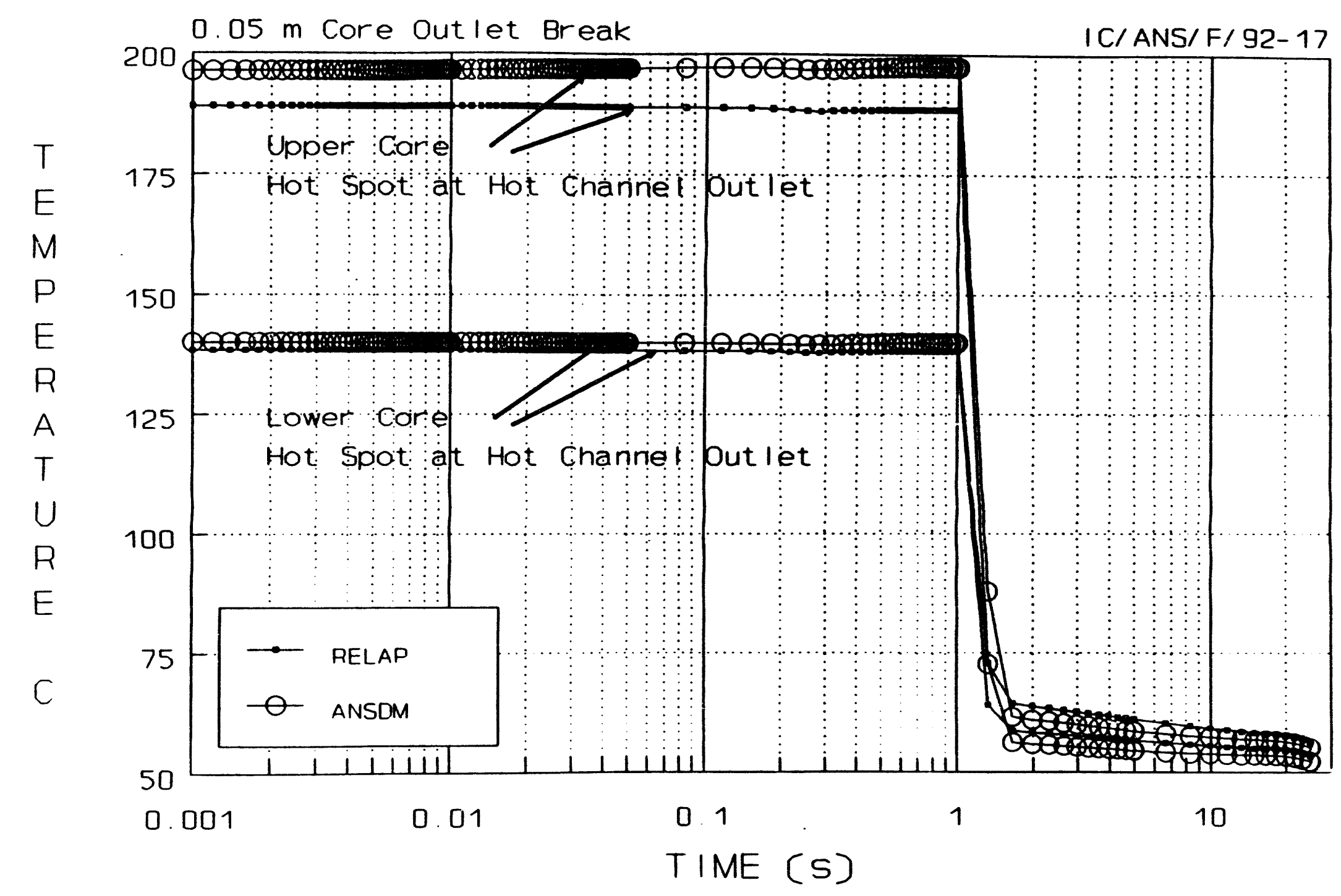

Fig. 10. Comparison in bulk coolant temperature at the hot channel outlet for the lower and upper cores during the 51-mmdiam core pressure boundary tube outlet break with 250-ms opening time. 


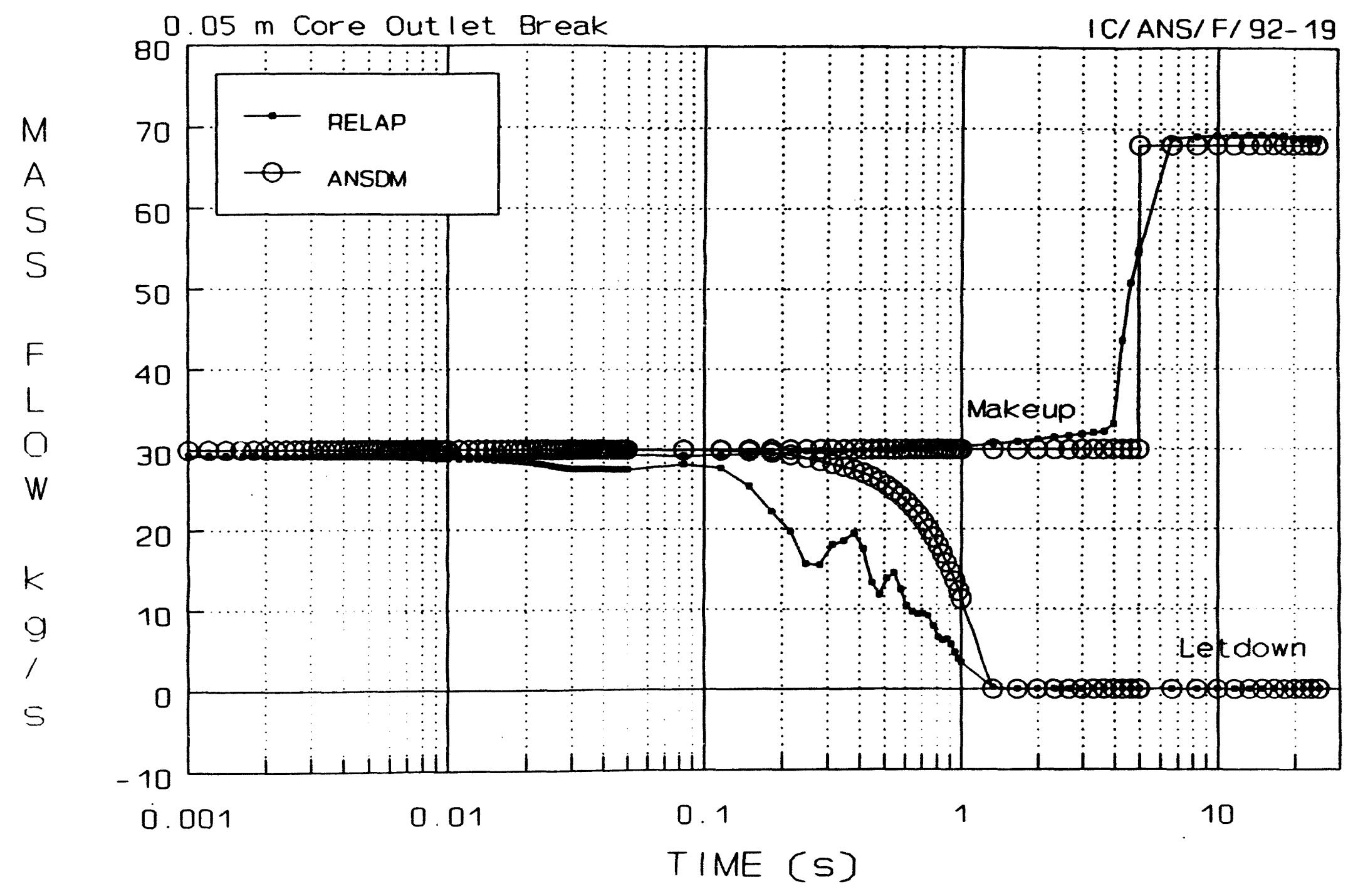

Fig. 11. Makeup and letdown fow comparison during the 51-mm-diam core pressure boundary tube outlet break with 250-ms opening time. 


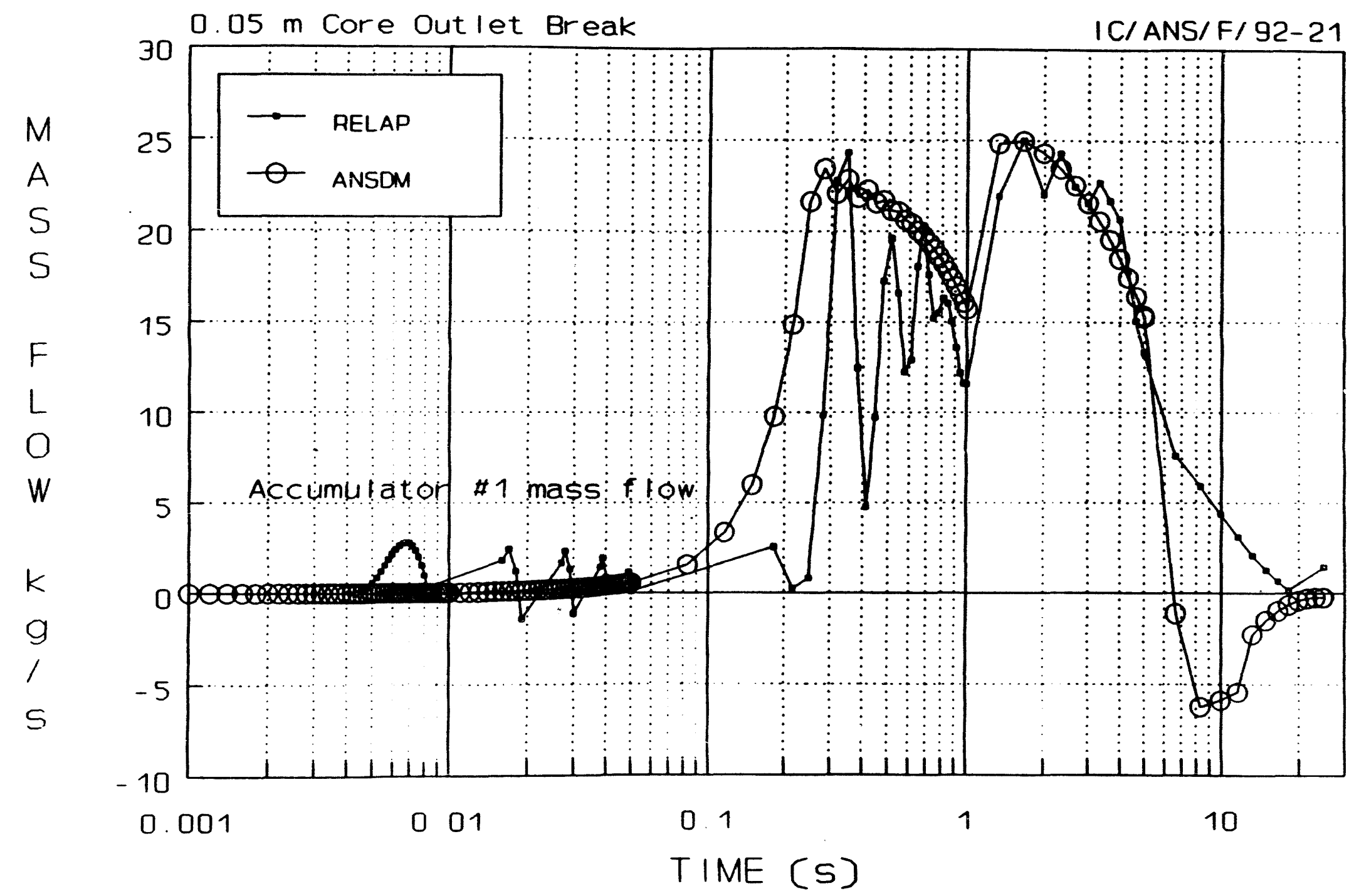

Fig. 12. Accumulator injection flow comparison during the 51-inm-diam core presaure boundary tube outlet break with 250-ms opening time. 
velocity while it is assumed to occur instantaneously in ANSDM. After the initial depressurization, ANSDM predicts a period of negative injection (i.e., flow back into the accumulators) that is not observed on the RELAPS trace. This period is not observable because the version of RELAP5 used for particular calculation has a default accumulator model that allows no return flow of primary coolant from piping back to the accumulators.

\subsubsection{Discunsion}

The small break comparicon was performed using RELAP5/MOD2/VERSION3t before the ANSR updates, including the three modifications described in Sect. 2.1.1, were available. As noted in Sect. 3.1.1, this caused a difference in wall temperatures of the fuel plates at steady-state conditions. The updated vexion RELAPS/MOD3/VERSION7AC became operational after the $51-\mathrm{mm}$ break comparison was completed, and is the version used for the remaining comparisons as presented in Sects. 3.2-3.4.

The inability of RELAPS to allow backflow of primary coolant from the coolant system to the accumulators is the result of an implicitly built-in check valve within the tank for the RELAP5 default accumulator model. This limitation was removed subsequent to the small break comparison. A new accumulator modal using pipe components with appropriate heat structures for wall heat transfer has been developed and is used for the remaining comparisons of Sects. 3.2-3.4.

\section{STATION BLACKOUT ACCIDENT}

A hypothetical, beyond-design-basis accident that includes a station blackout, a coincident loss of the pony motors, and a small LOCA resulting from a stuck open letdown valve has been simulated to allow comparison of predicted core cooling performance under depressurized, natural circulation conditions.

The station blackout (i.e., a loss of off-site power with failure of emergency diesel generators to start) is assumed to initiate the following ovents simultaneously: (1) main circulation pump trips and begins coastdown to zero speed; (2) main and standby pressurizing pumps begin coasting down to a stop; and (3) letdown isolation is initiated by a low core inlet pressure signal, and secondary coolant flow is lost. The main circulation pumps are tripped concurrently with the low pressure reactor scram, and they coast down over a time period determined by the balance between pump torque and inertia.

The initial conditions for the station blackout comparison are based on a reduced power and flow operating condition studied during the post-conceptual design report (CDR) period as shown in Table 9.

\subsubsection{Steady State}

The steady-state comparison for the power of $208.4 \mathrm{MW}$ is presented in Table 10 . The overall comparison agrees satisfactorily. The good agreement in the core pressure drop (difference between the core inlet and outlet pressure) requires the use of the Colebrook correlation. RELAP5 uses the Colebrook correlation that is calculated by a curve-fitting as a function of flow regimes, while ANSDM uses the Filonenko correlation. The accuracy of the curve fitting was evaluated and improved by INEL; however, updates were not available in time for this study. 
Table 9. Initial conditions for a station blackout comparison

\begin{tabular}{lcl}
\hline \multicolumn{1}{c}{ Parameter } & Value & \multicolumn{1}{c}{ Comments } \\
\hline Fission power & $208.4 \mathrm{MW}$, & $104.2 \%$ with $200 \mathrm{MW}$, nominal \\
Core inlet pressure & $2.41 \mathrm{MPa}$ & $95 \%$ of nominal \\
Core coclant velocity & $17.0 \mathrm{~m} / \mathrm{s}$ & Between fuel plates \\
Core inlet temperature & $45.2^{\circ} \mathrm{C}$ & $0.6^{\circ} \mathrm{C}$ sbove nominal \\
Accumulator volume & $5 \mathrm{~m}^{3}$ & Exch of three sctive sccumulators \\
Accumulator gas volume & $0.1 \mathrm{~m}^{3}$ & Eech of three sctive sccumulators \\
Pressure scram setpoint & $80 \%$ & $20 \%$ below nominal core outlet pressure \\
\hline
\end{tabular}

\section{Transient}

The sequence of events for the station blackout is shown in Table 11. Total (fission plus decay heat) power generated by the two models is compared in Fig. 13. The good agreement in power is consistent with the good agreement in reactor scram time. After that, both models agree to within 1\% of the nominal power to the end of calculations.

Figure 14 compares the coolant temperature at the lower core hot-channel outlet. RELAPS calculates a significantly warmer hot channel outlet temperature than ANSDM during the decay heat phase of the transient, even though both models agree fairly well at steady-state conditions, and RELAP5 calculates an -15\% lower total decay heat level. Since the total core power and flow velocities agree, this difference arises from the way in which the two codes distribute the decay heat to various core regions (control rods, reflectors, and core). ANSDM deposits $-94 \%$ of the power in the fuel plate during full power operation, but only $-65 \%$ during decay heat conditions because many of the gamma rays leave the fuel element. The RELAPS model deposits the same percentage of power $(-94 \%)$ in the fuel plate during full power operation as it does during decay heat conditions. Although the ANSDM distributions are probably more accurate, the RELAP5 approach is conservative. For the purpose of this benchmark effort, the ANSDM distributions were modified to agree with these assumed by RELAPS. With these modifications, both models agree satisfactorily as shown in Fig. 15. The remaining comparisons below were computed using the temporarily modified ANSDM inputs.

Main circulation pump speed during coastdown is compared in Fig. 16. ANSDM initially exhibited a much longer coastdown time because zero friction is assumed during coastdown. RELAP5 assumes that friction torque is $-2 \%$ of the nominal torque. When ANSDM input was reprogrammed to use the RELAP5 friction torque, the two models agreed very well not only in the pump coastdown but also in the average core coolant velocity (Fig. 17) and total core coolant mass flow (Fig. 18). A small mismatch between 25 and $150 \mathrm{~s}$ induces a mismatch in outlet temperatures as shown in Fig. 15.

Comparison in depressurization rate (see Fig. 19) at the lower core exit shows that the results differ within 10-20\%. This difference is explained by the differences in the letdown system modeling and the fact that a perfectly isothermal gas expansion inside the accumulator is assumed in ANSDM, while RELAP5 calculates nearly adiabatic behavior. In this comparison, the volume of each of the 
Table 10. Steady-state comparison for 200-MW nominal core

\begin{tabular}{|c|c|c|c|}
\hline Parameter & REILAP5 & ANSDM & PRSDYN \\
\hline Fission power (MW) & 208.4 & $208.4^{b}$ & $208.4^{b}$ \\
\hline Total mass flow (kg/s) & 1336 & $1336^{\circ}$ & $1336^{\circ}$ \\
\hline Coolant velocity at fuel element inlet (ms/s) & 17.0 & 16.9 & 16.7 \\
\hline Core inlet temperature $\left({ }^{\circ} \mathrm{C}\right)$ & 45.8 & 45.6 & 45.4 \\
\hline CPBT outlet temperature $\left({ }^{\circ} \mathrm{C}\right)$ & 81.2 & 81.8 & 81.3 \\
\hline $\begin{array}{l}\text { Hot channel outlet temperature in lower } \\
\text { element }\left({ }^{\circ} \mathrm{C}\right)\end{array}$ & 130 & 128.6 & 127.5 \\
\hline $\begin{array}{l}\text { Lower element outlet saturation temperature } \\
\left({ }^{\circ} \mathrm{C}\right)\end{array}$ & 203 & 201 & 202.7 \\
\hline Core inlet pressure (MPa) & 2.41 & $2.40^{\circ}$ & $2.40^{\circ}$ \\
\hline Core ontlet pressure (MPa) & 1.65 & $1.66^{e}$ & $1.64^{\circ}$ \\
\hline Main coolent pump inlet pressure (MPa) & 1.50 & 1.51 & 1.54 \\
\hline Main coolant pump outlet pressure (MPa) & 2.45 & $2.43^{d}$ & $2.43^{\circ}$ \\
\hline $\begin{array}{l}\text { Lower element hot channel heat flux at } \\
\text { outlet }\left(\mathrm{MW} / \mathrm{m}^{2}\right) \text {; includes } 95 \% \text { flow } \\
\text { excursion uncertainty }\end{array}$ & 3.29 & 3.15 & 32. \\
\hline $\begin{array}{l}\text { Costa flow excursion limit at lower element } \\
\text { hot channe'i outlet }\left(\mathrm{MW} / \mathrm{m}^{2}\right) \text {. }\end{array}$ & 22.97 & 23.14 & 23.5 \\
\hline
\end{tabular}

-ANSDM = Advanced Neutron Source dynamic model.

Input as parameter for benchmark. smaller.

Requires use of Colebrook \& White friction correlation. Usiag Filonenko, the pressure drop is $15 \%$

Preasure drops in cold leg adjusted upwards to account for unmodeled check valves, isolation valves, and pipe blends.

three accumulator tanks includes $4.9 \mathrm{~m}^{3}$ of heavy water and $0.1 \mathrm{~m}^{3}$ of nitrogen gas. If ANSDM is reprogrammed to assume an adiabatic gas expansion, the ANSDM and RELAP5 pressures agree satisfactorily, as illustrated in Fig. 20.

Since ANSDM was, as discussed above, temporarily modified so that it would distribute decay heat in the same manner as RELAP5, the long term ( $t>100 \mathrm{~s}$ ) natural ci-culation velocity and hot leg temperature match relatively well (see Figs. 15 and 17). This match is independent of the pump coastdown characteristics. Such good agreement indicates that both codes provide fairly consistent results on the low velocity pressure drops and temperature distributions. 
Table 11. Sequence of events for station blackout benchmark

\begin{tabular}{|c|c|c|}
\hline Time & RELAP5 & ANSDMP \\
\hline $\mathbf{0}$ & $\begin{array}{l}\text { Initialize reactor power to } 208.4 \mathrm{MW} \\
(200 \text { nominal at } 104.2 \%) \text {, and } 16.7 \mathrm{~m} / \mathrm{s} \\
\text { coolent velocity }\end{array}$ & $\begin{array}{l}\text { Initialize reactor power to } 208.4 \mathrm{MW}(200 \\
\text { nominal at } 104.2 \%) \text { and } 16.7 \mathrm{~m} / \mathrm{s} \text { coolant } \\
\text { velocity }\end{array}$ \\
\hline $\mathbf{0}$ & Trip makeup pump & $\begin{array}{l}\text { Trip makeup pump; flow decays } \\
\text { exponentially as exp }(-10.5)\end{array}$ \\
\hline \multirow[t]{2}{*}{$\mathbf{0}$} & $\begin{array}{l}\text { Inolwe secondary; flow reduced linearly } \\
\text { to zero in } 108\end{array}$ & $\begin{array}{l}\text { Trip secondery coolent pumps; flow } \\
\text { reduces exponentially as exp }(-1 / 2)\end{array}$ \\
\hline & • & $\begin{array}{l}\text { Artificially reduce secondary coolant loop } \\
\text { elevetion to } 0.1 \mathrm{~m} \text { to minimize natural } \\
\text { circulation and model the isolation } \\
\text { approximately }\end{array}$ \\
\hline $\mathbf{0}$ & $\begin{array}{l}\text { Fail the three letdown values "as is": } \\
\text { inhibit block valve from closing on low } \\
\text { pressure }\end{array}$ & $\begin{array}{l}\text { Fail the three letdown valves "as is"; } \\
\text { inhibit block valve from closing on low } \\
\text { preasure }\end{array}$ \\
\hline 6.74 & $\begin{array}{l}\text { REILAPS detects low pressure screm } \\
\text { conditions }\end{array}$ & \\
\hline 6.74 & $\begin{array}{l}\text { Main coolent pumps tripped; coestdown } \\
\text { to zero speed in }-25 \text { \& }\end{array}$ & \\
\hline 6.76 & & $\begin{array}{l}\text { ANSDM deiects low pressure scram } \\
\text { conditions }\end{array}$ \\
\hline 6.76 & & $\begin{array}{l}\text { Main coolant pumps tripped; coastdown to } \\
\text { zero speed in }-25 \text { s }\end{array}$ \\
\hline 7.02 & & $\begin{array}{l}\text { Inner control rods fully inserted from } \\
\text { critical position at BOC }\end{array}$ \\
\hline 7.09 & . & Outer rods fully inserted \\
\hline
\end{tabular}

-ANSDM = Advanced Neutron Source dynamic model.

BOC = beginning-of-cycle.

\subsubsection{Discussion}

The FE and CHF thermal limit ratios at the hot spot for the lower core are shown only for RELAP5 calculations in Fig. 21. Because the Costa FE limiting heat flux is always significantly higher than the actual heat flux at the lower core hot spot, it may be concluded that the core survives this station blackout transient without violating any safety margins. During this transient, there are two points of minimum margin-the first minimum occurs right after the reactor scrams $(-6.7 \mathrm{~s}$ into the transient), and the second minimum occurs at the transition ( $-40 \mathrm{~s}$ into the transient) from forced convection to natural circulation. 


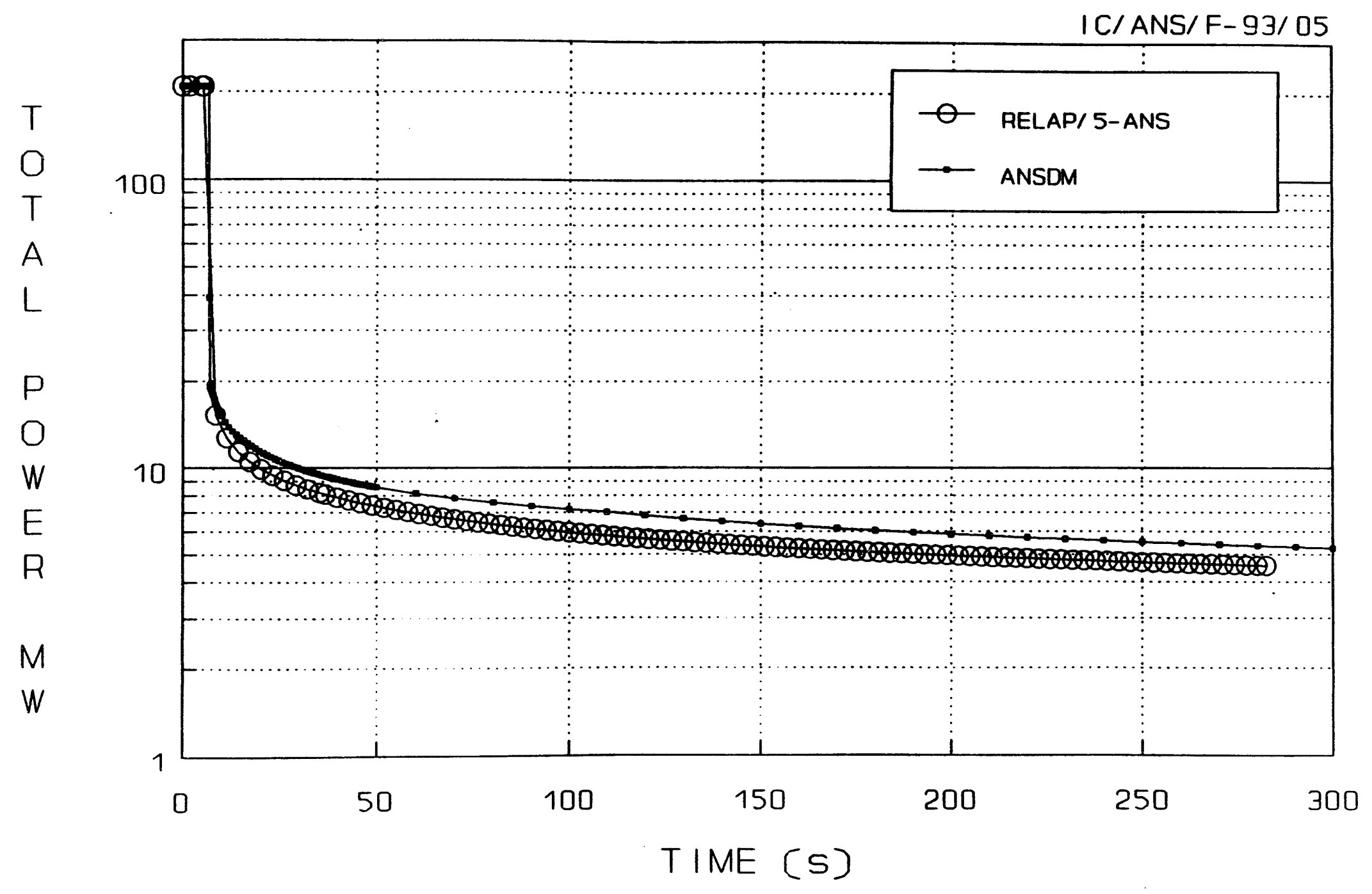

Fig. 13. Total (fission plus decay heat) power generated in the two models during the station blackout accident. 


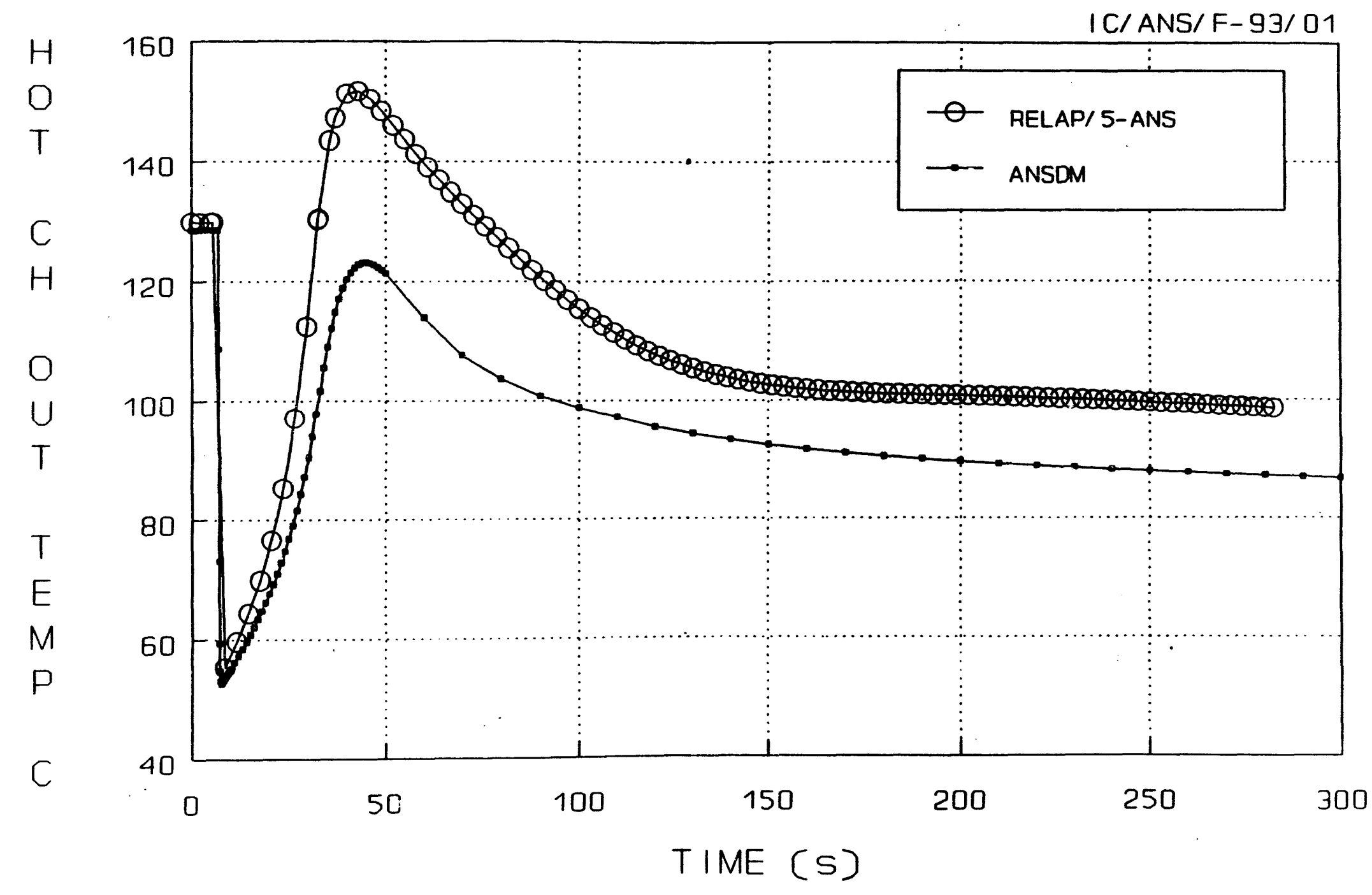

Fig. 14. Comparison in coolant temperature at the lower-core hot-channel outlet during the station blackout accident. (The Advanced Neutron Source dynamic model deposits only $65 \%$ of the decay heat on the fuel plate, whereas the Advanced Neutron Source reactor RELAP5 model deposits $94 \%$.) 


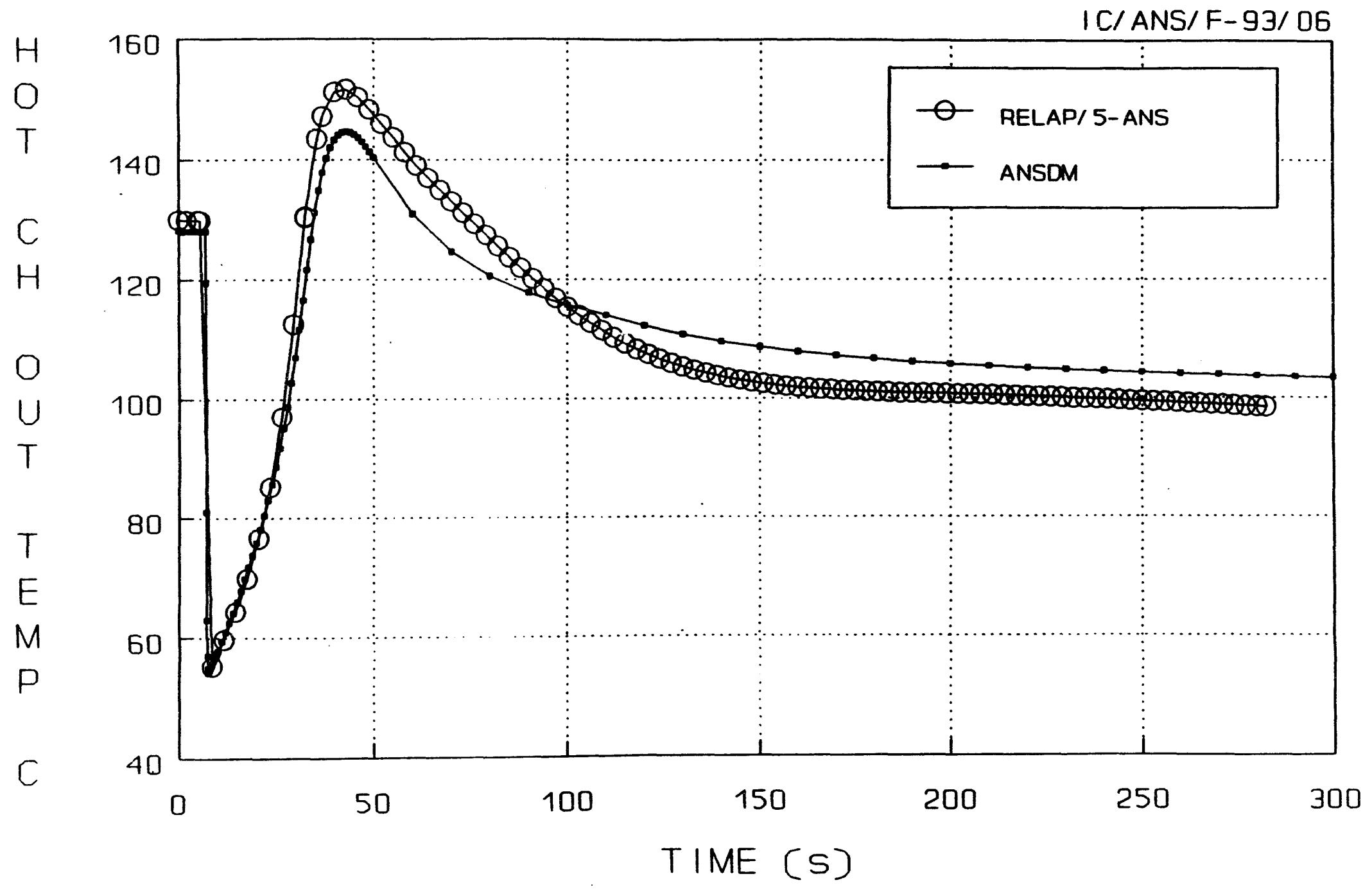

Fig. 15. Coolant temperature at the lower-core hot-channel outlet during the station blackout accident. If the Advanced Nentron Source dynamic model assumes regional distribution of decay heat power similar to RELAP5's, both models agree satisfactorily. 


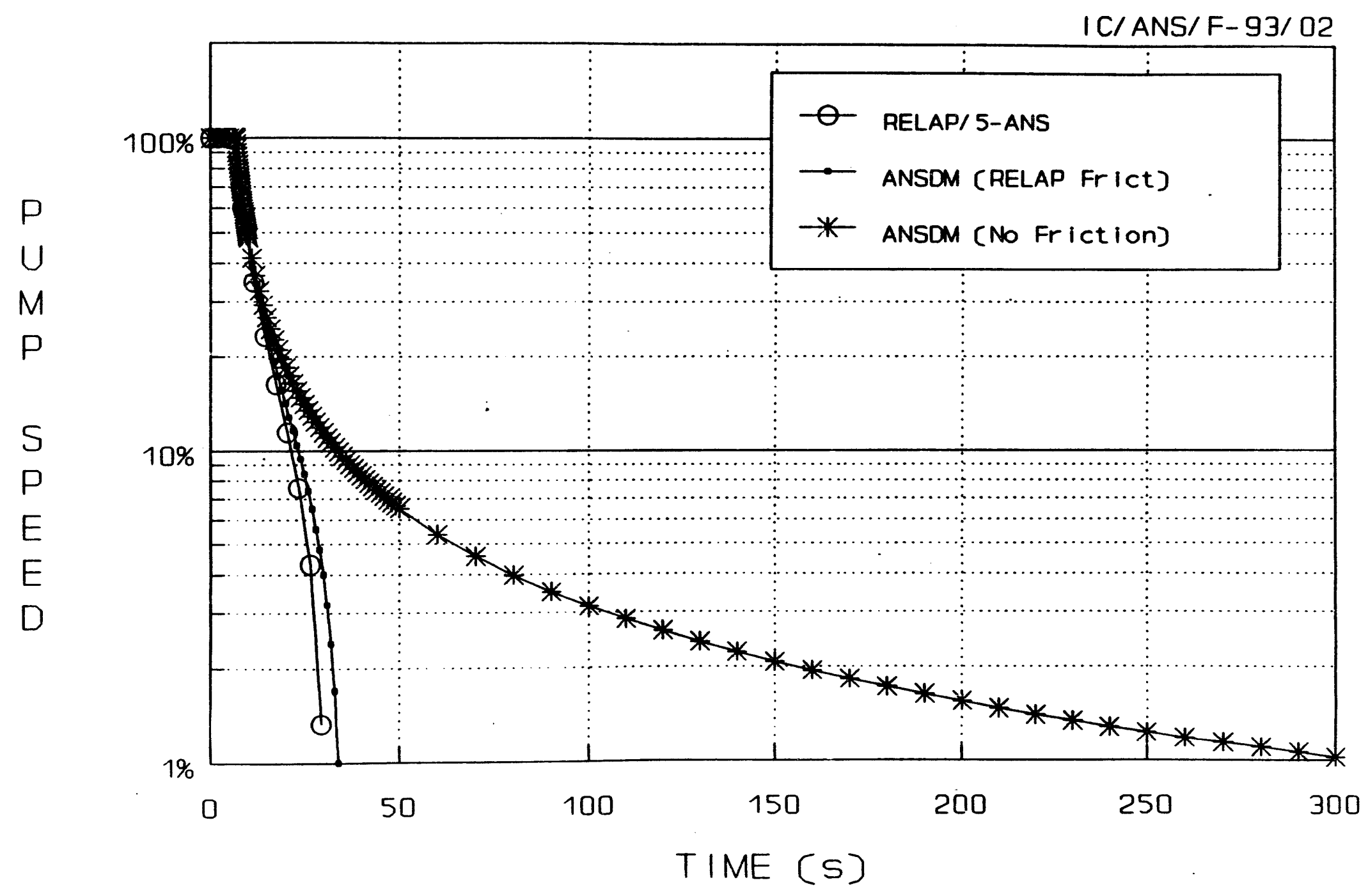

Fig. 16. Main circulation pump castdown speed during the station blackout aceident. [Depending on assumed friction, pump coastdown characteristics below pony speed (10-15\%) difier significanthy.] 
('øunjusaduat lop̧no u!

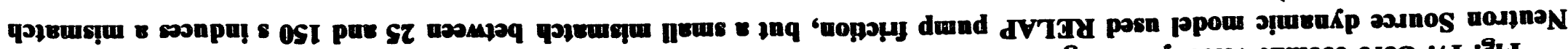

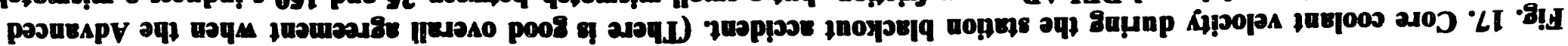

$$
\text { (S) } \exists W I \perp
$$

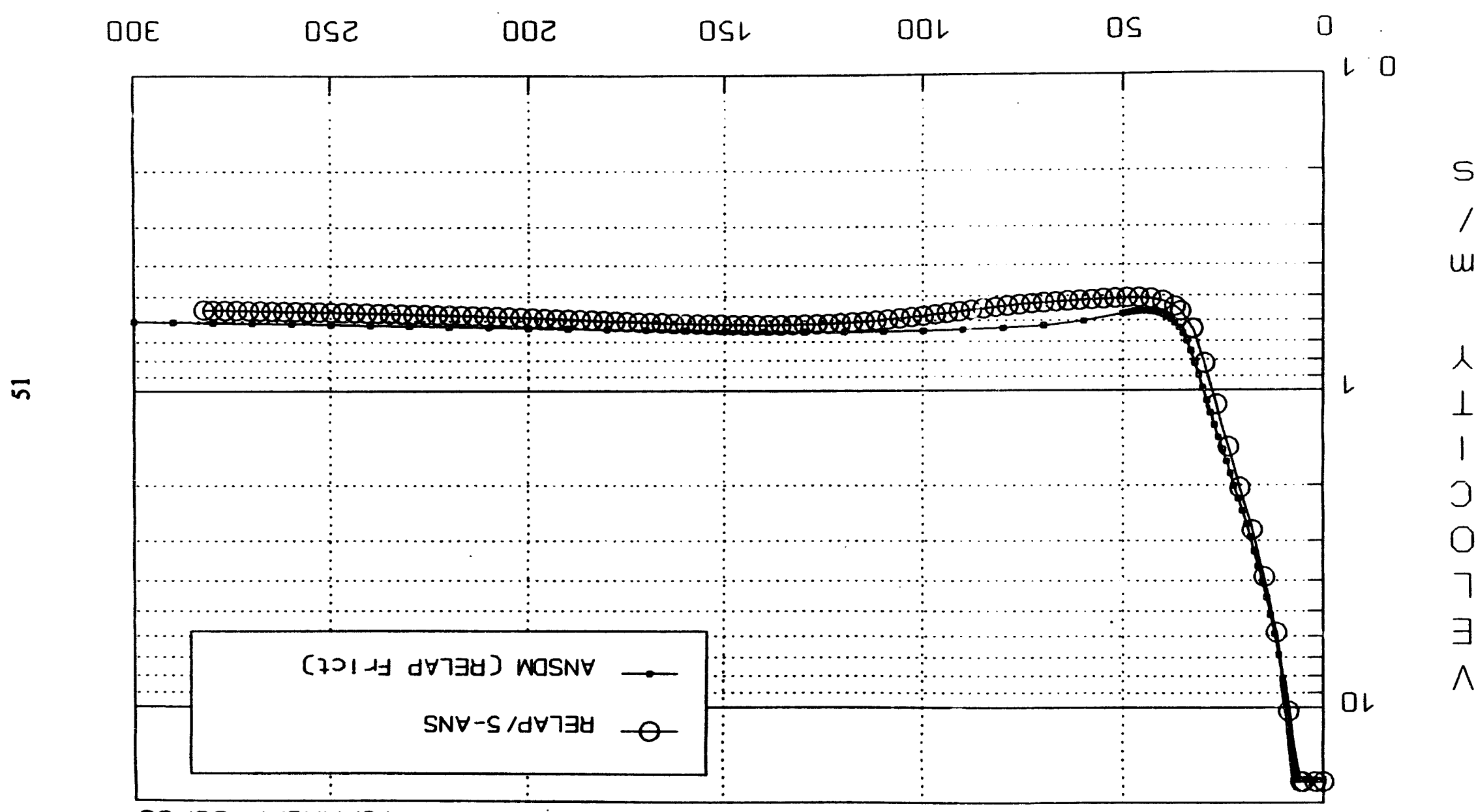

$80 / E 6-\unlhd / S N \forall / J I$ 


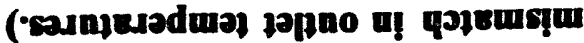

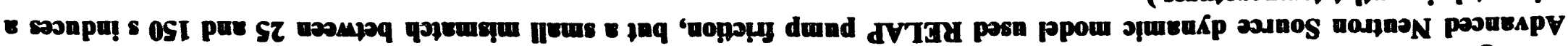

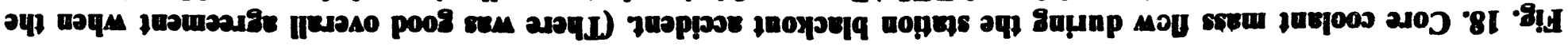

(S) $\exists W I \perp$

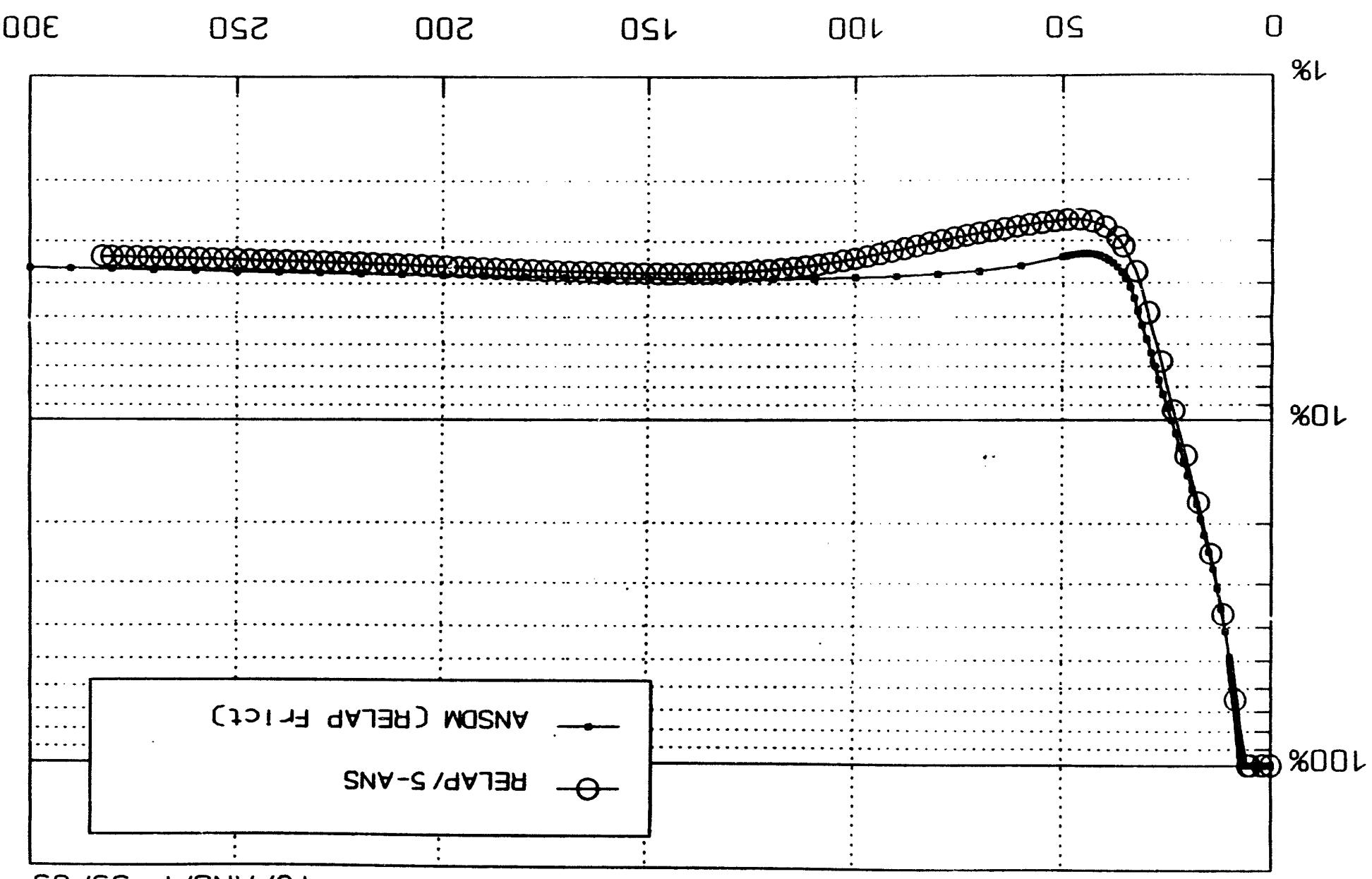

M

$\mathrm{O}$

7

$\exists$

$\approx$

$60 / E 6-\exists / S N \forall / J I$ 


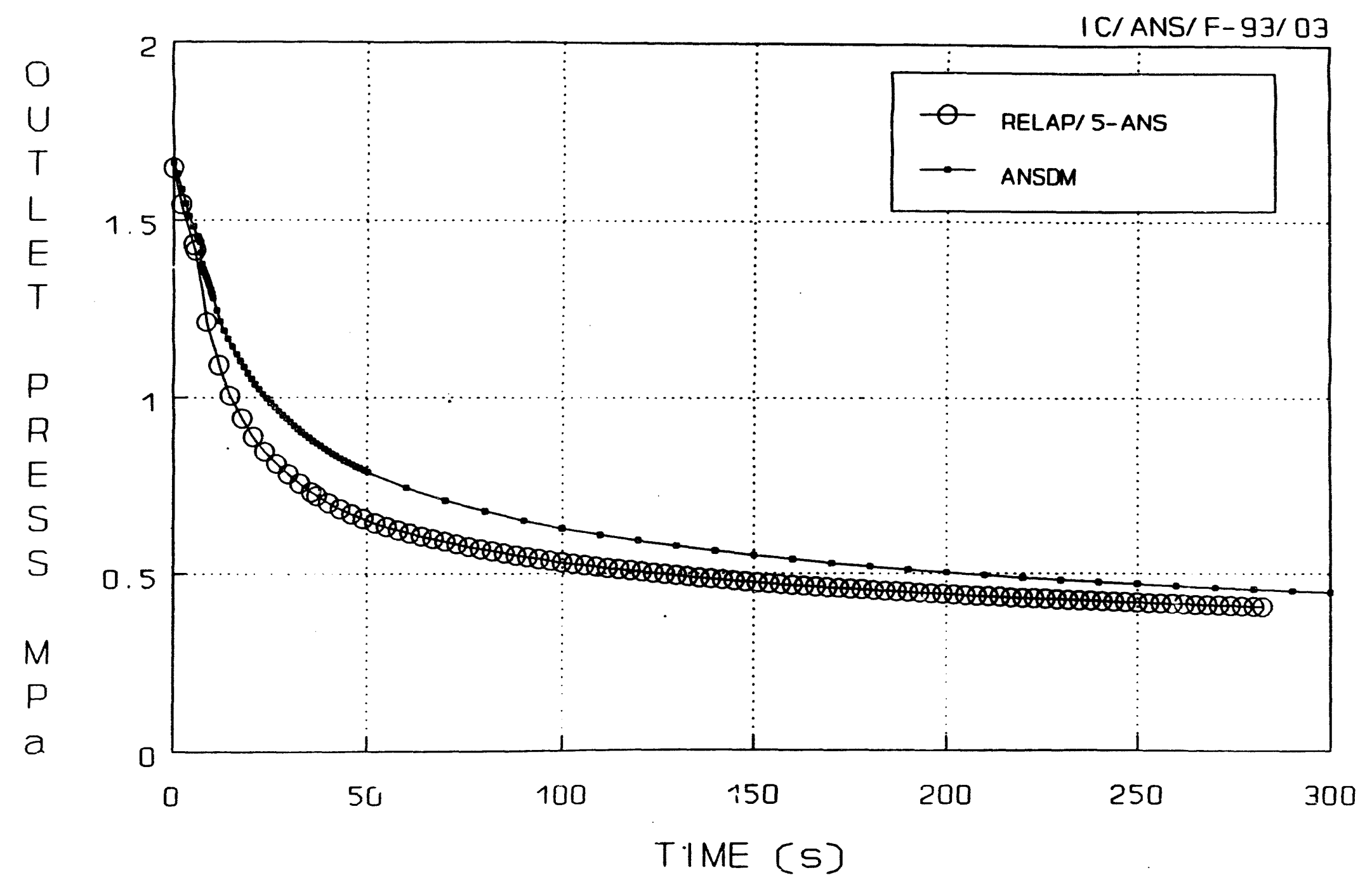

Fig. 19. Comparison in core outlet pressure during the station blackout accident. (The Advanced Neutron Source dynamic model assumes a perfect isothermal accumulator; the RELAP5 sceumulator is not perfectly isothermal.) 


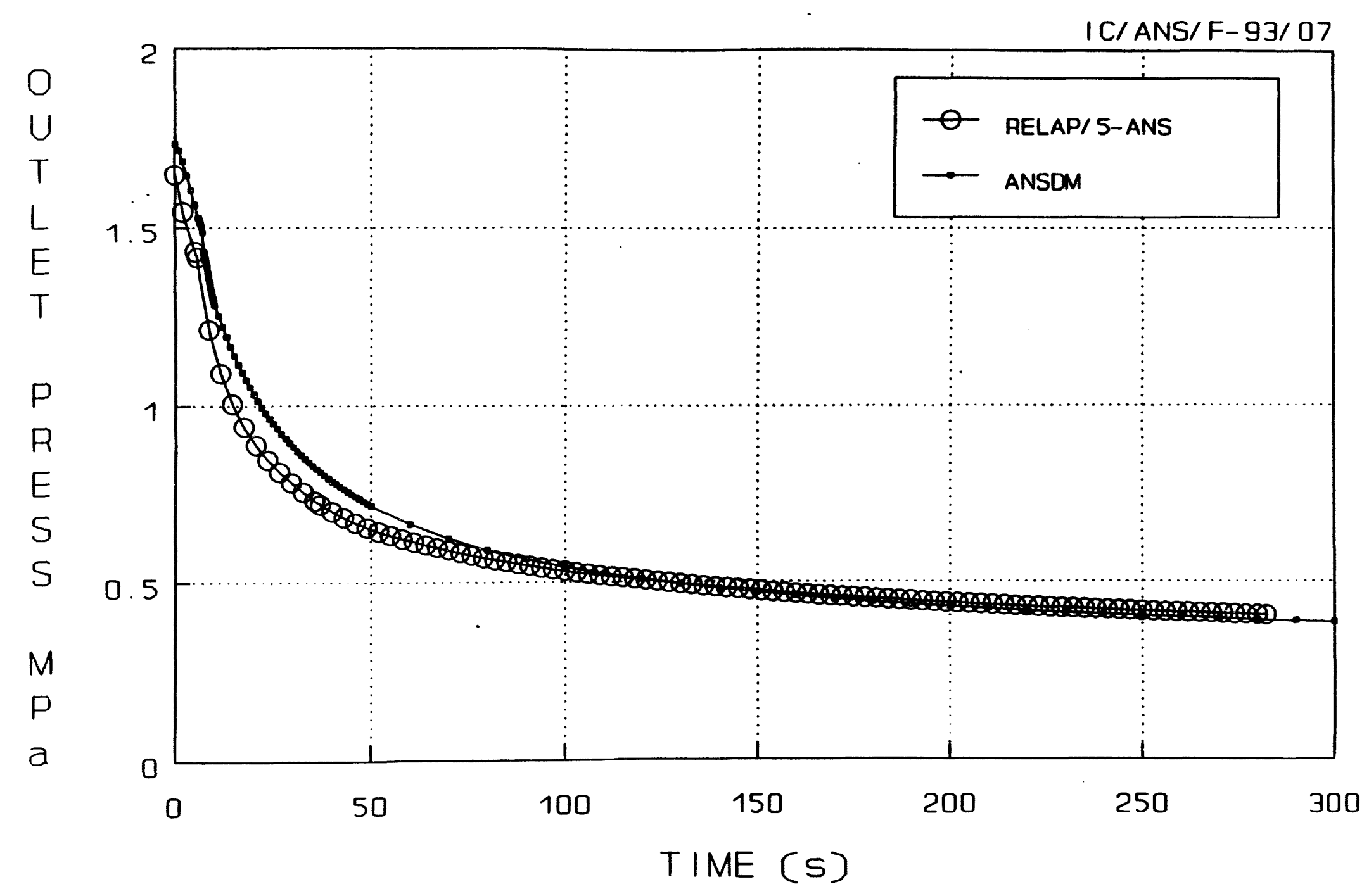

$\ddot{A}$

Fig. 20. Comparison in core outlet pressure during the station blackout aceident. IIf the Advanced Nentron Source dynamic model models an adiabatic aceumulator (with $0.1 \mathrm{~m}^{3} \mathrm{gas}$ volume), the pressures agree satisfinctorily in both models.] 


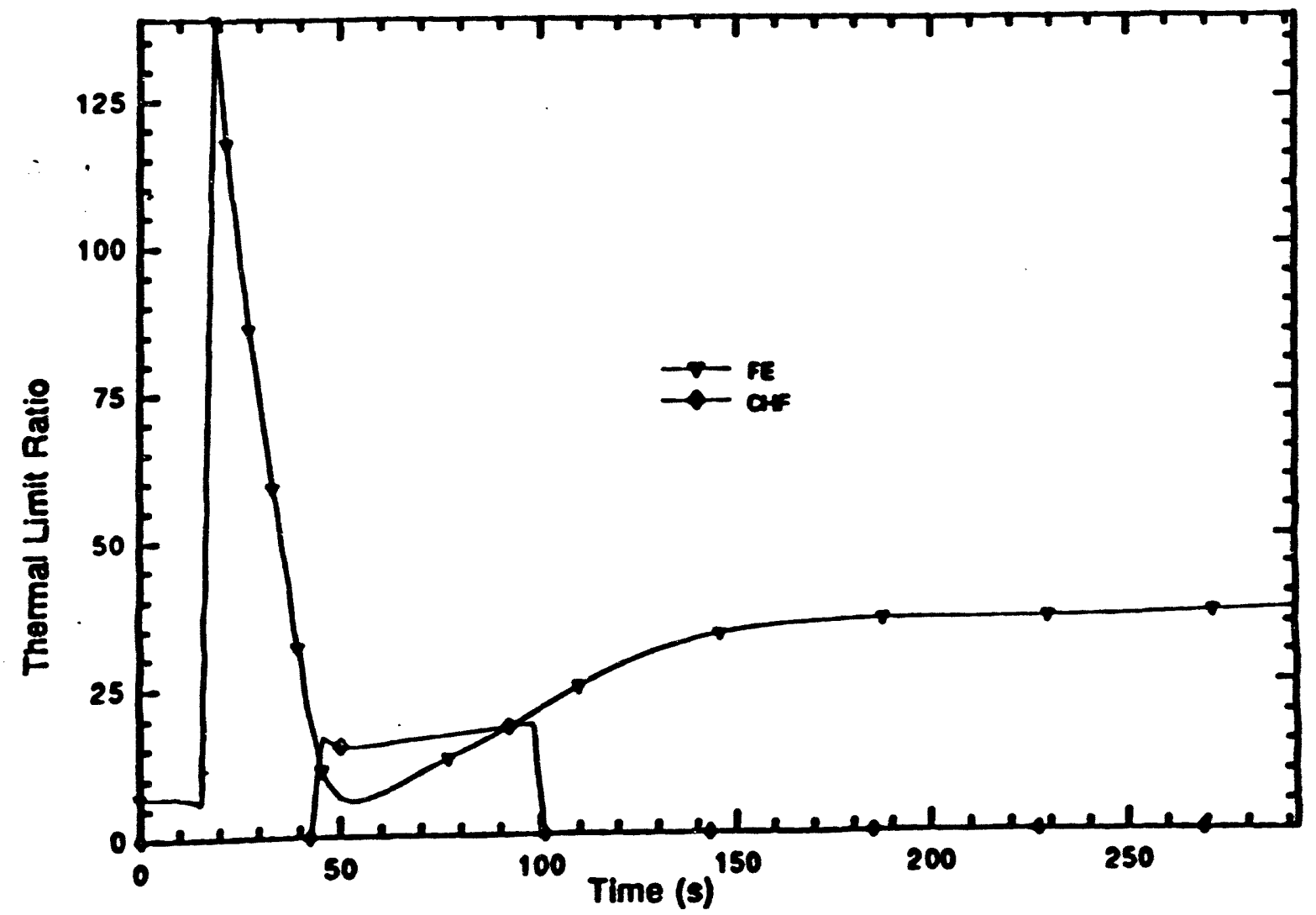

Fig. 21. RELAP5-calculated thermal limit ratios during the station blackout aceldent. (Note that the eritical heat fux values are not printed out by RELAPS if the wall temperature stays below the local coclant saturation temperature.) 
Core survivability during natural circulation critically depends on decay heat power and pump constdown chancteristics. All ANSR models agree to within $1 \%$ as to the nominal power following shutdown, but differences arise in the regional distribution (i.e., the fraction of decay heat that is deposited in the core, reflector, and control rod bypass regions) of post-shutdown heat load. The heat loed distribution is significantly different depending on whether the power originates from fission (where most power remains in the fuel plate) or from decay heat (where $-50 \%$ of the gamma-ray energy leaves the fuel plate). For this reason, different regional distribution values for fission power then for decay heat levels are used in ANSDM. In this way, $-94 \%$ of the power at nominal (100\%) conditions remains in the fuel plate, but only $-65 \%$ of the power remains in the plate at decay heat lovels.

The ANSR RELAPS model uses the same regional distribution values for nominal power than for decay heat levels, 50 that $-94 \%$ of RELAP5's power remains in the fuel plate during decay heat. The -65\% decay heat power used in ANSDM was extrapolated from numbers used in the III reactor (see Table 12). More accurate ANSR-specific MCNP results calculated by DNEL following the CSAR activities indicase that the decay heat distribution is closer to $72 \%$ in the core, $13 \%$ in the reflector. and 15\% in the CPBT bypass. For this benchmark effort, the input to ANSDM was modified to simulate the constant regional power distribution used in RELAPS, which is conservative.

Table 12. Podt-earam decay heat regional dituribution extrapolated from the Inditut Lave-Langevin

\begin{tabular}{lccl}
\hline $\begin{array}{c}\text { Type of } \\
\text { power }\end{array}$ & $\begin{array}{c}\text { Reflector } \\
(\%)\end{array}$ & $\begin{array}{c}\text { Bypes C.R.: } \\
(\%)\end{array}$ & $\begin{array}{l}\text { Core } \\
(\%)\end{array}$ \\
\hline Fiseion & 4.40 & 2.14 & 93.46 \\
Decay heat & 8.64 & 26.36 & 65 \\
\hline
\end{tabular}

C.R. = control rod chanel.

The pump coastdown characteristics are very relevant to natural circulation results. However, no ANSR-specific pump data are currently available. Given the lack of data, all natural circulation results performed to date should be viewed cautiously, particularly between 20 and $100 \mathrm{~s}$ into the transient. The closest approach to the safety limit occurs during this period where transition from forced convection to natural circulation takes place.

Accumulator performance affects the depressurization rate significantly. An accumulator with isothermal gas expansion responds faster than an adiabatic accumulator for a given pressure change. A rapid response results in a higher injection. Consequently, the pressure can be maintained higher at the hot spot where the thermal criteria is the most limited. In the comparison, both ANSDM and PRSDYN use analytical expressions for an ideal gas expansion, whereas the ANSR RELAP5 model uses a fixed nodalization grid to account for the gas-liquid interface heat transfer and wall heat transfer. However, the RELAP5 model can not account for the thermal and hydrodynamic effects of the honeycomb insent of the isothermalizer design. The baseline ANSR conceptual design includes the isothermalizer packing material inside the accumulators. 


\subsection{LARGE LOSS OF COOLANT ACCIDENT}

This is a post-CSAR comparison among three models (RELAP5, ANSDM, and PRSDYN) for a slow-opening (1.1 s) large DEG break at the core inlet. The break is located downstream of the inertial flow diode but upstream of the primary supply vessel adapter weldment (PSVAW). For ANSR, this is the worst possible location for a large break. Although ANS staff members do not believe that large breaks are credible, a large, beyond-design-basis DEG break was postulated for this analysis to demonstrate that cooling can be maintained during and after a large break that does open fully and with some rapidity. As illustrated in Fig. 22, the PSVAW is the component where the four cold legs combine and flow is routed into the core region.

For conceptual safety analysis, the policy for all events has been to modify the initial conditions from nominal (in the conservative direction) by the amount necessary to account for measurement error and routine control variations. The conservative direction to perturb the initial conditions is generally in the direction of decreasing CFF-higher power and coolant temperature and lower coolant pressure and flow.

The parameters shown in Table 13, modified for tunical safety analysis conservatisms to account for routine process control variations and heat bala.ce error, are important to this analysis.

Table 13. Parameters for a large loss of coolant accident

\begin{tabular}{lll}
\hline \multicolumn{1}{c}{ Paremeter } & \multicolumn{1}{c}{ Value } & \multicolumn{1}{c}{ Comments } \\
\hline Fiscion power & $344 \mathrm{MW}$, & $\begin{array}{l}104.2 \% \text { of } 330 \mathrm{MW}, \text { nominal (includes all heat deposited } \\
\text { in fuel, atructures, coolant, and reflectors) }\end{array}$ \\
Core inlet pressure & $3.22 \mathrm{MPa}$ & Nominal \\
Core coolant velocity & $25.0 \mathrm{~m} / \mathrm{s}$ & Between the fuel plates \\
Core inlet temperature & $45.6^{\circ} \mathrm{C}$ & $0.6 \mathrm{C}$ above nominal \\
Accumulator volume & $7.52 \mathrm{~m}^{3}$ & Each of three active accumulators \\
Accumulator gas volume & $0.52 \mathrm{~m}^{3}$ & Each of three active accumulators \\
Pressure scram setpoint & $80 \%$ & $20 \%$ below nominal core outlet pressure \\
\hline
\end{tabular}

\subsubsection{Steady-State}

The steady-state results agree well, as shown in Table 14. The same comment on pressure drop across the core as stated in Sect. 3.2.1 applies here. In addition, ANSDM underestimates the pressure drops in the loop (outside the core) by not accounting directly for check valves, isolation valves, and pipe bends.

\subsection{Transient}

During the first iteration to attempt to benchmark this transient, all three models agreed on flows and pressures but disagreed on heat flux and time to scram. As shown in Fig. 23, the three models agree extremely well on both total core flow and total break flow. It is seen that an almost 


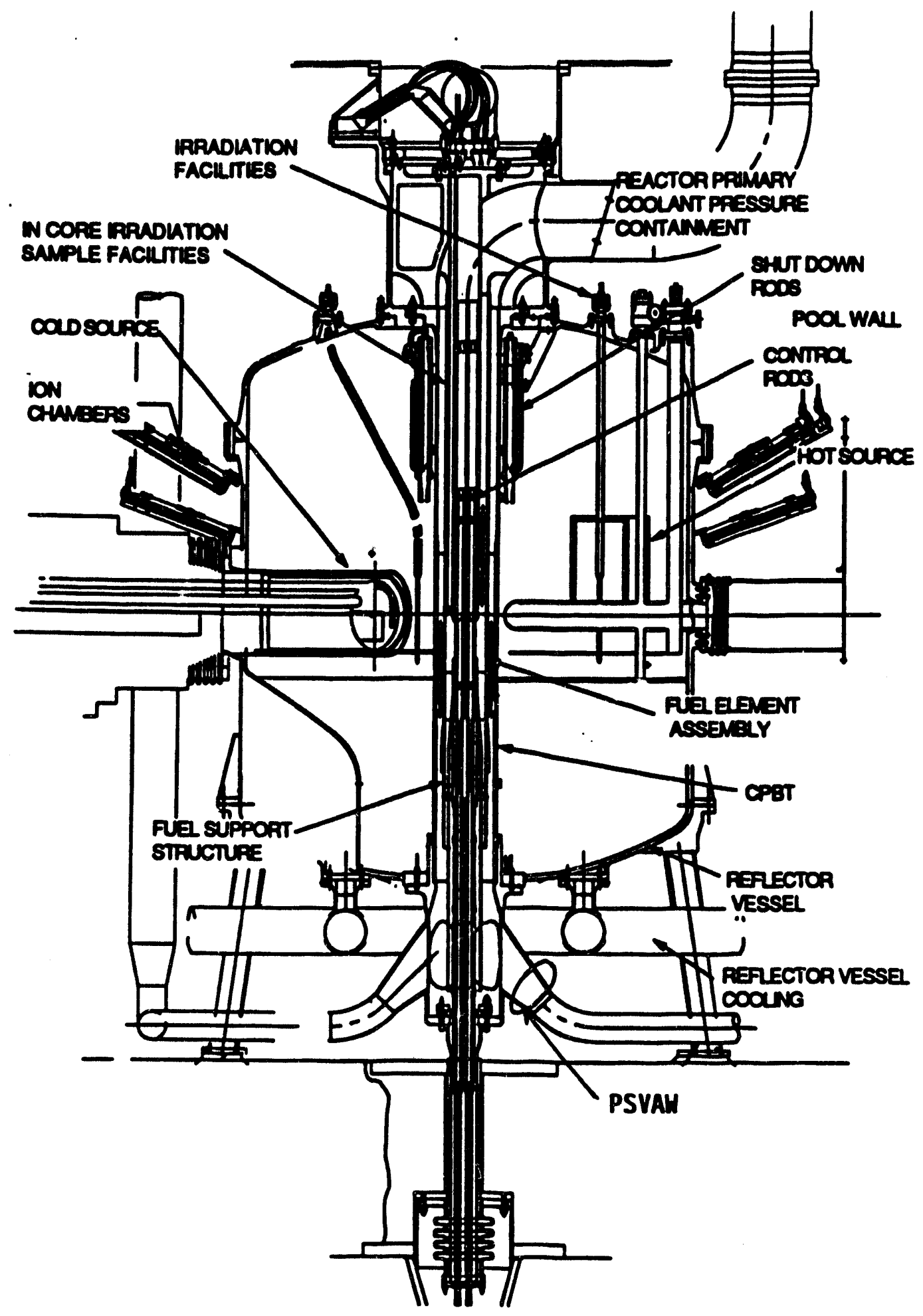

Fig. 22. Advanced Neutron Source reactor core region showing the primary supply vessel adapter weldment. 
Table 14. Steady-state comparison for 330-MW nominal core

\begin{tabular}{|c|c|c|c|}
\hline Parameter & RELAPS & ANSDM & PRSDYN \\
\hline Fission power (MW) & 344.0 & $343.9^{b}$ & $344.0^{\circ}$ \\
\hline Total mass flow (kg/s) & 1944 & $1994^{6}$ & $1994^{\circ}$ \\
\hline Coolant velocity at fuel element inlet $(\mathrm{m} / \mathrm{s})$ & 25.0 & 25.2 & 25.2 \\
\hline Core inlet temperature $\left({ }^{\circ} \mathrm{C}\right)$ & 45.6 & 45.2 & 45.0 \\
\hline CPBT outlet tempenture $\left({ }^{\circ} \mathrm{C}\right)$ & 84.5 & 852 & 85.0 \\
\hline $\begin{array}{l}\text { Hot channel outlet temperature in lower } \\
\text { element }\left({ }^{\circ} \mathrm{C}\right)\end{array}$ & 139.0 & 137.2 & 135.6 \\
\hline $\begin{array}{l}\text { Lower element outlet saturation temperature } \\
\left({ }^{\circ} \mathrm{C}\right)\end{array}$ & 202.0 & 196.1 & 201.0 \\
\hline Core inlet pressure (MPa) & 3.22 & $3.18^{b}$ & $3.22^{6}$ \\
\hline Core cutlet pressure (MPa) & 1.62 & 1.60 & 1.62 \\
\hline Main coolent pump inlet pressure (MPa) & 1.41 & 1.40 & 1.53 \\
\hline Main coolant pump outlet pressure (MPa) & 3.43 & $3.40^{\circ}$ & $3.43^{\circ}$ \\
\hline $\begin{array}{l}\text { Lower element hot channel heat flux at outbet } \\
\left(\mathrm{MW} / \mathrm{m}^{2}\right) \text {; includes } 95 \% \mathrm{FE}^{\prime} \text { uncertainty }\end{array}$ & 5.44 & 5.19 & : \\
\hline $\begin{array}{l}\text { Costa FE limit at lower-element hot-channel } \\
\text { outlet }\left(\mathrm{MW} / \mathrm{m}^{2}\right)\end{array}$ & 23.63 & 23.14 & \\
\hline
\end{tabular}

'ANSDM = Advanced Neutron Source dynamic model.

Input as parameter for benchmark.

'CPBT = core pressure boundy tube.

Requires use of Colebrook \& White friction correlation. If the Filonento correlation is used, the pressure drop is $15 \%$ smaller.

Prescure drops in cold leg adjusted upwerds to sccount for unmodeled check valves, ieolation valves, and pipe bends.

FE = flow excursion.

perfect match persists throughout the first half of a second into the transient, with the maximum discrepancy being limited to $-10 \%$ at $1 \mathrm{~s}$. Excellent agreements are also found in pressures at the lower fuel element inlet and outlet (see Fig. 24). All three models correctly predicted a similar depressurization rate in response to break flow. They also predicted a similar declining pressure drop across the core resulting from the diminishing core flow. When the system pressure approaches the pool pressure, the pressure drop across the core converges to the same constant as predicted by all models.

The Costa limiting and local surface heat fluxes at the hot spot in the lower core hot channel exit are compared in Fig. 25. Two disagreements are found in the time to scram and initial Costa limit.

ANSDM detects the scram (including sensor delay) in $385 \mathrm{~ms}$ and the scram takes effect (rods start inserting significantly) in $450 \mathrm{~ms}$. RELAP5 does not significantly insert the rods until 650 ms. 
Core Inlet $\left(14^{\prime \prime}\right)$ DEG Break

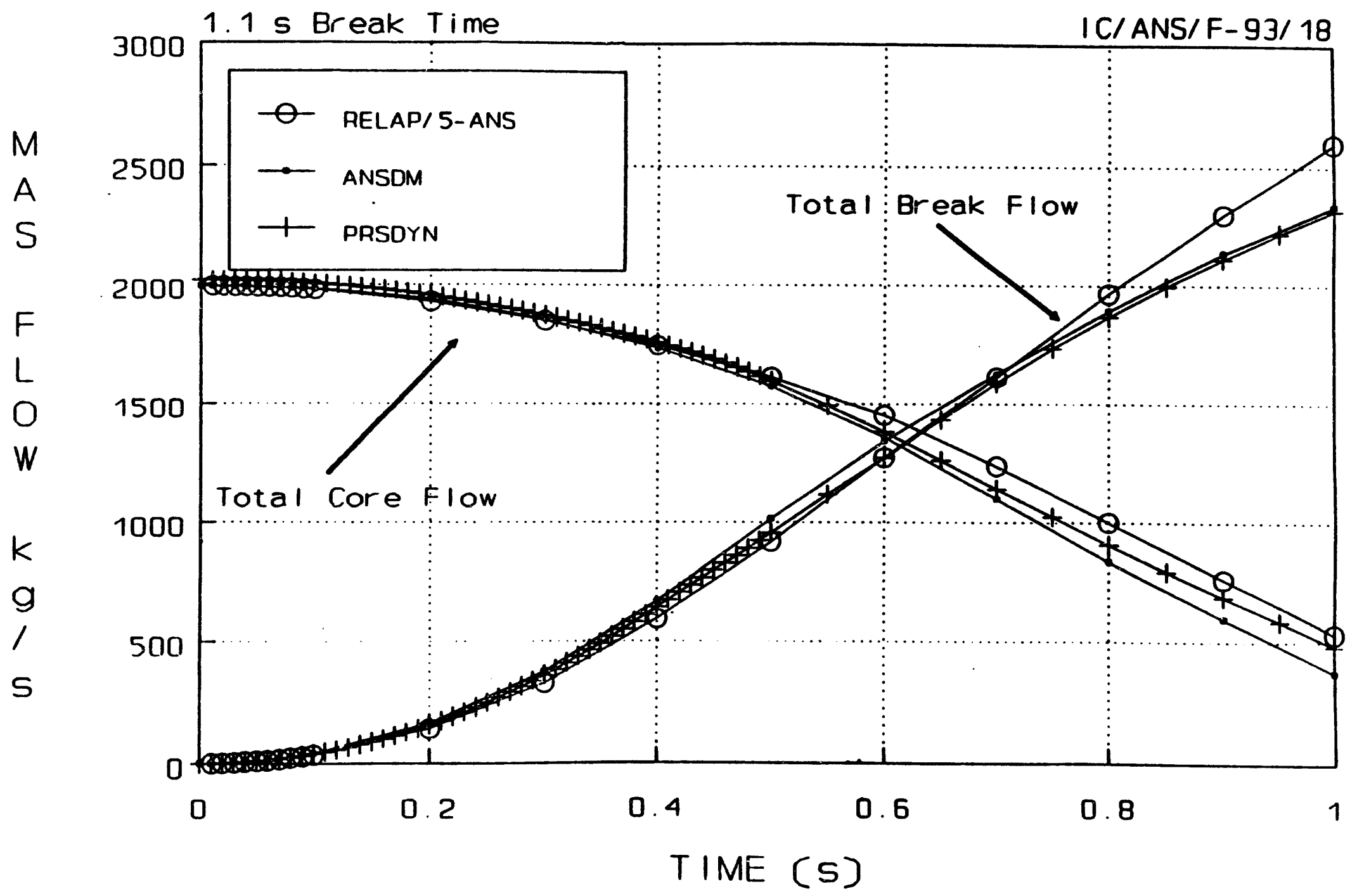

Fig. 23. Comparison in total core and break flows during the double-ended guillotine break at primary supply veasel adapter weldment with 1100-ms opening time. 


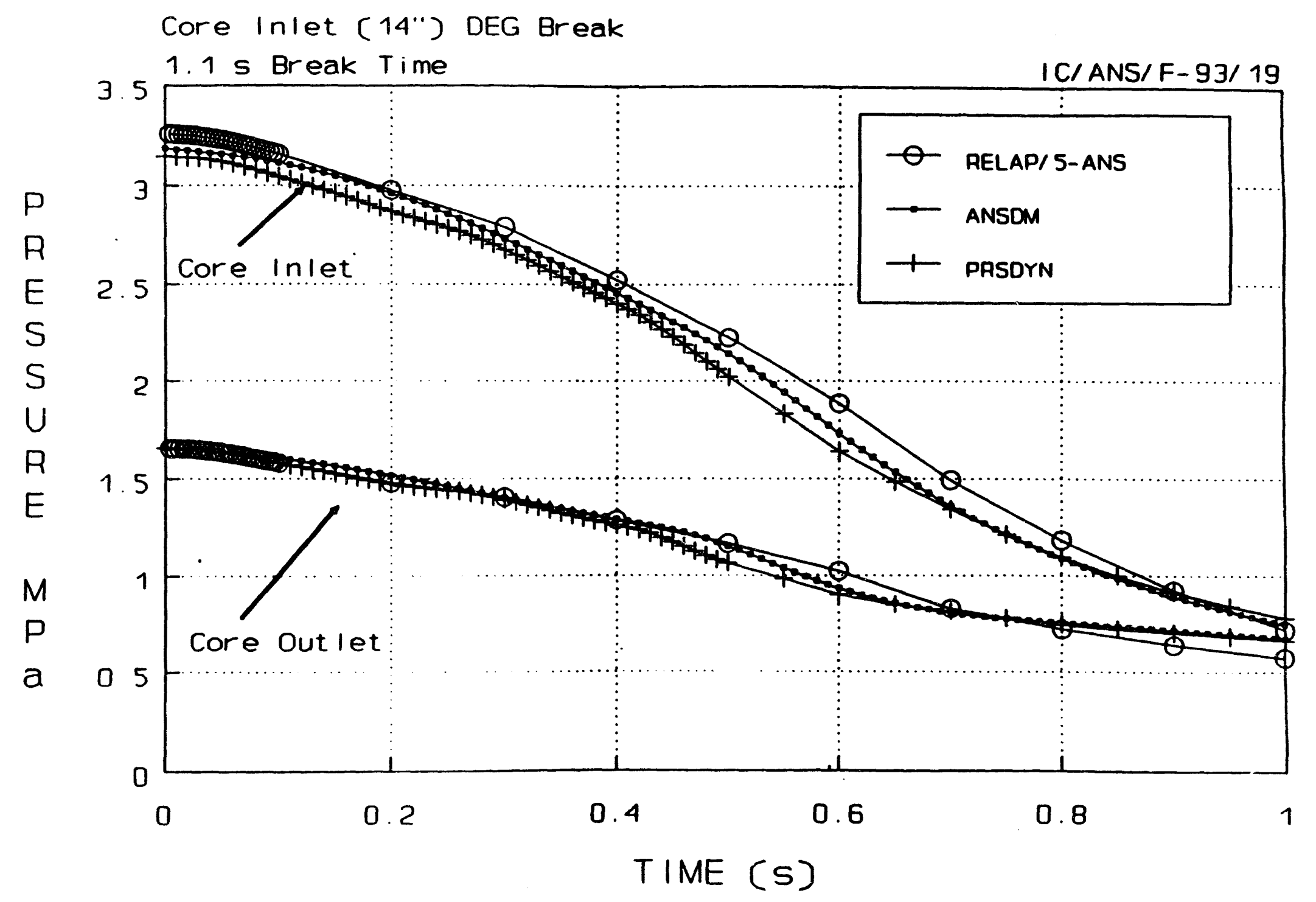

Fig. 24. Comparison in pressures at the lower core inlet and outlet during the double-ended guillotine break with 1100 -ms opening time. 


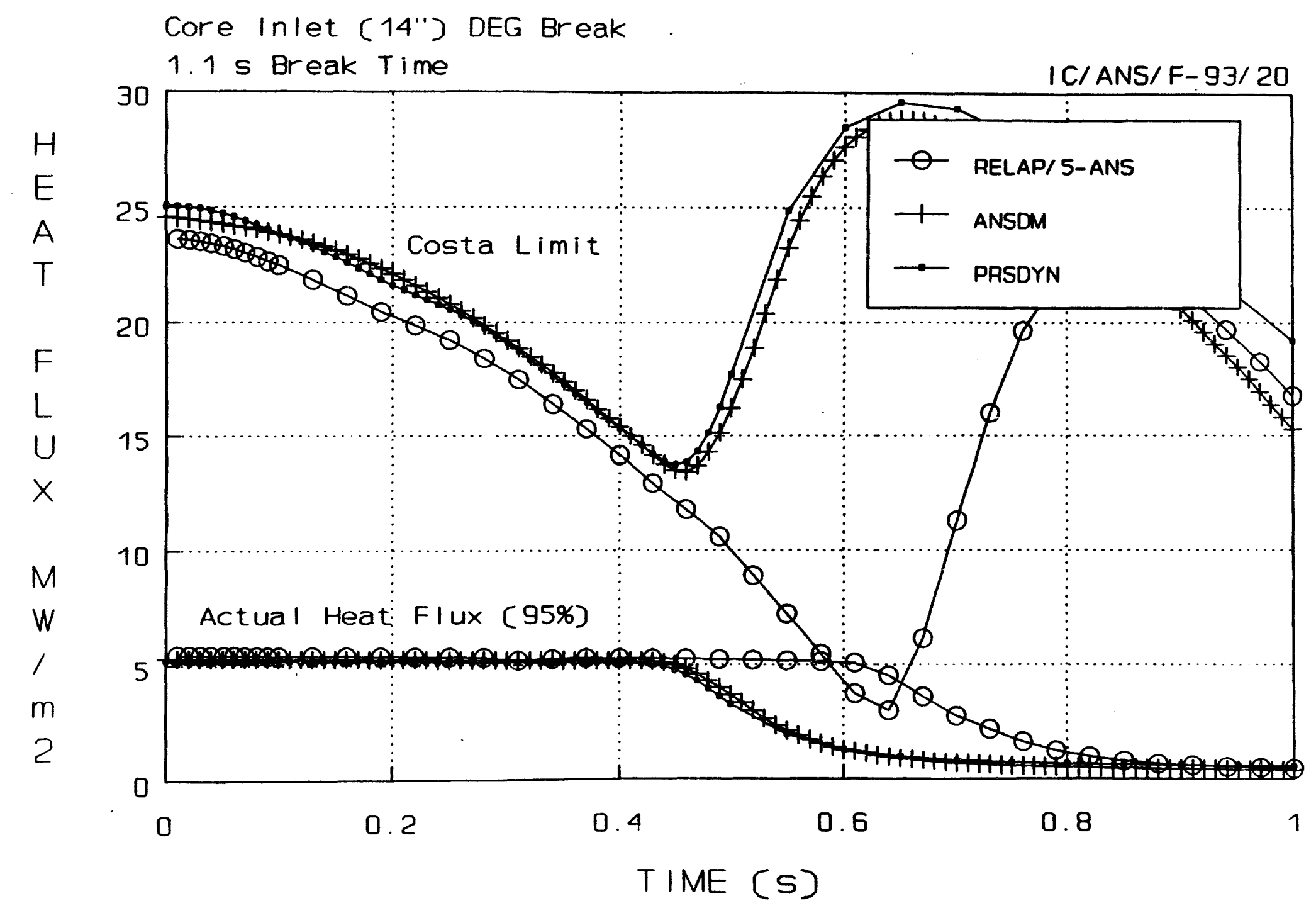

నิ

Fig. 25. Costa limit and local surface heat fuxes at lower core exit during the double-ended guillotine break with 1100-ms opening time. The difference in pressure scram setpoint causes RELAPS results to difier from the other models.) 
The difference in the Costa limiting heat flux is $-1 \mathrm{MW} / \mathrm{m}^{2}$ and may be the result of small differences in initial pressure at the hot spot location.

The difference in the scram time is the result of a difference in the assumed pressure scram setpoints. RELAPS used the setpoint based on $80 \%$ of the initial pressure, while ANSDM used $80 \%$ of the nominal pressure. The initial conditions are biased in this transient to account for uncertainties in the operating condition. This bias results in the initial pressure being 95\% of nominal; therefore, RELAP5 was scramming on a pressure of $-75 \%$ of nominal (i.e., 80 of 95\%), which accounts for the additional time delay. To complete the benchmark process, the ANSDM setpoint was modified to agree with the RELAP5-assumed setpoint, and good agreement was obtained as indicated in Fig. 26.

\section{3 .3 Discussion}

To allow a proper comparison of scram time (elapsed time between exceedance of the pressure setpoint and initiation of control rod motion), all models should have the same (1) sensor location, (2) pressure scram setpoint, (3) initial pressure at sensor location, and (4) delay time in pressure switch and control rod unlatching. When these factors are standardized, there remains a small difference in scram time that cannot be eliminated. This difference results from the finite time, limited by the speed of sound in heavy water, that it takes for pressure changes to be transmitted through the system. Therefore, a finite time is required for a depressurization wave to propagate from the break location to the sensor location. The shortest distance between these two points in the ANSR conceptual design is $-40 \mathrm{~m}$, and it requires $-30 \mathrm{~ms}$ for the depressurization wave to propagate from the PSVAW inlet to the limited volume air cell. RELAPS and PRSDYN account for this finite propagation time, but ANSDM assumes that the acoustic wave that transits the initiation of the depressurization propagates at infinite speed. Consequently, RELAPS and PRSDYN predict an additional delay in the scram time as opposed to the values obtained from ANSDM.

These factors are examined further to resolve initial discrepancies in scram time. On the sensor time delay, RELAP5 models the pressure sensor as a pure delay while ANSDM and PRSDYN model as a first-order-lag. However, all three models predict a resultant $\mathbf{3 0} \mathrm{ms}$ of instrument delay.

These findings indicate that sensor location and scram pressure setpoints are the most probable causes of scram time differences. ANSDM and PRSDYN have pressure detectors at the outlet of hot leg riser, and RELAP5 has the detector at the hot leg distribution header, downstream of the hot leg riser outlet. As shown in Fig. 27, pressure at the hot leg distribution header crosses the setpoint $-100 \mathrm{~ms}$ later than the riser outlet pressure.

During this benchmark, the calculations were found to demonstrate the importance of the selection of the scram low pressure setpoint. Figure 28 shows the Costa limiting heat flux as a function of setpoint pressure (expressed as a percentage of the nominal pressure at the detector location). Increasing the setpoint has an obvious beneficial effect for these slow-opening breaks.

It should be noted that there is a core flow reversal problem late in the transient. All three models predict the flow reversal and its approximate timing. The total core flow decreases initially as the break flows increase and continues to decline after the pump trip, becoming negative (flowing downward) at $-1.26 \mathrm{~s}$ into the transient as predicted by RELAP5 (see Fig. 29). Other flow rates at both ends of the break and from the accumulators are also shown. In this case, the slower depressurization rate and the lack of pressure oscillations give sufficient time for the accumulators to respond to the hreak. The break ylows upstream and downstream of the break are very similar, with both flows directed into the pool up to the time that the break is totally open. Then, because the 


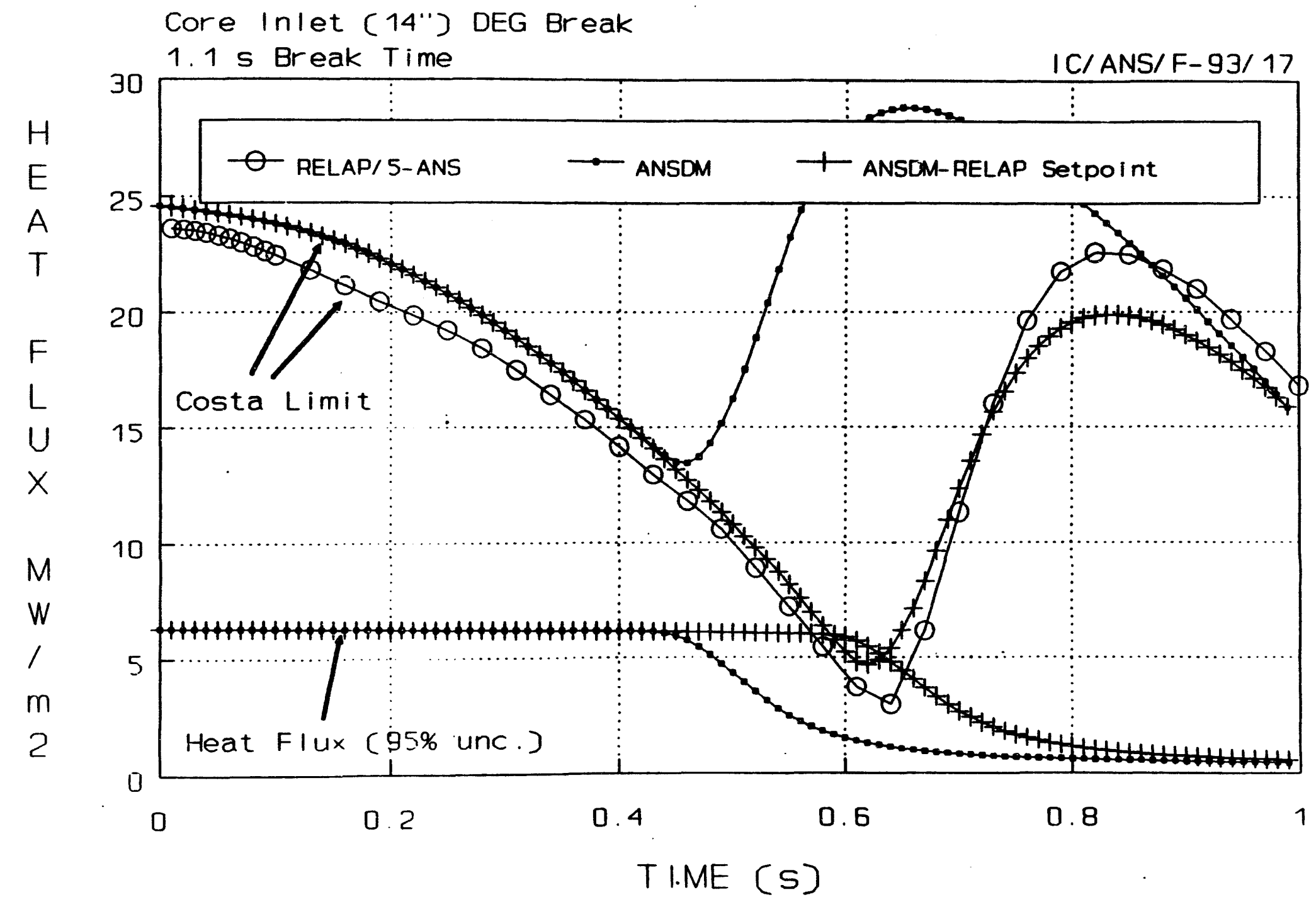

\&

Fig. 26. Good agreement in heat fluxes at the lower core exit during the double-ended guillotine break at primary supply vessel adapter weldment when three models used the same setpoint. 


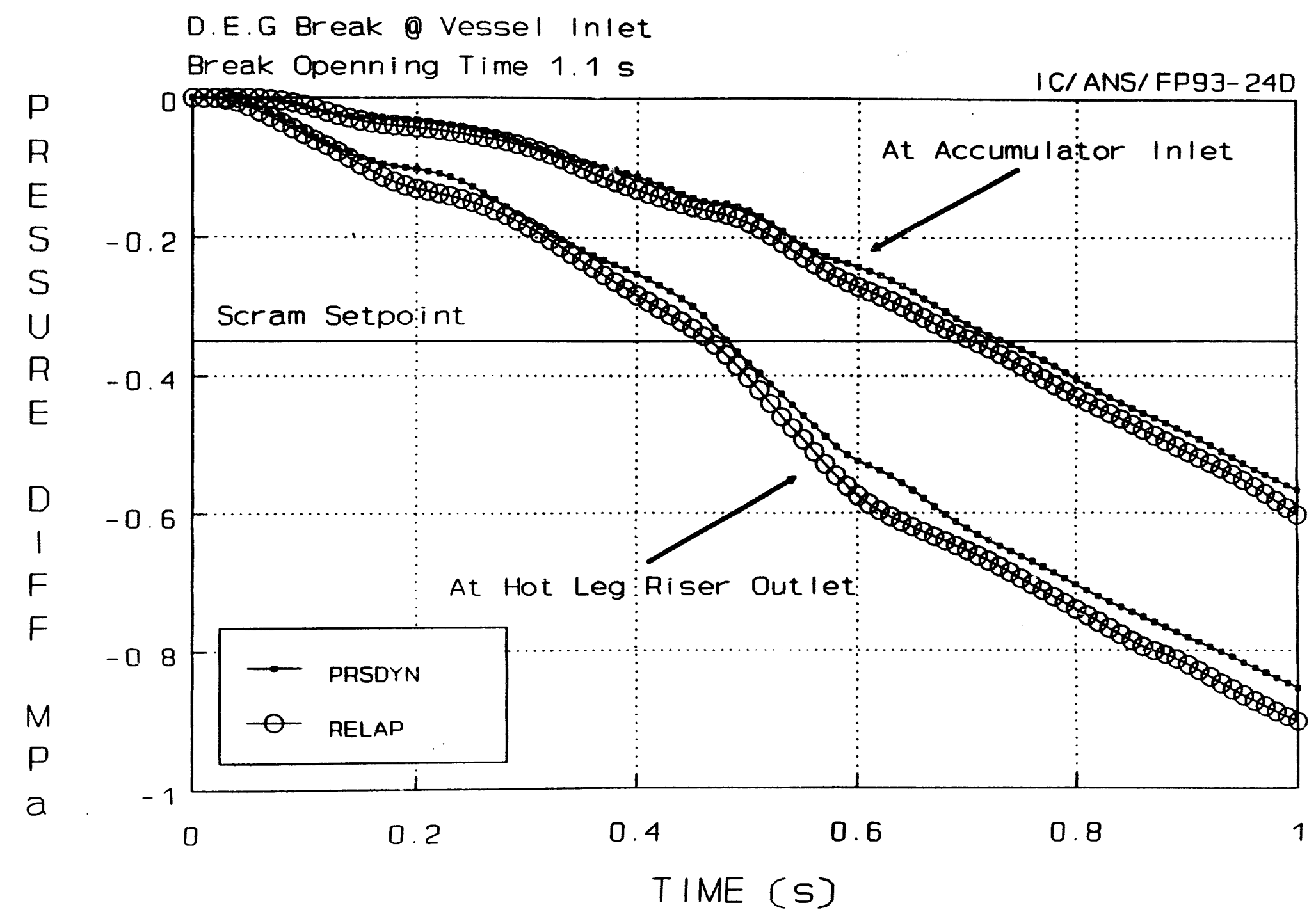

㝏

Fig. 27. Pressure difference (change from steady state) at the hot leg riser ontlet and accumulator inlet during the doubleended guillotine break with $1.1 \mathrm{~s}$ opening time. (The accumulator inlet is further from the core outlet than the hot leg riser outlet.) 


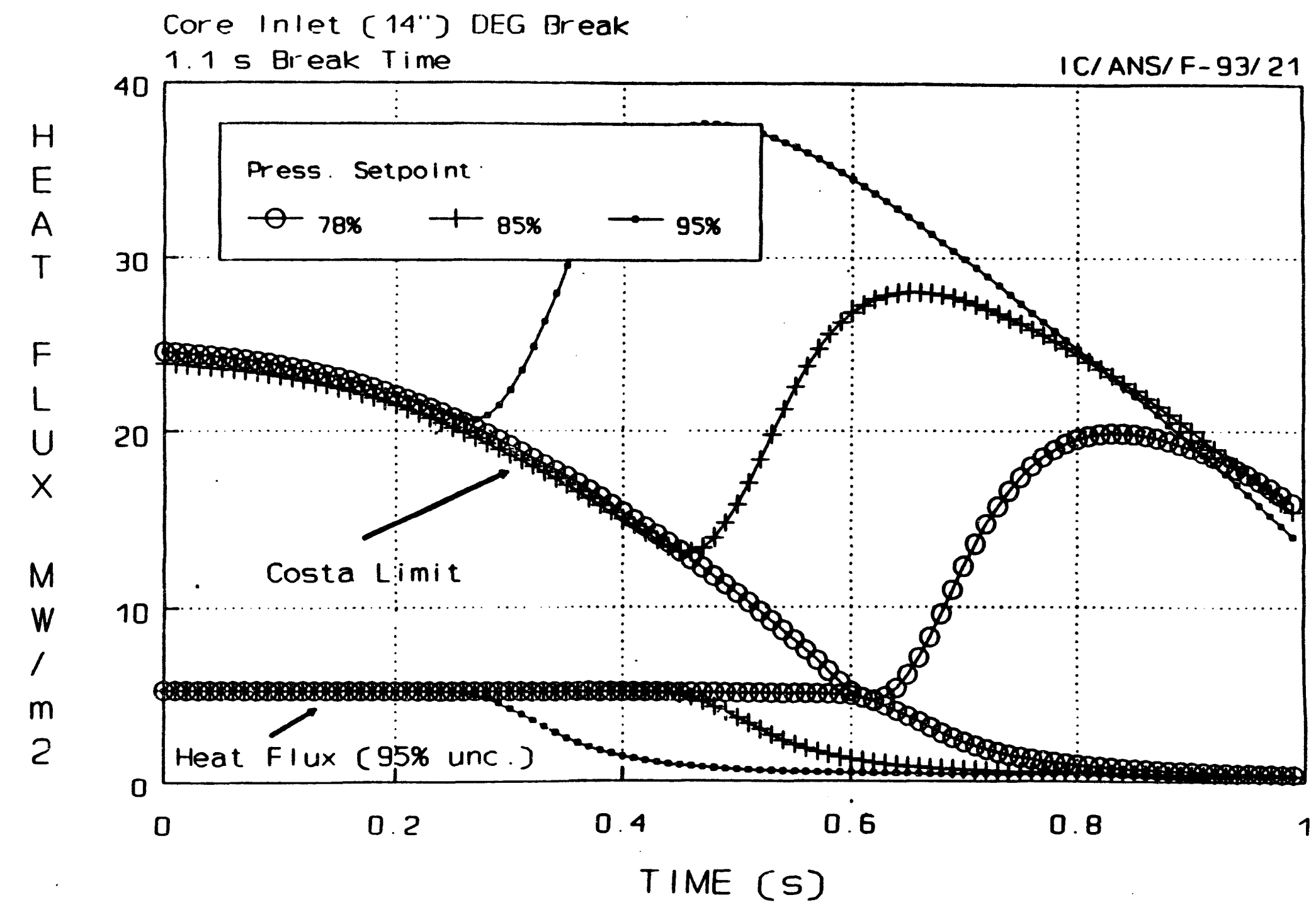

8

Fig. 28. Advanced Neutron Source dynamic model-alculated heat fuxes showing the importance of pressure setpoints in terms of the nominal value during the double-ended guillotine break with $1100-m$ s opening time. 


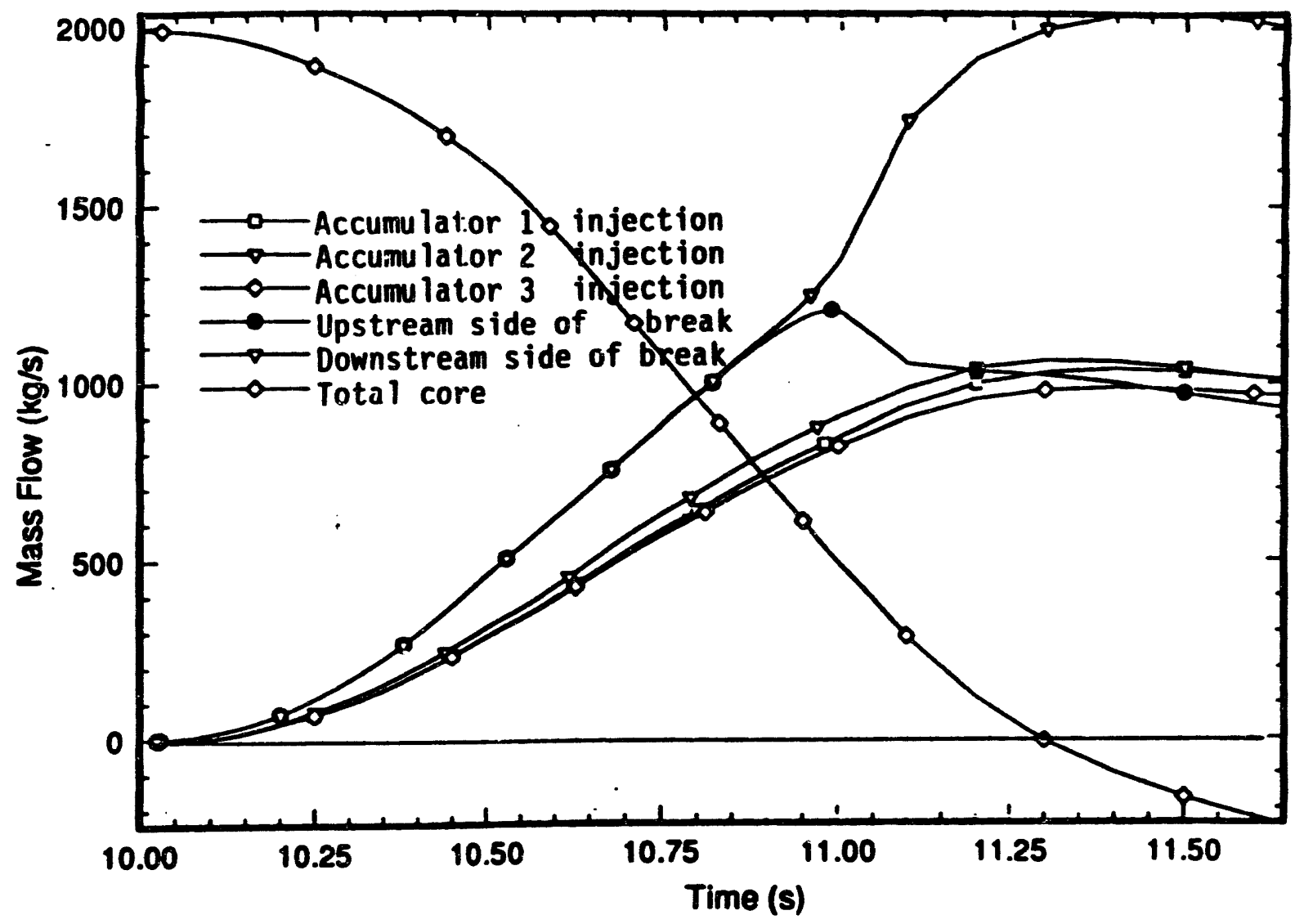

Fig. 29. RELAPS-calculated nows showing the total core flow, break flows upstream and downstream of the break, and individual eccumulator nows during the double-ended gullotine break with $1100-m$ spening time. (The core flow reversal cocurs at -1.38 into the transient.) 
downstream opening is connected to the PSVAW, which is supplied with coolant by the two intact loops, the flow out of this end of the break continues increasing as depressurization proceeds.

Core flow reversal would be a safaty prablem for ANSR because of its very high power density. Several options to prevent core flow revereal are proposed. These options include (1) lowering the pump trip setpoint as low as possible while avoiding or minimizing pump cavitation, (2) increasing the pump moment of inertia as much as possible to maintain a higher core flow while avoiding or minimizing pump cavitation, and (3) replacing the standard ono-stage gas apace sccumulator configuration with a two-etage configuration.

\subsection{REACTIVITY DNSERTION ACCDENT}

This reactivity ovent is chosen for comparison because the CSAR showed that the limiting ovent for the reactivity insertion transients is bounded by a $\$ 0.80$ reactivity step. It has conservatively been assumed that multiple beam tubes fail and both the alumimum and vacuum volumes are instantaneously replaced by $\mathrm{D}_{2} \mathrm{O}$, resulting in a positive reactivity step of $\$ 0.80$, even though no mechanism for this has been identified. This event is considered extremely unlikely, and, thus, the 95\% nonexceedance criterion is applied.

The event is initiated by a positive renctivity addition of $\$ 0.80$ inserted $\mathrm{a}$ a step at the beginning of the transient. The initial control rod position represents the BOC, xenon-free, which corresponds to $\sim 150-\mathrm{mm}$ sbove the core midplane. The control rod worths are those used in the CSAR (Tables 4.3-14 and 4.3-10). Seram-latch delaye are $30 \mathrm{~ms}$ for the inner rods and $120 \mathrm{~ms}$ for the outer rods. The neutron flux sensor is conservatively modeled with a "firat-order-lag" delay, r.mon of $25 \mathrm{~ms}$.

$$
\phi_{\text {man }}=\frac{\phi-\phi_{\text {man }}}{\tau_{\text {man }}} .
$$

The reactor scrams on "high-rate of-flux" if $R>0.28^{-1}$, where the rate of change of flux, $R$, is defined as follows:

$$
\frac{d R}{d}=\frac{\phi_{m}-R}{T_{m}}
$$

The rate of change of flux is approximately equal to the derivative of the detector fiux, but it is "low-pass" filtered with a time constant, $\tau_{-m}=250 \mathrm{~ms}, 20$ that small neutron flux fluctuation with small amplitude (<5\%) will not scram the reactor. In these calculations, the generation time of $\Lambda=1.3 \mathrm{~ms}$ and an effective delayed neutron fraction of $\beta=0.0078$ were used. (Note: These point kinetics parameters are most recent values and differ from the ones used in the CSAR reactivity-event calculations.) Also, the transient is initiated from CSAR nominal conditions-104.2\% power, 94.6\% pressure, and a core inlet temperature of $45.6^{\circ} \mathrm{C}$ (which is $0.6^{\circ} \mathrm{C}$ above nominal).

\subsubsection{Steady State}

The initial operating conditions are the same as those assumed for the core inle DEG break with 1100 -ms opening time. Thus, the steady-state comparison remains the same as presented in Table 14. 


\subsection{Transient}

Preliminary results showed that the fission power compared well, but not the heat power at the fuel surface (average heat flux times fuel surface area). The good comparison in fission power profile (see Fig. 30) is a result of using a similar point kinetics model for calculating the core power, the same reactivity vs time table after scram, the same rate-of-power-change scram setpoint, the same neutron generation time, and effective delayed neutron fraction. The discrepancies in heat power result from a difference in active fuel thermal inertia (product of density and specific heat). The difference in thermal inertia values was traced to the fact that RELAP5 accounted for the density and heat capacity of both the urmium silicide and the aluminum filler, while ANSDM used heat capacity values for pure aluminum. After ANSDM reprogramming to use the more sccurate thermal inertia in input, the two models compared excellently in the heat power profile as shown in Fig. 31. These thermal inertia values were used in the remaining comparisons.

The two models compare satisfactorily in the FE thermal limit ratio (see Fig. 32). A similar trend in CHF limit ratio is also indicated. Note that RELAPS does not print CHF values when the wall temperature is calculated to be less than the saturation temperature; therefore, there is no CFF data to be compared after $-0.2 \mathrm{~s}$ into the transient.

More detalled comparisons in the key parameters that affect the FE thermal limit ratio are presented in Fige. 33-35. The local surface heat flux at the exit of the lower core hot channel is compared in Fig. 33. Both models predict the correct trend-rising heat flux during the power excursion, declining after the reactor is scrammed, and finally approsching the decay heat power level.

Likewise, comparisons in the saturation temperature and local velocity (see Fig. 34) are satisfactory, with the maximum differences in saturation temperature and velocity staying below $-2.5^{\circ} \mathrm{C}$ and $0.8 \mathrm{~m} / \mathrm{s}$, respectively. Pressure and coolant temperature at the exit of the lower core hot channel are compared in Fig. 35. The deviations between the two models are within $5^{\circ} \mathrm{C}$ and $0.05 \mathrm{MPa}$ for the temperature and the pressure, respectively, at the time of the closest approach of the FE limit ratio.

\subsubsection{Discussion}

Some interesting observations between pressure and temperature at the lower core outlet shown in Fig. 35 call for special attention. As the power excursion occurs upon a positive reactivity step insertion, temperature rises, followed by the pressure rise, as expected. After the reactor is scrammed, the temperature declines and is followed by the pressure decrease as evidenced by the respective peaks predicted by ANSDM (both pressure and temperature peak at 120 ras). On the other hand, RELAP5 predicts a higher frequency for this pressure oscillation. Moreover, RELAP5 predicts a rapid initial pressurization rate that peaks earlier than that of the temperature peak (pressure peaks at 90 ms and temperature at $130 \mathrm{~ms}$ ).

Pressure increases around the coolant loop are not uniform during the power burst phase. RELAP5 predicts that an acoustic pressure transient is transmitted around the coolant system. The pressurization process in the system (illustrated in Fig. 36) is not threatening to any part of the pressure boundary because the maximum amplitude of pressure change is only $-0.035 \mathrm{MPa}$. In this figure, time zero refers to the onset of the power excursion and distance is measured from the core exit such that both ends of the $x$-axis refer to the core exit. Pressure change with respect to the initial steady state distribution is plotted at discrete times during the transient. At time zero, it is quiescent because there is no pressure disturbance. Soon after, the local pressure disturbance caused by the onset of power excursion inside the core begins propagating outwand upstream and downstream of the core. At time $24 \mathrm{~ms}$, the disturbance grows to about $5 \mathrm{kPa}$ at the core exit because of a slow temperature 


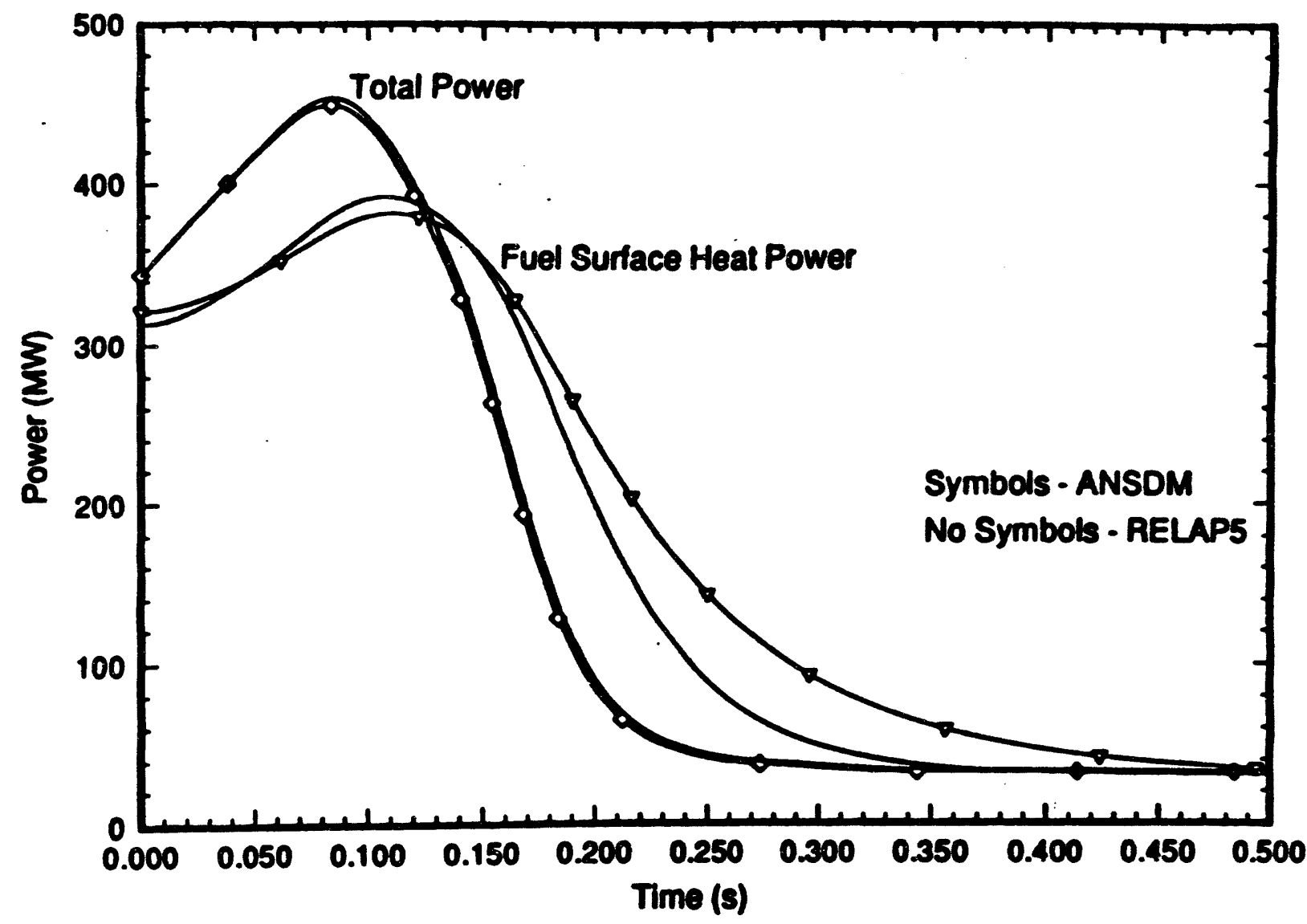

Fig. 30. Advanced Neutron Source dynamic model (ANSDM) ve RELAPS comparison in total and fuel surface heat powers for the $\$ 0.80$ reactivity step accident before correction of ANSDM fuel heat capacity. 


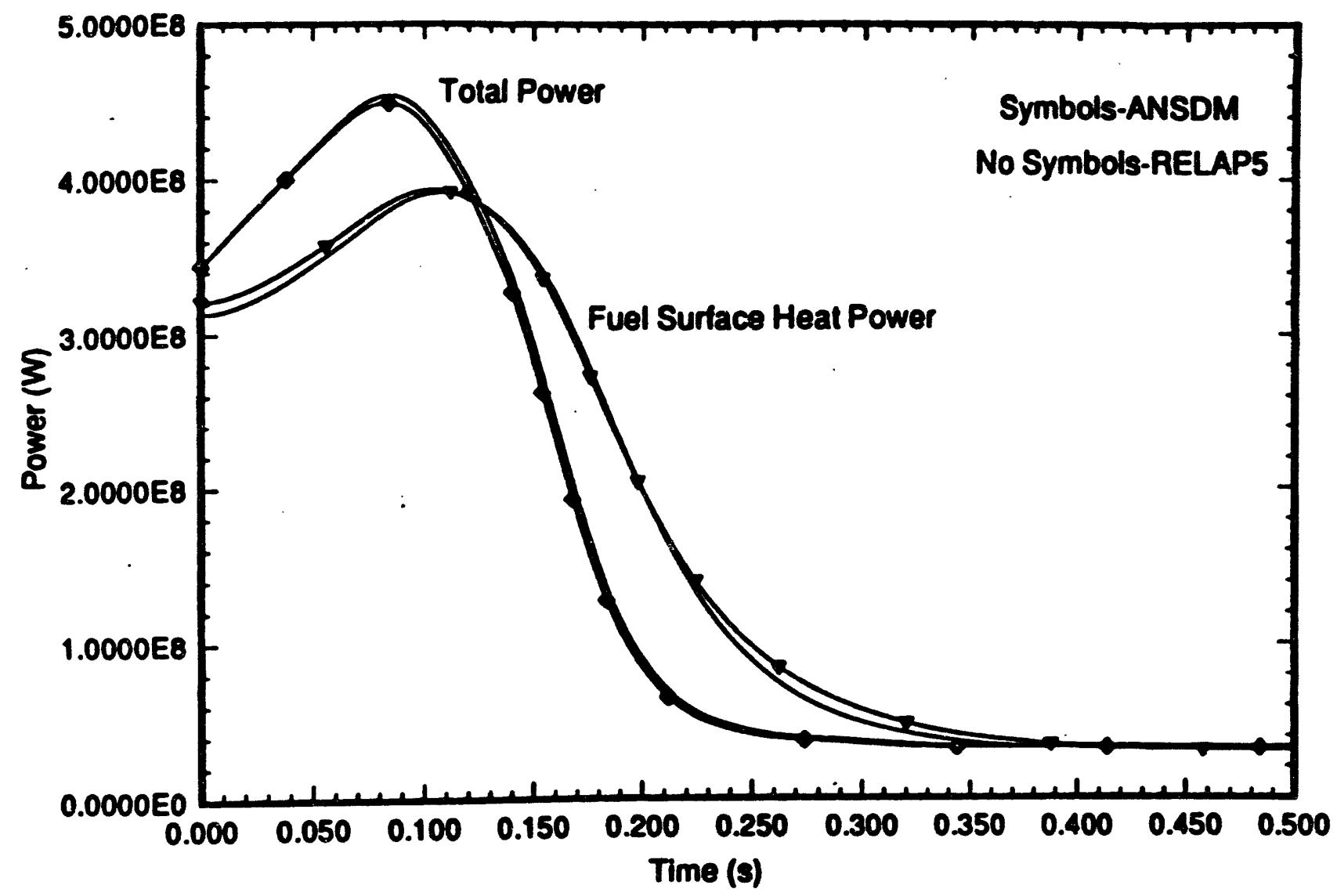

Fig. 31. Advanced Neutron Source dynamic model (ANSDM) ve RDLAPS comparison in total and fuel surface heat powers for the $\$ 0.80$ reactivity step accident after correction of ANSDM fuel heat capacity. 


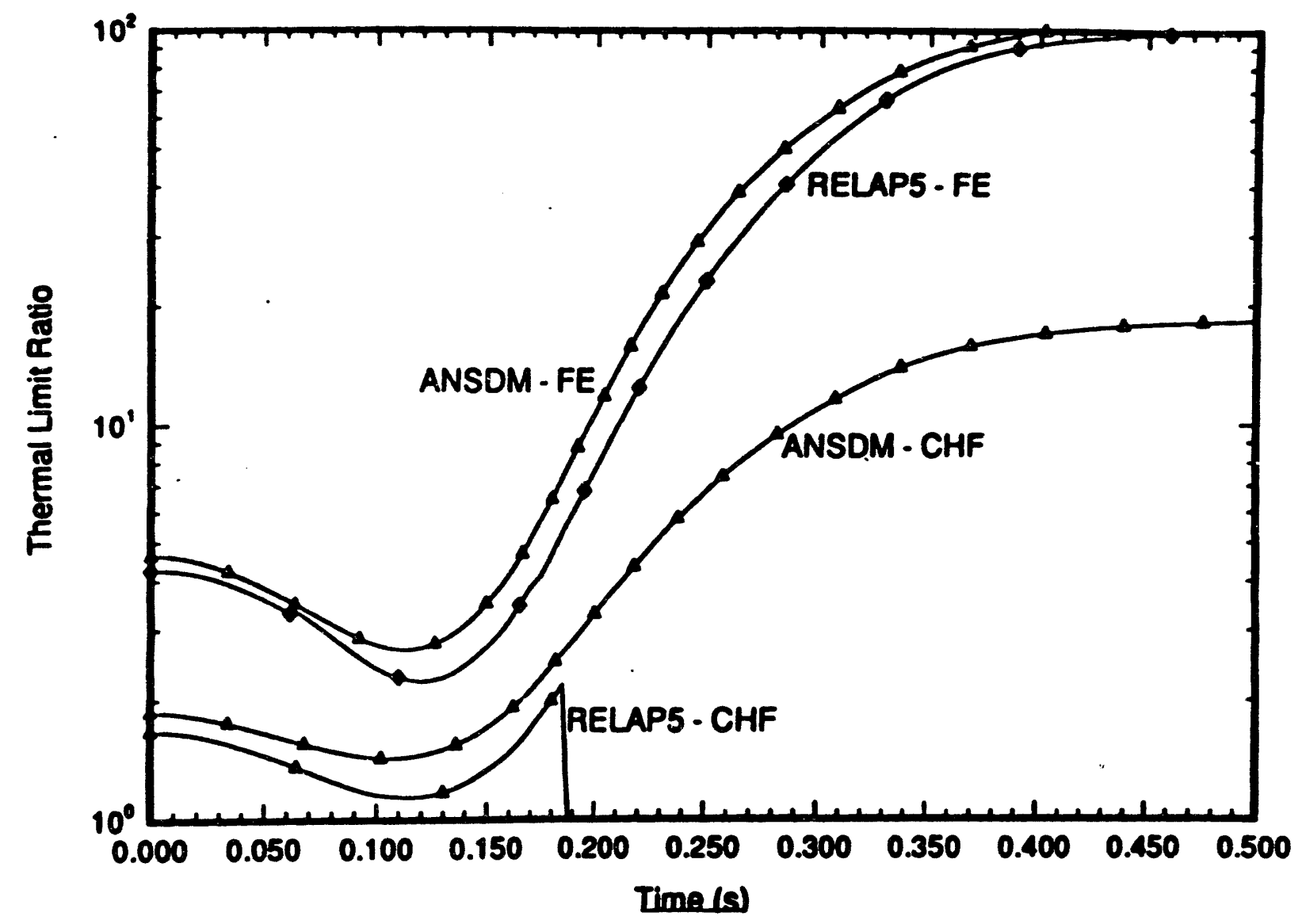

Fg. 32. Advanced Neutron Source dynamic model vo RELAPS comparison in thermal limit ratios for the $\$ 0.80$ reactivity step acdident. (Notes The critical heat fhux values are not printed out by RELAPS if the wall temperatiure stajs below the local coclant saturation temperature.) 


$$
\text { te }
$$




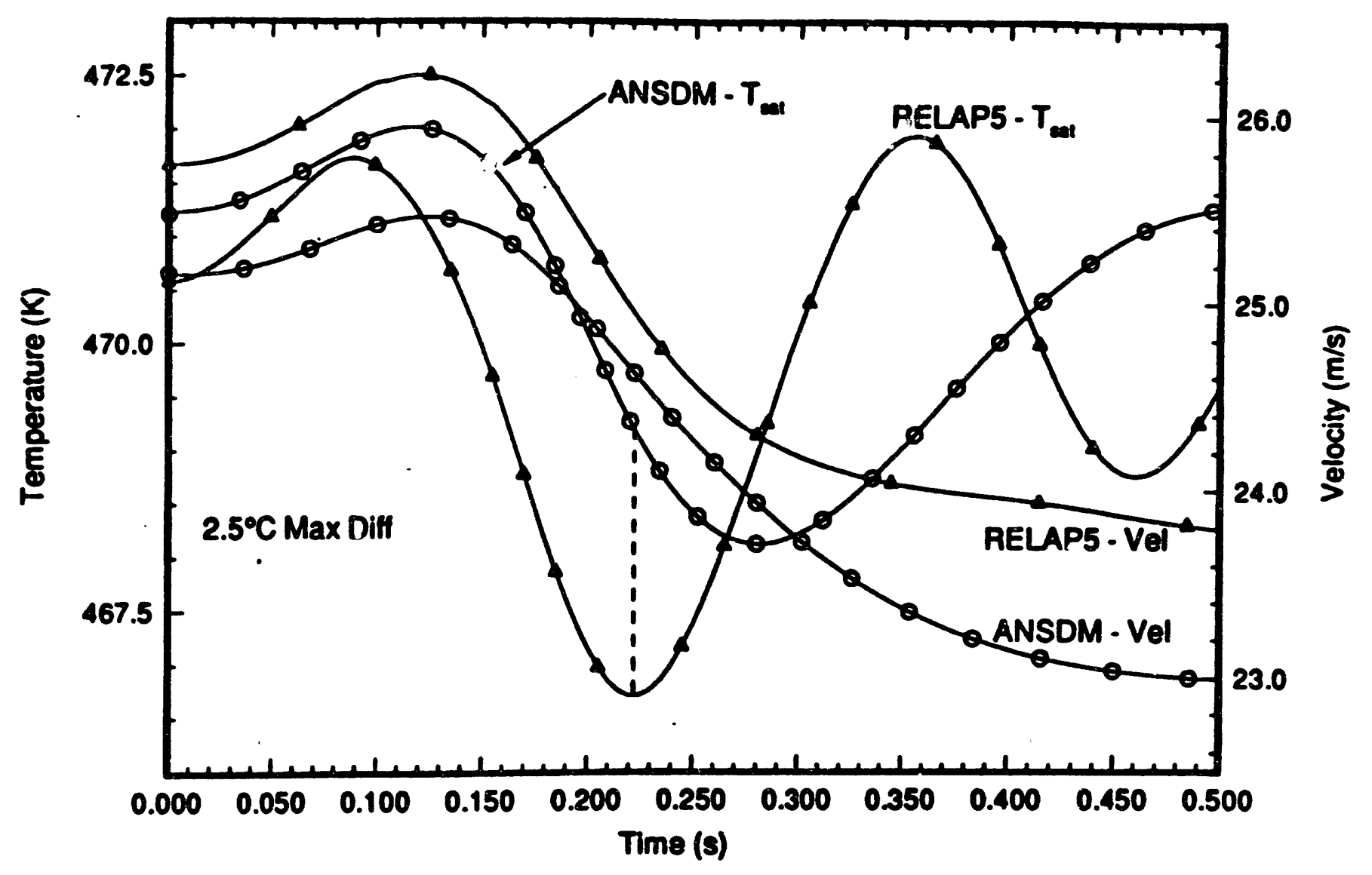

Fig. 34. Advanced Neutron Source dynamic model vs RELAPS comparison in the local coolant relocity and saturation temperature at the lower core exil for the $\$ 0.80$ reactivity step socident. 


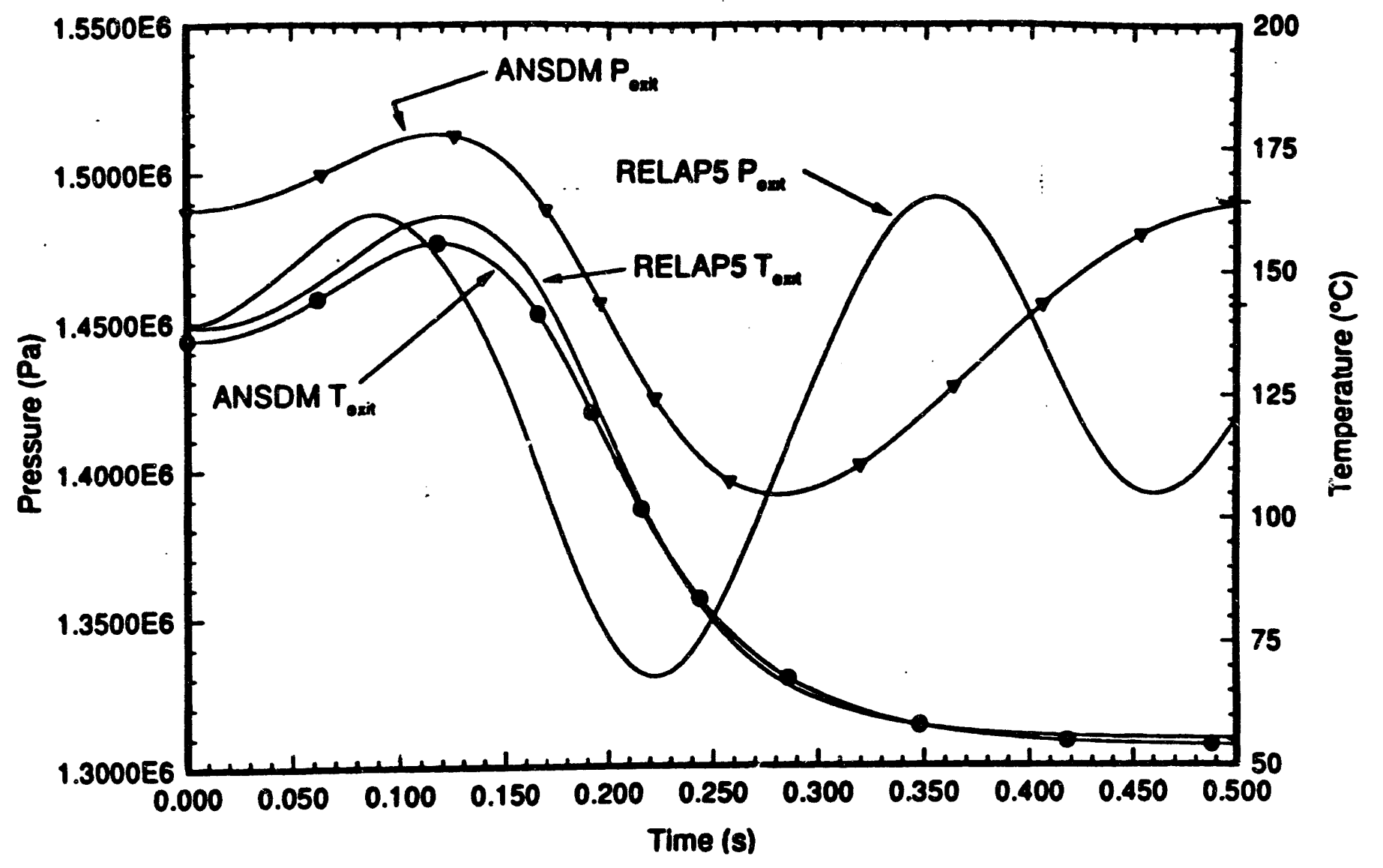

Fig. 35. Advanced Neutron Source dynamic model vs RELAPS comparison in the local pressure and coolant temperature for the $\$ 0.80$ reactivity step acdident. 


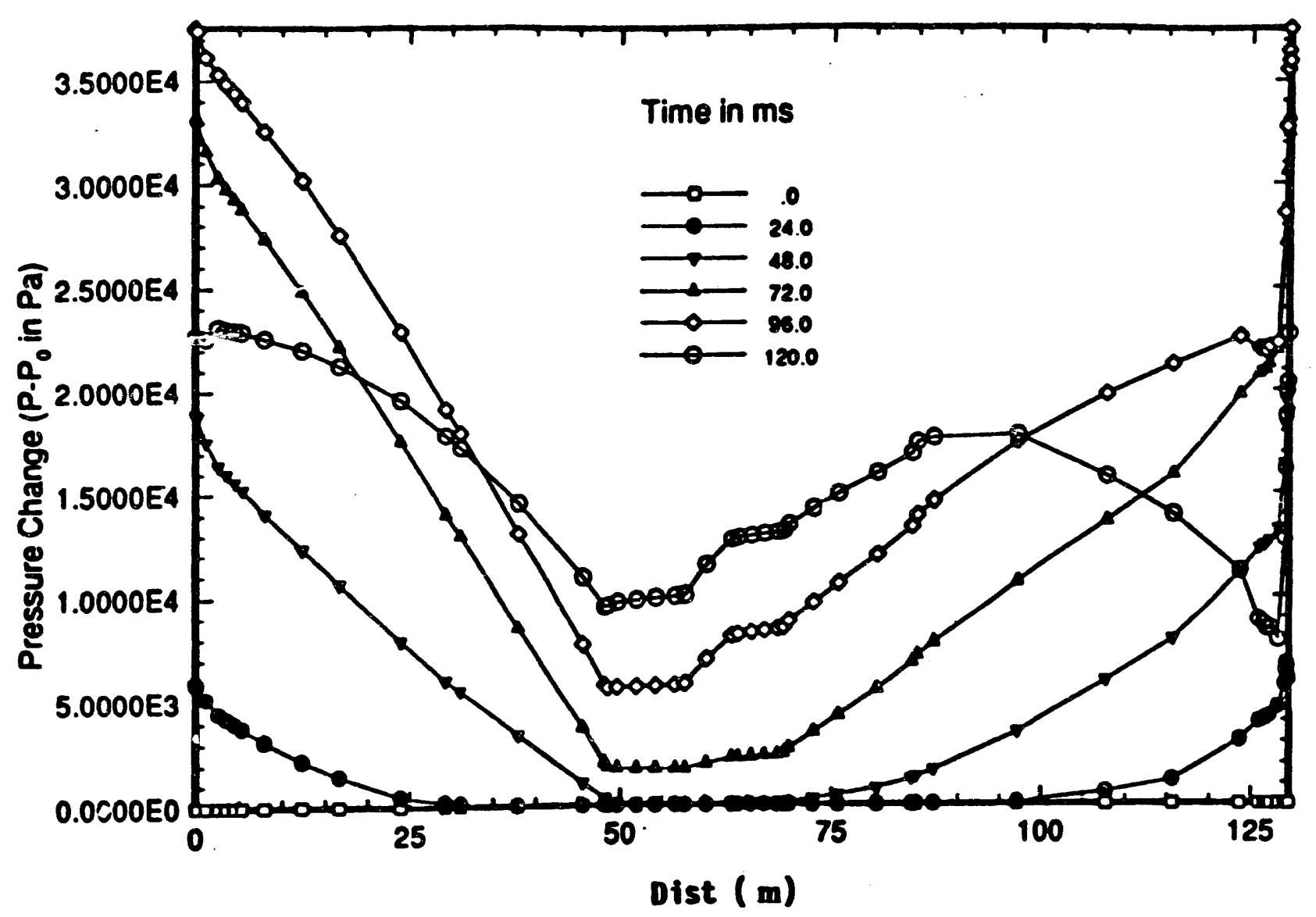

ฉ

Fig. 36. RELAP5-calculated pressure changes with reference to the steady-state showing the acoustic propagation during the power burst along the loop for the $\$ 0.80$ reactivity step accident. 
rise while the leading edge of the wave propagates a distance $-35 \mathrm{~m}$ from the core exit upstream and downstream (acoustic velocity of $1450 \mathrm{~m} / \mathrm{s} \times$ time of $24 \mathrm{~ms}=35 \mathrm{~m}$ ) as evidenced by a nearly symmetric pattem. The zone beyond $35 \mathrm{~m}$ is unaffected. As time progresses to $72 \mathrm{~ms}$, the pressure disturbance grows to $33 \mathrm{kPa}$ at the core exit and reaches the center portion of the loop as indicated by relatively small pressure changes. Thereafter, the waves lose their symmetry as a result of combined effects of differences in flow resistance of cold and hot legs and interferences from reflected waves. At $96 \mathrm{~ms}$, the pressure amplitude at the core exit peaks; however, at other locations in the system, the pressure continues to rise. The average pressure change from the initial steady state at any given time can be derived by integrating the corresponding area under each curve. Note that the depressurization process during the cooldown phase is not shown here.

RELAP5 predicts a rapid rise and earlier fall in pressure because the initial pressurization caused by the reactivity step change is highly localized and the core outlet pressure depends not only on the local temperature effects but also on the mass fluxes through the control volume, and the position of the acoustic wave. However, ANSDM assumes that the acoustic wave propagates at an infinite speed 80 that the pressure disturbance, once created inside the core, reaches everywhere in the system spontaneously. As a consequence, pressure (global rather than local) and temperature respond together. If the ANSDM predicted pressure disturbance should be plotted in the same graph (Fig. 36), every curve would appear as a horizontal line. 


\section{CONCLUSTONS AND RECOMMENDATIONS}

The overall conclusion from this exercise is that RELAP5, ANSDM, and PRSDYN will give very similar results if the input parameters are the same. With respect to the transient events calculated in this report, there are no important differences in code capabilities, with the single exception that ANSDM does not capture the sonic limitation on pressure wave propagation through the coolant system. This difference is significant only in very rapidly opening pipe break events. Major conclusions and recommendations are summarized in the following sections.

\subsection{CONCLUSTONS}

The overall comparisons establish the fret that a set of common input parameters (e.g., operating conditions, system configuration, correlations, etc.) is a prerequisite for a satisfactory steady-atate comparison. However, modeling differences in pump cosstdown characteristies, ges expansion behavior inside accumulators, and pressurizing/hetdown systems are not apparent during normal operating conditions. For a successful comparison in transient results, the set of input parameters further requires identical (1) initial conditions resulting from the steady-state operating conditions, (2) pump constdown characteristics including shaft friction torque, (3) gas expansion charecteristics inside accumulators, (4) pressuriaing/hodown system modeling, and (5) safety protection systems (such ss sensor locations, sensor delay time, setpoint, and reactivity profiles), and (6) Other characteristics (such as heat capacity) that may influence the transient.

For the small LOCA comparison (51 mm-diam break with 250-ms opening time at the CPBT outlet), it is shown that RELAP5 and ANSDM predictions agree reasonably well in spite of minor modeling differences, wch as nodalization scheme and friction correlations. Nevertheless, the importance of using common pump coastdown characteristics, letdown valve controlling logic, gas expansion behavior inside accumulators, and break opening formation characteristics is immediately recognized.

For the station blackout accident comparison, it has been shown that satisfactory agreement in results can be obtained if the same pump coastdown characteristics, decay heat power, and gas expansion behavior within accumulators are assumed for RELAPS and ANSDM. Also, it has been demonstrated that two FE margin minima exist. The first minimum occurs as the result of initial depressurization after the reactor is scrammed, and the second one occurs at the transition from the forced convection to natural circulation much later in the transient.

For the large LOCA comparison (DEG break with 1100-ms opening time at PSVAW), it was demonstrated that two FE margin minima exist. The first minimum occurs as the result of initial depressurization after the reactor is scrammed. Whether the core can survive depends strongly on the pressure sensor location and sensor setpoint as well as the initial conditions. The second minimum occurs when the accumulator injection flow overwhelms the diminishing upward core flow atter the pump is tripped.

For the reactivity insertion accident comparison (reactivity step of $\mathbf{S 0 . 8 0}$ ), it is shown that matching the fission power requires an identical reactivity profile along with an identical scram mechanism. More importantly, it is shown that RELAPS can reproduce the acoustic transient during the heatup and cooldown cycle upon the reactivity step change. Although the acoustic phenomena affects the safety margin insignificantly in the reactivity results, it significantly affects results for instantaneous large break LOCAs because of the delay it introduces between event initiation and the initiation of the reactor scram by the hot leg pressure switches. 


\subsection{RECOMMENDATIONS}

Since the majority of differences noted throughout this study resulted from different model input parameters, the single most important recommendation for future safety analysis is that the ANS Pmject should work on ways to ensure that the correct design data is conveniently available and used by analyets.

Other improvement to the ANSR thermal hydrwulic models (RELAPS, ANSDM, and PRSDYN) based on comparison findings is cummarised in Table 15. The following general recommendations can be applied to all models for further improvements.

Table 15. Improvement to the Advanead Neutron Source reactor thermathydraulic models based on comparison findings

\begin{tabular}{|c|c|c|}
\hline Parameter & ANSDMe and PRSDYN & REI_APS \\
\hline Point linetics & 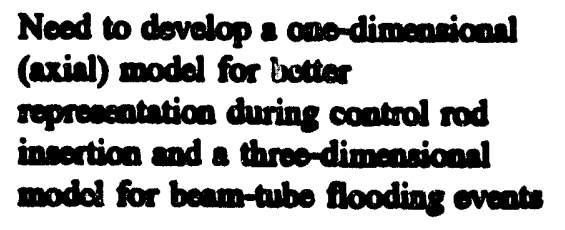 & 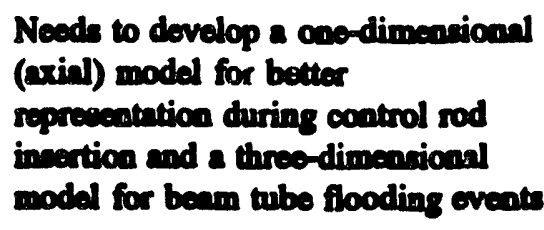 \\
\hline Decay heat partition & & $\begin{array}{l}\text { Needs to dovelop capacity for port- } \\
\text { reram docay heat recional } \\
\text { distribution }\end{array}$ \\
\hline Pual thermal inertia & $\begin{array}{l}\text { Need to include appropriato thermal } \\
\text { inertin for both urnivim allicide and } \\
\text { aluminum filler (pure aluminum } \\
\text { curreatly asoumed) }\end{array}$ & \\
\hline Preavure drop over the core & & $\begin{array}{l}\text { Improved Colebrook friction } \\
\text { correlation by calibrating to THTL" } \\
\text { data }\end{array}$ \\
\hline Accumulator model & $\begin{array}{l}\text { Need to dovelop capability for } \\
\text { representing flow into tank and } \\
\text { boneycomb inet beat etructure }\end{array}$ & $\begin{array}{l}\text { Needs to dovelop capability for } \\
\text { reprecenting flow into tank and } \\
\text { bonoycomb insert beat atructure }\end{array}$ \\
\hline Pump model & $\begin{array}{l}\text { Neod to dovelop capability for } \\
\text { reprecenting (1) pump moment of } \\
\text { inertia, (2) pump friction torque } \\
\text { (zero torque currently anmed), and } \\
\text { (3) pump cavitation }\end{array}$ & $\begin{array}{l}\text { Developed and implementod a } \\
\text { HFIR'-like pump cavitation modal }\end{array}$ \\
\hline
\end{tabular}

ANSDM = Advanced Nectron Sounce dynumic model.

THTL = thermat-hydraulic teat locp.

HFIR = High Flux leotope Reactor. 
The reactivity profile has an important bearing in determining the power. It is recommended that a unified reactivity vs time table be used when updated information in total rod length and total rod worth becomes available.

During natural circulation, decay heat is critical in determining the survivability of the core. It is recommended that the partition of the decay heat into various regions in core and noncore components must be revised and updated using the more accurate ANSR-specific MCNP results calculated by INEL after completion of the CSAR.

Degradation of pump performance can be important upon onset of cavitation. Once pump cavitation occurs, the reduced core flow could affect the safety margin. Thus, it is recommended that all models include a pump cavitation model based on the real ANSR pump performance curves and net positive suction head (NPSH) required data to assess cavitation effects on the safety margin and quantify the duration of cavitation.

If the following specific recommendations are incorporated, RELAP5 analyses can be significantly improved.

The discrepancy in pressure drop across the core appears to be caused by an ill-fitted friction correlation used in RELAPS for ANSR flow conditions. Therefore, it is recommended that INEL examine and verify the curve fitting of the Colebrook correlation over various flow regions against the analytical expression, as well as data, if possible. The final code implementation should be documented and released for future safety analyses. Actually, the final implementation, documentation, and release have already occurred, and the updated version RELAP5/MOD3/VERSION8k0 is operational at ORNL.

Accumulator performance affects the depressurization rate significantly. To improve the accumulator model to accommodate the thermal and hydraulic effects of the isothermalizer, it is recommended that a lumped-parameter model using RELAPS control variables or other methods be developed. This model will represent the basic accumulator phenomena and reduce the accumulator behavior to a pressure or flow rate boundary condition on the primary coolant system piping. 


\section{REMERRENCES}

1. J. Costa, Measurement of the Momentum Pressure Drop and Study of the Appearance of Vapor and Change in the Void Fraction in Subcooled Boilling at Low Pressure, presented at the Meeting of European Group Double-Phase, Winfrith, France, 1967, translated from French as ORNL/TR90/21, Martin Marietta Energy Systems, Inc., Oak Ridge Natl. Lab., 1990.

2. Conceptual Safery Analysis Report, Chap. 15, ORNL/ANS/INT-33/V4, Martin Marietta Energy Systems, Inc., Oak Ridge Natl. Lab., June 1992.

3. V. H. Ransom, at al., RELAP5/MOD2 Code Manual, Volumes I-IV, NUREG/CR-4312, EGG2396, Auguat 1985.

4. D. G. Morris and M. W. Wendel, High Flux Isotope Reactor System RELAPS Input Model, ORNL/M-11647, Martin Marietta Energy Systems, Inc., Oak Ridge Natl. Lab., January 1993.

5. G. C. Slovik, U. S. Rohatgi, and J. JC, RELAPS/MOD2.5 Analysis of the HFBR for a Loss of Power and Coolant Accident, Brookhaven National Laboratory, Upton, New York, BNL-52243, May 1990.

6. S. T. Polkinghorne, T. K. Lareon, and B. J. Buescher, "RELAPS Simulation of Advanced Test Reactor Scaied LOCA Experiments 7, 8, 12, and 14," Nud. Technol. 93, 240-251 (February 199i).

7. J. S. Bollinger and C. B. David, "Benchmarking of the RERAPS/MOD2.5 r-0 Model of an SRS Reactor to the 1989 L-Reactor Tests (U)," Joint RXLAPS and TRAC-BWR International User Seminar, Chicago, September 1990.

8. C. S. Miller and R. W. Shumway, RELAPS/MOD3 Code Qualty Assurance Plan for ORNL ANS Narrow Channel Flow and Heat Transfer Correlations, EGG-NE-10326, EG\&G, Inc., Idaho Falls, Idaho, November 1992.

9. P. W. Dittus and L. M. K. Boelter, "Heat Transfer in Automobile Rediators of the Tubular Type," University of California Pub. Eng., No. 13, pp. 443-461, reprinted in Intl. Comm. Heat and Mass Transfer 12, 3-22 (1985).

10. B. S. Petukhov, Heat Transfer and Friction in Turbulent Pipe Flow with Variable Physical Properties, Advances in Heat Transfer 6, 528 (1970).

11. W. R. Gambill, "Generalized Prediction of Burnout Yeat Flux for Flowing, Subcooled, Weting Liquids," Chem. Eng. Prog. Symp. Series 59, (41), 71-87, (1963).

12. R. J. Weatherhesd, Nucleate Bolling Characteristics and the Critical Heat Flux Occurrence in Subcooled Axial-Flow Water Systems, ANL-6675, Argonne National Laboratory, Chicago, March 1963. 
13. D. C. Groeneveld, S. G. Cheng, and T. Doan, “1986 AECL-U0 Critical Heat Flux Lookup Table," Heat Transfer Eng. 7 (1-2) 46-62 (1986).

14. P. Griffith at al., "Counter Flow Critical Heat Flux," AICHE, Paper No. 25, presented at 15th National Heat Transfer Conference, San Francisco, August 1975.

15. J. F. Briesmeiter, ed., MCNP-A General Monte Carlo Code for Neutron and Photon Transport, LA-7396-M, Rov. 2, Los Alamos National Laboratory, Los Alamos, 1986.

16. D. R. Vondy, T. B. Fowler, and G. W. Cunningham, The BOLD-VENTURE Computational System for Nuclear Reactor Core Anabysis, Version II, ORNL-5711, Union Carbide Corporation, Ouk Ridge Natd. Lob., 1981.

17. A. J. Stepanoff, Centrifugal and Axial Flow Pumps, 2nd ed., John Wiley a Sons, Now York, 1957.

18. D. B. Collins a al., "Pump Operation with Cavitation and Two-Phase Flow," Proceedings 4th Western Canadian Heat Transfer Conference, Winnipes, Manitoba, May 1972.

19. American National Standards Institute/American Nuclear S-ciety (ANSWANS), American National Standard for Decay Heat Power in Light Water Re_ctors, ANSUANS5.1-1979 (1979).

20. ACr-Advanced Continuous Simulation Language, Reference Mamual, Edition 10, Mitchel and Gauthier Associates, Concosd, Massachuseds, 1991.

21. C. O. Bennett and J. E. Myers, Momentum Heat and Mass Transfer, 3rd edition, McGraw Hill, Now York, 1982.

22. F. Kreith, Principles of Heat Transfer, 3rd edition, Intext Educational Publisher, New York, 1967.

23. M. W. Wendel, REIAPS LOCA Analysis Parametric Strudies, C-HFIR-91-020, April 1992. 


\section{MNTERNAL DISTRIBUTION}

1. C. W. Alerander

2. D. J. Alecrander

3. R. R. Allea

4. E. E. Aleton

5. J. L. Andereon

6. B. R. Applacan

7. J. G. Arterburn

8. R. E. Bettle

9. R. S. Booth

10. W. W. Bowman

11. R. A. Brown

12. G. J. Bunick

13-17. J. H. Campbell

18. P. F. Cento

19. N. C. J. Chen

20. K. W. Childs

21. K. K. Chipley

22. J. E. Cleaves

23. J. T. Cleveland

24. G. L. Copeland

25. W. G. Craddick

26. J. R. Dixon

27. F. P. Dryer

28. K. Farrell

29. D. K. Felde

30. R. E. Fenstermaker

31. G. F. Flanagan

32. J. D. Freels

33. M. L. Gildner

34. H. A. Glovier

35. D. C. Haberkost

36. R. M. Harrington

37. J. B. Hayter

38. D. M. Hetrick

39. S. E. Holliman

40. M. M. Houser

41. R. O. Hussung

42. M. Ibn-Khayat

43. D. T. Ingersoll

44-47. R. L. Johnson

48. J. E. Jones, Jr.

49. R. A. Lillie
50. M. A. Linn

51. P. S. Litherland

52. A. T. Luens

53. J. A. March-Leuba

54. B. S. Maron

55. G. T. Mays

56. S. V. Mcorath

57. T. J. McManamy

58. G. R. McNutt

59. J. T. Mihalezo

60. R. M. Moon

61. D. G. Morris

62. D. L. Moses

63. R. E. Pawel

64. H. R. Payne

65. P. J. Perez

66. C. C. Queen

67. S. Raman

68. C. T. Ramsey

69. J. S. Rayside

70. W. R. Reed

71. J. P. Renier

72. J. B. Roberto

73. R. E. Rothrock

74. T. L. Ryan

75. J. P. Schubert

76. D. L. Selliy

77. H. B. Sh. nir

78. M. Simas Tov

79. C. D. . redge

80. R. P. Taleyarthan

81. D. W. Theisen

82. P. B. Thompeon

83. K. R. Thoms

84. S. R. Tompkins

85. B. D. Warnick

86. M. W. Wendel

87. C. D. Weat

88. J. L. Westbrook

89. D. M. Williams

90. P. T. Williams

91. B. A. Worley 
92. G. T. Yahr

93. G. L. Yoder

94. ORNL Patent Office

95. Central Rewarch Library

Document Reference Section
96. Laboratory Records Department

97. Laboratory Records, RC

98. Y-12 Technical Library

\section{EXTERNAL DISTRRBUTION}

99. R. Awen, U.S. Department of Energy, NE-473, Washington, DC 20585.

100. L. Chang, Brookhaven National Laboratory, Upton, NY 11973.

101. K. K. Conway, Laboretory Fecilities Branch, U.S. Department of Energy, Oak Ridge Operations Office, CE-523, P.O. Box 2001, Onk Ridge, TN 37831-2001.

102. C. D. Flecther, Idaho National Engineering Laboretory, P.O. Box 1625, Idaho Falls, ID 83415-3885.

103. R. R. Fullwood, Broothaven National Laboratory, Uptoon, NY 11973.

104. W. R. Gambill, Routh 5, Box 220, Clintom, TN 37716.

105. A. F. Henry, Profeceor, Department of Nuclear Engineering, Masenchuseus Institute of Technolozy, 77 Maseachusents Averuse, Cambridge, MA 02139.

106. R. A. Hunter, Director, Office of Facilltien, Fud Cycle, and Test Programs, Nuclear Energy Division, U.S. Department of Energy, NE-47, Weahington, DC 20585.

107. T. L. Kerlin, Univeraity of Trenneasee, College of Engineering, 315 Pasqua Engineering Building, Knoxville, TN 37996-2300.

108. J. A. Lake, Manager, Nuclear Engincering and Reactor Deaign, Idaho National Engincering Laboratory, P.O. Box 1625, Idsho Falle, ID 83415.

109. J. E. Mays, Recearch and Teat Reactor Fuel Elemeats, Babcoct and Wilcox Co., P.O, Box 785, Lynchburg, VA 24505.

110. J. P. Mulkey, U.S. Departmeat of Energy, NE-473, Washington, DC 20585.

111. W. T. Ooettertuis, Materials Sciences Division, Office of Besic Energy Sciences, Office of Energy Research, U.S. Departmeint of Energy, ER-132, Washington, DC 20585.

112. J. M. Ryskamp, Idaho National Engineering Laboratory, P.O. Box 1625, Idaho Falls, ID 83415-3885.

113. J. L. Snelgrove, Coordinator, Engineering Applications, RERTR Program, Argonne National Laboratory, 9700 South Cass Avenue, Argonne, Ill 60439.

114. I. Thomas, Acting Associate Director, Materials Science Divison, Office Of Energy Research, U.S. Department of Energy, ER-13, Washington, D.C. 20585.

115-117. U.S. Department of Energy, ANS Project Office, Oak Ridge Operations Office, FEDC, MS-8218, P.O. Box 2009, Oak Ridge, TN 37831-8218.

118. H. G. Wood, III, Associate Profeseor, Department of Mechanical and Aerospace Engineering, Thornton Hall, University of Virginia, Charlottesville, VA 22901.

119. Office of Scientific and Technical Information, P.O. Box 62, Oak Ridge, TN 37831. 

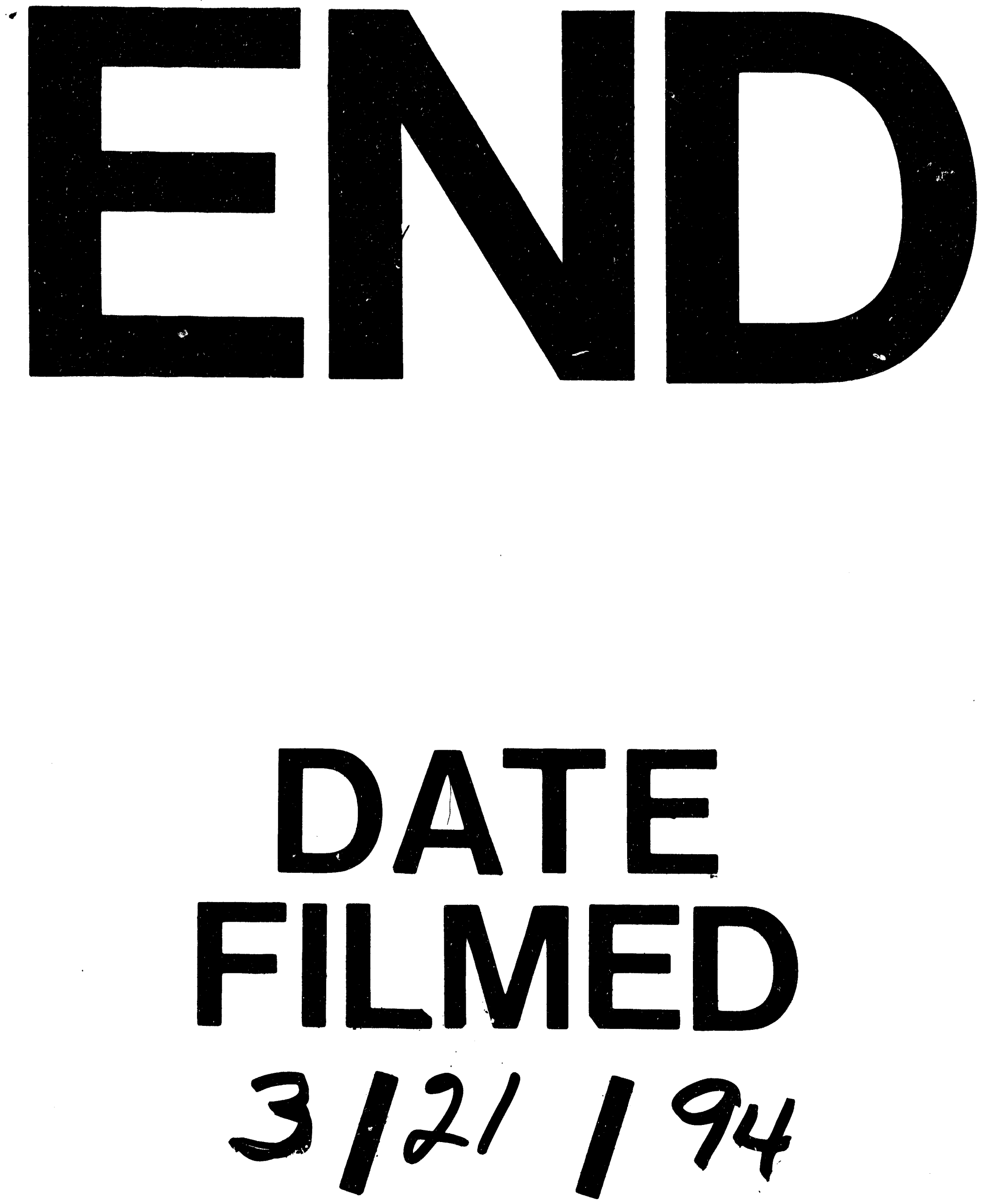

1 
